Florida International University FIU Digital Commons

$11-6-2017$

\title{
Technobiology Paradigm in Nanomedicine: Treating Cancer with MagnetoElectric Nanoparticles
}

Emmanuel Stimphil

Florida International University, estim001@fiu.edu

DOI: $10.25148 /$ etd.FIDC004020

Follow this and additional works at: https:// digitalcommons.fiu.edu/etd

Part of the Biomedical Commons, Electrical and Electronics Commons, Electromagnetics and Photonics Commons, Nanotechnology Fabrication Commons, and the Signal Processing Commons

\section{Recommended Citation}

Stimphil, Emmanuel, "Technobiology Paradigm in Nanomedicine: Treating Cancer with MagnetoElectric Nanoparticles" (2017). FIU Electronic Theses and Dissertations. 3546.

https://digitalcommons.fiu.edu/etd/3546 


\section{FLORIDA INTERNATIONAL UNIVERSITY}

Miami, Florida

TECHNOBIOLOGY PARADIGM IN NANOMEDICINE:

TREATING CANCER WITH MAGNETOELECTRIC NANOPARTICLES

A dissertation submitted in partial fulfillment of the

requirement for the degree of

DOCTOR IN PHILOSOPHY

in

ELECTRICAL ENGINEERING

by

Emmanuel Stimphil 
To: Dean John L. Volakis

College of Engineering and Computing

This dissertation, written by Emmanuel Stimphil, and entitled Technobiology Paradigm in Nanomedicine: Treating Cancer with Magnetoelectric Nanoparticles, having been approved in respect to style and intellectual content, is referred to you for judgment.

We have read this dissertation and recommend that it be approved.

Stavros Georgakopoulos

Osama Mohammed

Jean Andrian

Sakhrat Khizroev

Date of Defense: November 6, 2017

The dissertation of Emmanuel Stimphil is approved

John L. Volakis

Dean of College of Engineering and Computing

Andrés G. Gil

Vice President for Research and Economic Development

Dean of the University Graduate School

Florida International University, 2017 


\section{DEDICATION}

I dedicate my dissertation to my family and friends for supporting me and inspiring me throughout my professional and personal life. 


\section{ACKNOWLEDGMENTS}

I would like to express my sincere appreciation to my advisor Dr. Sakhrat Khizroev for all his insight and support which has made all the difference in the completion of this study. Secondly, I want to acknowledge the National Institution of Health (NIH) FIU NIGMS-RISE (Grant \#R25 GM061347) for financial support and career development resources made available throughout my graduate studies. I would like to acknowledge my committee members Dr. Osama Mohammed, Dr. Jean Andrian and Dr. Stavros Georgakopoulos for all their many research discussions which have shaped this work every step of the way. I would like to acknowledge my classmates/friends for all the motivational talks Mark Stone, Krystine Pimentel, Brayan Navarrete, Ping Wang, Tiffanie Stewart, Ali Hadjikhani, Rakesh Guduru, Alexandra Rodzinski, and Abhignyan Nagesetti. Finally, I would like to acknowledge and thank my family for all their support. 


\author{
ABSTRACT OF THE DISSERTATION \\ TECHNOBIOLOGY PARADIGM IN NANOMEDICINE: \\ TREATING CANCER WITH MAGNETOELECTRIC NANOPARTICLES \\ by \\ Emmanuel Stimphil \\ Florida International University, 2017 \\ Miami, Florida

\section{Professor Sakhrat Khizroev, Major Professor}

Today, cancer is the world's deadliest disease. Despite significant progress to find a cure, especially over the last decade, with immunotherapy rapidly becoming the state of the art, major open questions remain. Each successful therapy is not only limited to a few cancers but also has relatively low specificity to target cancer cells; although cancer cells can indeed be eradicated, many normal cells are sacrificed as collateral damage. To fill this gap, we have developed a class of multiferroic nanostructures known as magnetoelectric nanoparticles (MENs) that can be used to enable externally controlled high-specificity targeted delivery and release of therapeutic drugs on demand. First, the underlying physics of MENs was studied, as it relates to different externally applied sequences of a.c and d.c. magnetic fields to facilitate (i) high-specificity targeting driven by a physical force rather than antibody matching, (ii) a delivery mechanism that enhances cellular uptake (via nanoelectroporation) of therapeutic drugs across the cellular membrane of cancer cells only, and (iii) an externally controlled mechanism that releases the therapeutic drug on-demand. Secondly, the application of MENs as a nuclear magnetic resonance (NMR) nanoprobe was explored. The intrinsically coupled ferromagnetic and 
ferroelectric phases allowes the nanoparticle to be used as sensitive nanoprobe detectors of biological cells; based on the knowledge that the cellular membrane is an electrically charged medium which creates an ideal environment for MENs to distinguish between cancer and normal cells. Lastly, through in-vivo and in-vitro studies, MENs were used as drug delivery vehicle capable of crossing the blood brain barrier (BBB) and delivering recently discovered MIA690 peptide drug (via nanoelectroporation) to glioblastoma multiforme (GBM) brain cancer cells. Glioblastomas are tumors that arise from astrocytes in the brain; that are highly malignant and reproduces quickly due to their large network of blood vessels. In the following study, we report the binding efficacy of MIA690 to magnetoelecric nanoparticles as well as present an unprecedented targeted and on-demand release to glioblastoma cells through special sequences of a.c. and d.c. magnetic fields. The potential therapeutic and diagnostic impact of MENs for future medicine is beyond the scope of this study, as MENs can be used to treat any type of cancer. 


\section{TABLE OF CONTENT}

CHAPTER

PAGE

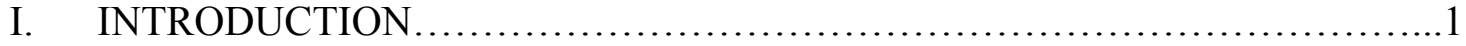

Gold Nanoparticles (AuNPs)........................................

Iron Oxide Nanoparticles............................................ 7

Multiferroic Nanoparticles............................................. 9

Experimental Background....................................... 10

Conclusion..................................................... 12

II. PHYSICS CONSIDERATION IN TARGETED ANTICANCER

DRUG DELIVERY BY MAGNETOELECTRIC NANOPARTICLES............13

Underlying Physics................................................ 16

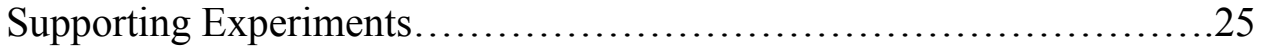

Conclusion ........................................................

Materials \& Procedures.................................................. 33

III. NUCLEAR MAGNETIC RESONANCE SENSITIVE

NANOPROBE FOR CANCER CELL DETECTION BY

MAGNETOELECTRIC NANOPARTICLES................................35

Experimental Results............................................. 37

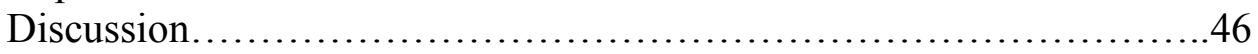

Conclusion........................................................... 50

Materials \& Procedures...............................................50

IV. DELIVERING PEPTIDES TO GLIOBLASTOMA CELLS

BY WAY OF MAGNETOELECTRIC NANOPARTICLES.....................55

Experimental Results..................................................

Discussion...................................................... 71

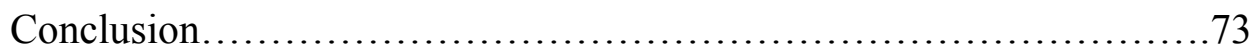

Materials \& Procedures............................................. 73

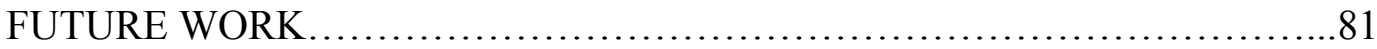

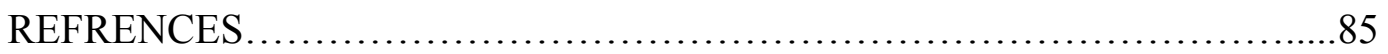

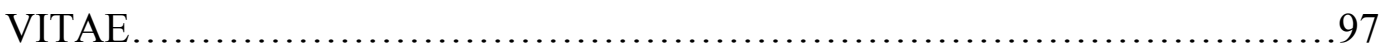




\section{LIST OF FIGURES}

FIGURES

PAGE

1.1. Gold Nanoparticles (AuNPs) for delivering therapeutic agents and imaging cancerous cells.

2.1. Illustration of the dependence of the cut-off distance, $r_{c}$, on application

of an external d.c. magnetic field, $\mathrm{H}$.

2.2. Illustration of the drug release mechanism via application of an a.c. magnetic field....

2.3. Illustration of targeted and release mechanism of delivering a therapeutic load to a cancer cell

2.4. Confocal microscopy imaging of the uptake of Flutax-2 by cell line MES-SA/DX5.

2.5. Optically measured field dependence of the drug uptake per mg of protein for cancer and normal cell lines SKOV-3 and HOMEC.

2.6. The dependence of the release of the drug, paclitaxel, on the a.c.

field strength and frequency.

2.7. AFM image of normal endothelial and cancerous glioblastoma cell line.

2.8. AFM image of the surface membrane of glioblastoma cells......................30

3.1. Characterization measurements of MENs. .38

3.2. Continuous Wave (CW) Nuclear Magnetic Resonance (NMR) spectra of cell media without MENs.

3.3. Continuous Wave (CW) Nuclear Magnetic Resonance (NMR)

Spectra of cells with magnetic nanoparticles

3.4. Continuous Wave (CW) Nuclear Magnetic Resonance (NMR) spectra of cells with MENs.

3.5. Continuous Wave (CW) Nuclear Magnetic Resonance (NMR) Spectra of cell media with MENs for cancer cells.

3.6. AFM image of the surface membraneof normal and cancer brain cells.... 
3.7. Inverse Fourier Transform (IFT) representation of Continuous Wave (CW)

Nuclear Magnetic Resonance (NMR) spectra..

4.1. Atomic Force Microscopy and Transmission Electron Microscopy

Image of Magnetoelectric Nanoparticles.....................................58

4.2. Vibrating Sample Magnetometer measurments of Magnetoelectric

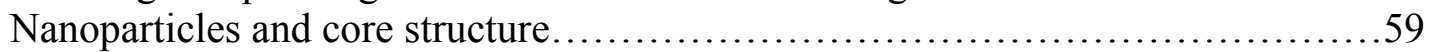

4.3. Bioconjugation of MIA690 to GMO-MENs ..................................60

4.4. Bradford assay results using MIA690 peptide.................................62

4.5. MIA690 peptide uptake relative to protein content in cell lysate...................63

4.6. Intracellular MIA690 release relative to cell viability..........................65

4.7. A.C. magnetic fields on heat dissipation of MENs and cell viability...............67

4.8. MENs uptake in malignant glioblastoma cells.................................69

4.9. Energy-Dispersive Spectroscope- Scanning Electron Microscopy

Image of MENs found in the parenchyma brain tissue.............................. 70 


\section{LIST OF ACRONYMS}

\begin{tabular}{|c|c|}
\hline AFM & Atomic Force Microscopy \\
\hline $\mathrm{AC}$ & Alternating current \\
\hline AuNPs & Gold nanoparticles \\
\hline $\mathrm{BBB}$ & Blood brain barrier \\
\hline CNS & Central nervous system \\
\hline $\mathrm{DC}$ & Direct current \\
\hline DNA & Deoxyribonucleic acid \\
\hline DI & Deionized \\
\hline EDC & N-(3-Dimethylaminopropyl)-N'-ethyl-carbodiimide hydrochloride \\
\hline EDS & Energy Dispersion Spectroscopy \\
\hline EDTA & Ethylene-diamine-tetraacetic Acid \\
\hline EPR & Enhanced Permeability and Retention \\
\hline $\mathrm{FC}$ & Field Cooling \\
\hline FTIR & Fourier Transform Infrared Spectroscopy \\
\hline GMO & Glycerol Monooleate \\
\hline HIV & Human Immunodeficiency Virus \\
\hline HER-2 & Human epidermal growth factor receptor 2 \\
\hline HOMEC & Human ovarian Epithelial cells \\
\hline $\mathrm{ME}$ & Magneto-electric \\
\hline MEN & Magneto-electric Nanoparticles \\
\hline MFM & Magnetic Force Microscopy \\
\hline MFN & Multiferroic Nanoparticles \\
\hline
\end{tabular}




$\begin{array}{ll}\text { MNPsB } & \text { Magnetic Nanoparticle Bio-sensing } \\ \text { MOKE } & \text { Magneto-optical Kerr Effect } \\ \text { MPI } & \text { Magnetic Particle Imaging } \\ \text { MRI } & \text { Magnetic Resonance Imaging } \\ \text { NIH } & \text { National Institutes of Health } \\ \text { NIGMS } & \text { National Institute of General Medical Sciences - Research } \\ \text { NMR } & \text { Initiative for Scientific Enhancement } \\ \text { OC } & \text { Nuclear Magnetic Resonance } \\ \text { PBS } & \text { Ovarian cancer } \\ \text { PCR } & \text { Phosphate Buffered Saline } \\ \text { PPMS } & \text { Polymerase Chain Reaction } \\ \text { PTX } & \text { Physical Property Measurement System } \\ \text { PEG } & \text { Paclitaxel } \\ \text { PET } & \text { Poly ethylene glycol } \\ \text { PLGA } & \text { Positron emission tomography } \\ \text { SEM } & \text { Poly(lactic-co-glycolic acid) } \\ \text { SPIONPs } & \text { Scanning electron Microscope } \\ \text { TKOV-3 } & \text { Superparamagnetic iron oxide nanoparticles } \\ \text { ZFM } & \text { Tibrating Sample Magnetometry } \\ & \end{array}$


CHAPTER I: INTRODUCTION 


\section{Motivation}

The cardiovascular system permits the transportation of drugs to almost every cell in the body; however, transporting a drug specifically into a tumor cell past the cellular membrane without affecting surrounding normal cells remains a key challenge in addressing the cure for cancer. Targeted therapies have emerged as a promising approach in cancer treatment, the development of monoclonal antibodies (mAbs) to target overly expressed specific epitopes throughout the body has become a standard practice $(1,2)$. Alternatively, on-going research to address this fundamental challenge in cancer treatment by way of nanoparticles is being designed to be used as drug delivery vehicles. Current nanoparticle based drug delivery systems conjugated with mAbs indeed display novel properties; due to their unique sizes and shapes they help steer the drug loaded nanoparticles to specific targets while meeting a wide range of requirements for overcoming biological barriers throughout the circulatory system. However, they are also extremely inefficient due to their dependence on the cellular microenvironment and the cells' physiological condition for triggering drug delivery; Nanoparticles have been functionalized for triggered drug release through various means such as external applied temperatures(3, 4), ultrasound(5), intracellular $\mathrm{pH}(6-8)$, and magnetic fields(9, 10). Nevertheless, these approaches are inadequate and inefficient. To address this problem, we have developed a new class of multiferroic nanostructures known as magnetoelectric nanoparticles (MENs). These nanoparticles allow an external magnetic field the ability to control an intrinsic electric field on the surface of the nanoparticles which in turn controls the molecular mechanism of the ionically-bonds therapeutic drug onto the nanoparticle as 
well as the underline physical-interaction between the drug-loaded nanoparticle and surround cells. In this dissertation, the following specific aims will be addressed.

Specific Aim 1: Explore the underlying physics of magneto-electric nanoparticles to understand how they're able to address the fundamental challenges we are currently facing in cancer treatment. We will study the following MENs properties: (a) the targeting mechanism driven by a physical force rather than antibody matching, (b) the delivery mechanism that enhances the cellular uptake of therapeutics to cancer cells only; without affecting surrounding normal cells, and (c) the externally controlled mechanism that releases the therapeutic load on-demand (Chapter II).

Specific Aim 2: The presence of MENs' intrinsic magnetoelectric (ME) effect allow the conversion of electric energy to magnetic energy and vise-a-versa. We will explore an application in which MENs are used as nuclear magnetic resonance (NMR) sensitive nanoprobes. Based on the cancer cell type and corresponding nanoparticle-cell association, MENs will be used to identify biological cells. Currently, the signal magnetic resonance imaging (MRI) and magnetic particle imaging (MPI), is mainly dependent on the magnetic saturation and the density of the current contrasting agents. Adding the dimensionality of the intrinsic electric properties of the microenvironment and equating those properties with MENs' (ME) effect will establish a characteristic signature of individual cells depending on the cancer cell type and progression stage (Chapter III). Specific Aim 3: Through in-vitro and in-vivo studies the abilities of MENs to cross the blood brain barrier (BBB) and provide high-specificity drug delivery via 
nanoelectroporation to treat human glioblastoma multiforme (GBM) brain cancer cells, respectively, will be explored (Chapter IV).

\section{Background}

For decades, researchers have attempted to develop means for targeting and delivery of therapeutic drugs to diseases with high efficiency, precision, and solubility to maximize the bioavailability of the therapeutic drug. More recently, several nanomaterals with various compositions and biological properties have been designed to carry therapeutic drugs to targeted sites. These nanomaterials show promising results of delivering therapeutics to the targeted site with more precision when compared to conventional drug delivery methods. This allows for minimizing the drug dose levels in treating the illness, which in turn reduces the side effect caused from toxicity to surrounding normal cells. Aside from the targeting and delivering applications, nanomaterials have been widely used in cell imaging, diagnostics, and detection to mention a few. The more widely used nanomaterals for these applications have been gold nanoparticles (AuNPs), iron oxide $\left(\mathrm{Fe}_{3} \mathrm{O}_{4}\right)$ nanoparticles, and more recently magneto-electric nanoparticles. An overview of the commonly used nanomaterials and their applications will be discussed in the following sections. 


\section{Gold Nanoparticles (AuNPs)}

Gold nanoparticles (AuNPs) are one of the most widely used nanomaterial in the field of nanomedicine. The drug release mechanisms of AuNPs conjugated with mAb to adequately deliver the drug to a cell have been shown to rely highly on a physiological stimulus; i.e., internal stimuli such as the cells' pH level and intracellular enzymes; and external stimuli such as light and temperature (11-13). AuNPs have also been used in photothermal therapy to eradicate cancer cells; Due to the strong electric field at the surface of the noble metal, when the nanoparticles accumulate near the cancer site and irradiated with an external laser source $(14,15)$, the absorption and scattering of the electromagnetic radiation producing enough heat to eradicate the surrounding tumor cells. Due to the light emission and scattering properties of AuNPs, they are also used as nanoprobes for locating and imaging tumors, the emitted radiation is captured using light scattering and surface plasmon resonant absorption spectroscope to produce an image of the tumor site(16). An illustration of AuNPs for delivering therapeutic drugs and for imaging is shown in Fig. 1.1a and b, respectively. 


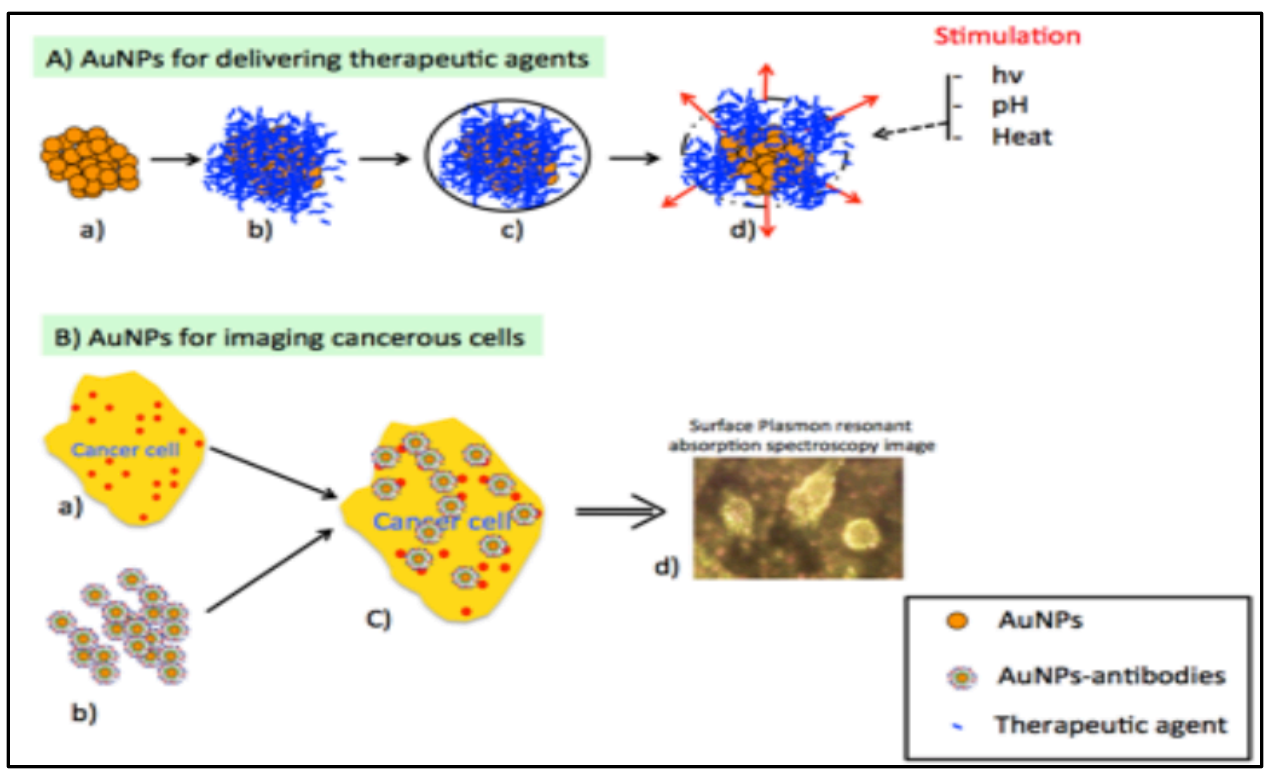

Figure 1.1 Gold Nanoparticles (AuNPs) for delivering therapeutic agents and imaging cancerous cells. A) AuNPs for delivering the therapeutic agents. a) bare-AuNPs, b) AuNPs loaded with therapeutic agent (proteins/DNA/RNA/drugs), c) encapsulation of AuNPs loaded with therapeutic agents, and d) release of therapeutic agents by the physiological ( $\mathrm{pH}$ and temperature) and external stimulatons (lights).B) AuNPs for imaging cancerous cells. a) cancer cell surface with biomarkers, b) AuNPs, tagged with anti-biomarkers, c) accumulations of biomarker tagged-AuNPs on cancer cell surface, and d) a surface plasmon resonant absorption spectroscope image showing only cancer cells through AuNPs accumulation (Guduru et al).

The advantages of AuNPs are: (i) biocompatibility due to its' inert and non-toxic nature, (ii) simplicity to fabricate and functionalization the surface of the nanoparticle, and (iii) physical properties of light emission and scattering which enables them to be nanoprobes for cancer cell imaging. The disadvantages of AuNPs are: (i) Inefficient drug release mechanism due to the dependence on the microenvironment conditions, (ii) Inability to image deep-tissue carcinoma due to the limitation of visible light penetration of a few hundred microns and (iii) targeted ability is completely driven by antibody matching which limits the application to those specific biomarkers. 
Iron oxide nanoparticles

More recently the use of iron oxide nanoparticles, especially $\mathrm{Fe}_{3} \mathrm{O}_{4}$ (magnetite) has become extremely popular due to their biocompatibility and their non-toxic nature. The development of various medical applications has been possible due to their unique properties. The ability of these nanoparticles to react to a magnetic force has been utilized in applications such as drug delivery, cell isolation and labeling, tissue repair, and hyperthermia. In the following sections an overview of these applications will be discussed.

Drug delivery

Like AuNPs, $\mathrm{Fe}_{3} \mathrm{O}_{4}$ nanoparticles which are magnetic nanoparticles (MNPs) can be used as drug delivery vehicles tailored to carry a wide range of therapeutics (drugs, DNA/RNA, and proteins) to the targeted site. Unlike AuNPs, MNPs non-zero magnetic moment allows the nanoparticle can be guided to the tumor site using an external magnetic field gradient, which eliminates the need to use mAbs for targeting. To avoid these nanoparticles from being recognized by the reticuloendothelial clearance system the MNPs' surface is modified with a hydrophilic molecule known as poly ethylene glycol (PEG).

\section{Cell labeling and Cell Isolation}

Cell labeling using MNPs begin by first conjugating the MNPs with mAbs to target specific cell types throughout the circulatory system. Once the antigen-antibody reaction or receptor is identified, the tagged MNPs is uptaken by the cell through mediated 
endocytosis or phagocytosis. Due to the magnetic properties of the nanoparticle we can use magnetic resonance imaging (MRI) and magnetic particle imaging (MPI) to detect and track the labeled cells. Due to the high saturation magnetization MPI can directly detect the signal from these nanoparticles to produce a 3D location and concentration of the nanoparticles within the circulatory system. The iron oxide nanoparticles are cleared naturally by the body through the mononuclear phagocyte system, which is then broken down in the liver and stored as iron to produce hemoglobin. The process of cell isolation from a biological fluid can be accomplished through incubating the tagged MNPs with cells in a Petri dish, once the MNPs attaches to the desired cells, wash away the excess cell labeled MNPs on a magnetic rack which in turn isolates the desired cells.

To summarize, the main advantages of using magnetic nanoparticles over non-magnetic nanoparticles are: (i) MNPs are able to be used as targeting vehicles for cancer cell, (ii) MNPs have the ability to be a contrast agent for MRI and MPI imaging, (iii) MNPs are able to be guided to any region in the body using an external magnetic field, and (iv) the temperatures of MNPs can be increased using high frequency magnetic fields to release therapeutic drugs off the surface of the nanoparticle as well as be used for thermal therapy to eradicate cancer cells. 


\section{Multiferroic Nanoparticles}

Multiferroics are materials that exhibit more than one of the ferroic order parameters such as ferromagnetism, ferroelectric, and ferroelasticity in the same phase. In the case of nanoparticles, we will focus on a multiferroic known as magnet-electric nanoparticle which demonstrates both ferroelectric and ferromagnetism parameters. The magnetic to electric energy conversion and vise-versa exploits the properties of two different phases, from two different materials simultaneously. The ferromagnetic material has a magnetostrictive property that connects to the piezoelectric property of the ferroelectric material. Thus, when an external magnetic field $(\Delta \mathrm{H})$ is applied, magnetostrictive stress is applied to the magnetic material causing a dipole ferromagnetic phase transfer to the ferroelectric phase causing a polarization $(\Delta \mathrm{P})$ to the associated electric field $(\Delta \mathrm{E})$. Performance of these materials is based on the phase transfer efficiency, known as magneto-electric coefficient $(\alpha=\Delta \mathrm{P} / \Delta \mathrm{H})$ or magneto-electric voltage coefficient $\left(\alpha_{\mathrm{E}}=\right.$ $\Delta \mathrm{E} / \Delta \mathrm{H})$. The magneto-electric coefficients of commonly used composites are shown in Table.1.

Table 1: Magnetoelectric coefficients of two-phase systems. (Note: $\mathrm{BaTiO}_{3}, \mathrm{~Pb}(\mathrm{Zr}, \mathrm{Ti}) \mathrm{O}_{3}$ (PZT) are ferroelectric materials; and TbxDy1-xFe 2 (Terfenol-D), ferrites, and manganite are ferromagnetic materials. ME coefficient measured in $\mathrm{mv} \mathrm{cm}^{-1} \mathrm{Oe}^{-1}$ )

\begin{tabular}{|c|c|c|c|}
\hline Morphology & Materials & $\begin{array}{c}\text { ME } \\
\text { coefficient }\end{array}$ & Ref. \\
\hline Composite & $\mathrm{BaTiO}_{3}$ and $\mathrm{CoFe}_{2} \mathrm{O}_{4}$ & 50 & $(66)$ \\
\hline Composite & Terfenol-D and PZT in polymer matrix & 42 & $(67)$ \\
\hline $\begin{array}{l}\text { Laminated- } \\
\text { composites }\end{array}$ & Terfenol-D and $\mathrm{PZT} / \mathrm{PZT}$ (in polymer matrix) & 3000 & $(68)$ \\
\hline Laminate & $\mathrm{Terfenol-D/PZT}^{-}$ & 4800 & $(69)$ \\
\hline Laminate & $\mathrm{La}_{0.7} \mathrm{Sr}_{0.3} \mathrm{MnO}_{3} / \mathrm{PZT}$ & 60 & $(70)$ \\
\hline Laminates & $\mathrm{NiFe}_{2} \mathrm{O}_{4} / \mathrm{PZT}$ & 1,400 & $(70)$ \\
\hline
\end{tabular}


The particulate composite morphology of these two-phase systems allows for better control of the magneto-electric effect due to the shape effects. The spherical shape of the composite provides a better transfer of magnetostrictive stress from the ferromagnetic phase to the ferroelectric phase. These two-phase systems have been the gold-standard for decades in many fields involving electronics, but more recently our group has implemented these two-phase systems to biomedical applications coining the term “Technobiology".

\section{Experimental Background}

Magnetic-Nanoprobe Bio-sensing

Early detection of cancer is key to creating a cancer-free world and helping those living with cancer. Researchers have proven that early stage treatment of premalignant abnormal cells is more effective and increases the rate of a successful treatment and extended life. However, traditional techniques have proven to be inefficient in cost, performance, and development. In the past, the screening of cancer has led to false positive and false negative results and consequently extremely invasive procedures have been performed. As a result, more recently there has been increased interest in magnetic nanoparticles bio sensing. Due to a new dimensionality provided by the presence of externally-controlled magnetic moments, magnetic nanoparticle bio sensing promises to enable high-specificity screening and fast diagnostics of cancer cells. Currently, the main challenge is coupling the magnetic nanoparticle to intrinsic information at the cellular or intracellular level with sufficiently high efficacy to process the information with current magnetic detection systems (17-19). In chapter 3 of this dissertation, using a two-phase 
nanoparticle composite we will investigate the coupling of magneto-electric nanoparticles to the electric signature of cells. The signatures obtained from each cell will correspond to a specific cell type and cancer progression stages bringing us one step close to rapid identification and early detection of cancer cells.

\section{Multiferroic Nanostructure Drug Deliver}

Multiferroic nanostructures exist when the crystal structures of two or more primary ferroic materials' properties are united in the same phase. In the case of our coreshell magneto-electric nanoparticles (MENs), composed of a spinel-core cobalt iron oxide $\left(\mathrm{CoFe}_{2} \mathrm{O}_{4}\right)$ and perovskite-shell barium titanate $\left(\mathrm{BaTiO}_{3}\right)$, at the nanoscale creates a nanotechnology capable of being externally controlled to deliver therapeutic drugs to cancer cells on demand with record-high specificity(20). Furthermore, such control can be physically separated via application of d.c. and a.c. magnetic fields, respectively. The control is achieved because, unlike traditional purely magnetic nanoparticles, MENs display a non-zero magnetoelectric (ME) effect due to their strongly coupled magnetostrictive and piezoelectric properties. Because of the ME effect, MENs provide a unique way to use external magnetic fields to control intrinsic electric fields which underlie the chemical bonds between the nanoparticle and the loaded drug as well as the interaction between the drug-loaded nanoparticle and the cellular microenvironment. In chapter 4 we will investigate how MENs are able to deliver therapeutic peptides past the blood brain barrier (BBB) to glioblastoma multiforme (GBM) brian cancer. 


\section{Conclusion}

The discovery of these exceptional capabilities of magneto-electric nanoparticles bridges the gap between nanotechnology and biology unprecedentedly. Throughout this dissertation, we will demonstrate that the intrinsic quantum mechanically coupled ferromagnetic and ferroelectric properties within these nanoparticles can be used for high-specificity therapeutic drug delivery. Furthermore, the intrinsic coupling between the magnetostrictive and piezoelectric phases allow MENs to be used as nuclear magnetic resonance sensitive nanoprobes for rapid cancer screening. In parallel, we will explore the underlying mechanism that defines the cell-nanoparticle interaction; which will lead to the optimization of these nanoparticles to be tailored to any type of cancer and/or normal cell. 
CHAPTER II: PHYSICS CONSIDERATION IN TARGETED ANTICANCER DRUG DELIVERY BY MAGNETOELECTRIC NANOPARTICLES 


\section{Introduction}

Adequately high specificity to target cancer cells while sparing normal cells remains one of the greatest challenges in cancer therapy to date (21-23). Ongoing research has attempted to address this fundamental challenge by using nanoparticles as targeted delivery vehicles. Due to their small sizes and unique shapes, nanoparticles can help steer a therapeutic load to specific targets and meet a wide range of requirements for overcoming numerous biological barriers (24-30). There are endless types of nanoparticle delivery systems, both passive and active, constantly being developed. Passive systems mostly rely on exploiting the enhanced permeability and retention (EPR) effect, which exists due to the high leakiness of tumor blood vessels and the lack of a lymphatic system for drainage (31-34). The delivery specificity can be further improved by adding an active delivery mechanism, for example, through conjugating nanoparticles with monoclonal antibodies (mAbs) tailored to recognize over-expressed tumor-specific biomarkers (35-41). In addition, nanoparticles must be able not only to provide highspecificity targeted delivery but also to ensure that the therapeutic load is not prematurely released in the plasma or interstitial space before it reaches the intended target (42-45). Therefore, nanoparticles have been further functionalized to control drug release by externally applied temperature $(46,47)$, ultrasound $(48,49)$, intracellular $\mathrm{pH}$ level $(50)$, intracellular enzymes (51), or magnetic fields (52-55). Nevertheless, all these approaches still have inadequately low efficacy.

In parallel, there has been a focus on using the phenomenon of electroporation for enabling a high-efficacy high-specificity cellular uptake of a drug (56-63). In this case, an electric field above a cell-specific threshold causes a dielectric breakdown of the cell 
membrane (64). This breakdown field is different for cancer and normal cells of the same type. For example, application of an electric field on the order of $1 \mathrm{kV} / \mathrm{cm}$ can create sufficiently large pores allowing for an enhanced cellular uptake of molecules by cancer cells while it takes a factor of two or five higher field to achieve this effect in the normal cells. Although very promising, the electroporation involves relatively high electric fields at a relatively large scale and thus comes with collateral damage.

This chapter presents a basic physics model to help understand how a class of multiferroic nanoparticles known as magnetoelectric nanoparticles (MENs) could address key challenges in modern cancer therapy (65-73). Indeed, MENs provide (a) targeting mechanism driven by a physical force rather than antibody matching, (b) a delivery mechanism that enhances the cellular uptake of a therapeutic load across cancer cell membranes only, without affecting normal cells, (c) an externally controlled mechanism that releases the drug-load on demand, last but not least (d) due to the presence of a magnetic moment, they can be used for image-guided therapy. With the above said, MENs present a novel platform to treat cancer not from the perspective of bioinformatics but rather from the perspective of molecular-level physics, such an approach, hereinafter referred to as technobiology which is complementary to the traditional biotechnology approach. 


\section{Underlying Physics}

Difference between MENs and magnetic nanoparticles (MNPs)

MENs should not be confused with traditional magnetic nanoparticles (MNPs), e.g., superparamagnetic iron oxide nanoparticles (SPIONs) (74-77) or other superparamagnetic and non-superparamagnetic ferromagnetic or ferrimagnetic nanostructures used for targeted delivery or magnetic imaging (78-81). Like MNPs, MENs have a non-zero magnetic moment and therefore can be transported via application of an external d.c. magnetic field with a non-zero spatial gradient. Also, the negative feedback loop required for image-guided navigation can be closed through existing magnetic imaging techniques such as magnetic resonance imaging (MRI) or magnetic particle imaging (MPI) (82-84). However, unlike MNPs, MENs offer a novel functionality - an energy-efficient control of intrinsic electric fields on the surface of the nanoparticles via application of external d.c. and a.c. magnetic fields. Due to the magnetoelectric effect (ME) effect property of MENs, the external magnetic field controls the electric fields that underlie the intrinsic molecular interactions between specific cells and the drug-loaded nanoparticles as well as the interaction between MENs and the loaded drug. An immediate consequence of this capability is the freedom to engineer an adequately strong bond between the nanoparticles and the drug to avoid an undesired release of the therapeutic load before it reaches the target; only when an a.c. magnetic field is applied, this strong bond is "turned off" on demand. This mechanism of using an a.c. field to controllably break the bond between MENs and the load has been previously described with regard to the topic of delivery of antiretroviral therapy across the blood-brain barrier (BBB) to treat HIV-1 virus hidden deep in the brain (85). In 
addition, due to the ME effect, using MENs opens a pathway to exploit intrinsic electric properties of the cell membrane at the nanoscale for enabling targeted high-specificity delivery without relying on any bioactive mechanism. The cell membrane, consisting of numerous ion channels, is an electrically polarizable medium, and its electric charge strongly depends on the cellular microenvironment, e.g., its $\mathrm{pH}$ level. As a result, cellular properties for cancer and normal cells are significantly different when exposed to local electric fields $(86,87)$. This difference is the basis for using electroporation for inducing a high-specificity drug uptake by cancer cells. According to the conventional approach using electroporation-based cancer treatment, a relatively large electric field, on the order of $1000 \mathrm{~V} / \mathrm{cm}$ is applied at the macroscale, which inevitably results in undesired side effects. With MENs, this property of electroporation can be scaled down to the nanoscale. As a result, the MEN-induced electroporation, hereinafter referred to as nanoelectroporation, would result in significantly reduced side effects because the relatively high field is limited to the nanoscale region in proximity to each nanoparticle. In addition, the specificity factor (SF), defined as the ratio of the average number of nanoparticles penetration into a cancer cell versus the average number of nanoparticles penetration into an adjacent normal cell under equivalent conditions, can be significantly increased in the case of the nanoelectroporation, as discussed below in more detail. Due to this nanoelectroporation ability, MENs not only further improve the specificity of the EPR-based delivery but also add another targeting mechanism to enable passive delivery at the intracellular level and thus pave a way to treatment of both primary and secondary tumors at different cancer progression levels. Finally, because of the fundamental nature of this externally controlled approach, MENs can be used to treat all kinds of cancers 
including fast-progressing brain tumors and other solid and liquid tumors. Brachytherapy would be one example of a current approach which could be completely replaced by MENs. Brachytherapy uses a sealed radioactive pellet, e.g., made of iridium, placed close to a tumor site through catheters (92). When activated, the pellet emits radiation which kills both cancer and normal cells a few millimetres away. Using field-activated MENs instead of the strongly radioactive pellet can significantly improve the specificity of the treatment and thus reduce or eliminate side effects.

Synthesis and characterization of MENs

MENs can be synthesized according to standard chemical procedures described in previous studies. One of the most popular room-temperature configurations is the coreshell nanostructure made of a magnetostrictive core, e.g., CoFe2O4, and a piezoelectric shell, e.g., BaTiO3 (88-91). By default, in this dissertation, the average size of MENs is approximately $30 \mathrm{~nm}$ and the average size of the core is approximately $10 \mathrm{~nm}$. X-Ray diffraction (XRD) measurements have confirmed the cubic and tetragonal crystal structures of the core and shell, respectively. Depending on the application, whether it is for a drug delivery, a neural stimulation, or 3D navigation and/or imaging, MENs can be further coated with thin functionalization layers serving as linkers to the therapeutic load or to enable hydrophilic or hydrophobic surface suitable for the microenvironment of interest. The ME coefficient, $\alpha$, for these nanostructures is known to be in a range from 10 to over $100 \mathrm{mV} \mathrm{cm-1} \mathrm{Oe-1,} \mathrm{depending} \mathrm{on} \mathrm{the} \mathrm{phase} \mathrm{compositions}$ and the quality of the interface between the core and the shell. The saturation magnetization of these particular MENs is on the order of $10 \mathrm{emu} / \mathrm{g}$, which is an order of 
magnitude smaller than that for high-moment iron oxide nanoparticles. Considering the core is made of a relatively high anisotropy structure, these MENs are not superparamagnetic and have a room temperature coercivity on the order of $100 \mathrm{Oe}$. On a final note, it is worth noting that in general MENs are not limited to this particular composition. There are many other compositions which display a non-zero ME effect. Furthermore, it is likely that in the future MENs will be made of biodegradable organic materials; for example, carbon based nanostructures which have already been shown to display a non-zero ME effect (93).

\section{Targeting by MENs}

In general, there are two fundamentally different approaches to targeting with MENs, using local and systemic administration of nanoparticles, respectively. For the local administration, MENs could be either directly injected into a tumor site or navigated to the target site via application of localized magnetic fields after the nanoparticles are administrated in the vasculature. For example, it has been shown that using MRI-guided navigation with a pulsed sequence of field gradients, magnetic nanoparticles could be localized at any point in a $3 \mathrm{D}$ space with a spatial precision of less than $0.1 \mathrm{~mm}(94)$. For the systemic administration, MENs could be administrated intravenously. In either case, the delivery and uptake specificity could be further significantly improved due to the following physics.

Unlike purely active delivery approaches, e.g., using mAbs, T-cells (CAR TCell), or cancer vaccines, MENs offer a passive delivery mechanism, which is complementary to the well-known EPR effect (95). The EPR effect ensures delivery of 
drug-loaded nanoparticles into relatively large tumor aggregates but not in relatively small aggregates made of one or few cancer cells. In contrast, due to a different underlying physics, MENs-driven targeting works equally well with cell aggregates and individual cells. Because MENs generate their own electric fields, which in turn can be controlled by external magnetic fields, they can specifically electroporate cancer cells only without affecting surrounding normal cells, as described below in more detail. In this case, the localization range of the nanoparticle-generated electric field is defined by the nanoparticle's average size, which is approximately $30 \mathrm{~nm}$. In turn, this localization range is orders of magnitude smaller than the characteristic cell size, which is on the order of a few microns. Therefore, MENs could be used to target primary and metastasized cancer cells even at a very early stage of cancer progression. Last but not least, because of the existence of an externally controlled surface charge, MENs bring another dimension to targeted delivery; not only can they increase the specificity factor but also can provide new functions of externally controlled cancer cell penetration and drug release via application of external magnetic fields. In a trivial approximation, the electric field generated by a MEN at a point on the cell membrane consists of two terms:

$$
\mathrm{E}=\mathrm{k} \frac{3(\mathrm{p} \cdot \hat{\mathrm{r}}) \hat{\mathrm{r}}-\mathrm{p}}{\mathrm{r}^{3}}+\frac{\mathrm{kQ}}{\mathrm{r}^{2}} \hat{\mathrm{r}},
$$

where $\mathrm{k}$ is the Coulomb constant, $\mathrm{Q}$ and $\mathrm{p}$ are the MEN's electric charge and dipole moment, respectively, and $\mathrm{r}$ is the distance between the nanoparticle and the observation point on the membrane. The first term is determined by the magnetic-field dependent electric dipole moment due to the ME effect, $p=\alpha \mathrm{H}$, where $\alpha$ is the ME coefficient and $\mathrm{H}$ is the external magnetic field. The second term is determined by the surface electric charge which is formed according to the colloidal chemistry when MENs 
are placed in a solution, e.g., the blood or the lymph. In this case, a double charged layer is formed around the nanoparticle's surface because of the interplay of chemical and electrical forces. The surface charge can be determined by measuring Zeta potential. Furthermore, previously it has been shown that this surface charge can be further increased with an external magnetic field increase; in other words, the field dependence of the surface charge also depends on the ME effect. It can be noted that the surface charge term has a more significant effect because it drops with a distance substantially slower $(\sim 1 / \mathrm{r} 2)$ compared to the dipole charge term $(\sim 1 / \mathrm{r} 3)$.

Because both MENs and the cell membranes have the same charge polarity, MENs can easily go through a capillary without being engulfed by the surrounding cells. However, when MENs are in close proximity to the cell membranes (within a distance on the order of a micron), their electric field (on the order of $0.1 \mathrm{~V} / \mu \mathrm{m}$, as shown below mostly due to the charge) is sufficiently strong to induce a local dielectric breakdown in the cancer cells but not too strong $(\$ 1.5 \mathrm{~V} / \mu \mathrm{m})$ where it may cause this effect in the normal cells. This dielectric breakdown is reflected in a local change of the lipid bilayer of the cellular membrane. Such a field-dependent local change leads to cellular uptake of the drug-loaded nanoparticles through the membrane surface. Indeed, it is known that the conductivity of the intermediate cancer cell membrane is by three orders of magnitude larger than that of the normal cell membrane (97). The high-conductivity membrane induces a local attraction force between MENs and the cancer cell due to the electrostatic "mirror" effect. Here, it is worth noting that this nanoelectroporation effect could be further increased through application of a pulsed magnetic field sequence. In this case, the intermediate high-conductivity breakdown state effectively lasts longer and thus the 
efficacy of this treatment is significantly increased. That is the reason why the a.c. field application might be more effective compared to the d.c. field application. However, to simplify the explanation, the following description is focused on the d.c. case. In a first order approximation, there are two distinct states of the membrane. In its normal state, the membrane is non-conducting. In this case, the negatively charged MENs are pushed away from the negatively charged membrane surface. On the contrary, during the intermediate nanoelectroporation process, the membrane surface of the cancer cells is conducting and thus MENs are attracted to the cancer cells. According to the "mirror image" model, the attraction force could be estimated with this expression,

$$
F_{\text {mirror }}=\mathrm{kQ}^{2} / 4 \mathrm{r}^{2} \text {, }
$$

where the factor $1 / 4$ is due to the fact that the effective distance between the real and image charges is $2 r$, while $r$ is the distance between the nanoparticle and the membrane surface. Furthermore, as previously shown, the effective surface charge and thus this attraction force can be further increased with an increase in the externally applied magnetic field. This magnetic field dependence of the charge can be found through an experimental measurement of Zeta potential, $\mathrm{V}(\mathrm{H})$, in a phosphate buffer solution (PBS) with a $\mathrm{pH}$ level similar to that in the blood, $\mathrm{Q}=\mathrm{V}(\mathrm{H}) \mathrm{d} / \mathrm{k}$. Now, it is possible to estimate the cut-off distance between the nanoparticle and the membrane surface, $\mathrm{r}_{\mathrm{C}}$, below which the electric field would be above the nanoelectroporation threshold on the order of $0.1 \mathrm{~V} / \mu \mathrm{m}$ for the cancer cells: $\mathrm{r}_{\mathrm{C}}=0.5(\mathrm{kQ} / \mathrm{E})^{1 / 2}$. For example, it has been shown that application of a magnetic field on the order of 300 Oe could increase the cut-off distance by a factor of two. Such an increase would significantly increase the number of the nanoparticles capable of triggering local nanoelectroporation and 
consequently would significantly increase the specificity factor of targeted delivery. This concept of MEN-based targeting is illustrated in Figure 1. It could be noted that this overly simplified theory does not take into account the laminar flow in the circulation.

(a)

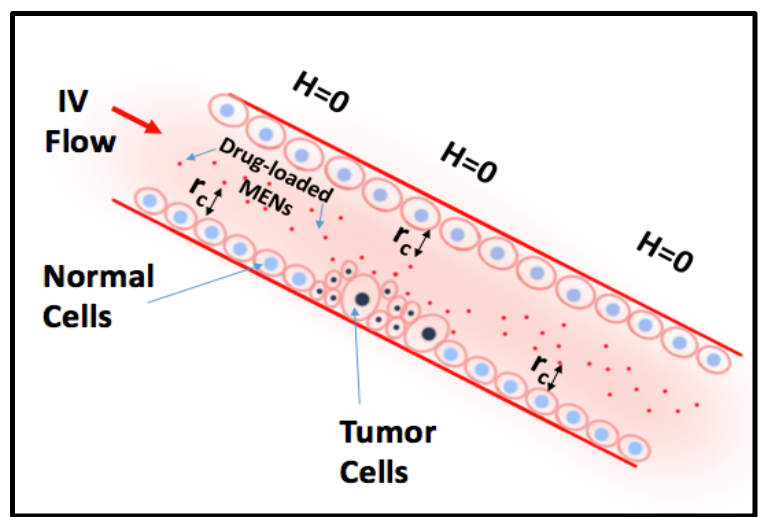

(b)

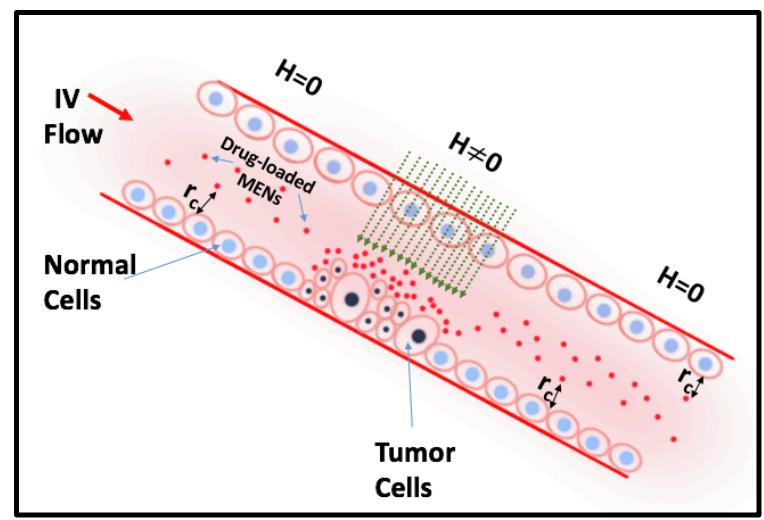

Figure 2.1. Illustration of the dependence of the cutoff distance, rc, on application of an external d.c. magnetic field,H. (a) The nanoparticles within this distance from the membrane surface target the cancer cells due to the high-specificity nanoelectroporation effect. (b) The distance is increased with an increase in the magnetic field.

\section{On-demand drug release by MENs}

After the drug-loaded MENs enter the cancer cells, the drug can be released off the nanoparticles on demand via application of an a.c. external magnetic field. In this case, as previously shown, even a relatively small magnitude a.c. field $(\leqslant 50$ Oe $)$ in the near-d.c. frequency ranging from 10 to over $100 \mathrm{~Hz}$ is sufficiently strong to release substantial amount of the drug into the cancer cells. It has been hypothesized that application of an a.c. field "shakes" the drug off the nanoparticles by significantly weakening the electricfield bond which holds the two together, as illustrated in Fig. 2.2 According to the trivial model, the electric dipole moment induced by an external magnetic field due to the ME. 
effect is $\Delta \mathrm{P}=\alpha \mathrm{H}$; therefore, the displaced surface charge density on the diametrically opposite side of the nanoparticle would be $\sigma \mathrm{ME} \sim \pm \alpha \mathrm{H}$. In other words, the magnetically triggered electric dipole moment breaks the symmetry of ionic bonds around the nanoparticle. To a zeroth approximation, when the displaced surface charge is comparable to the charge involved in an original bond, $\sigma \mathrm{ME} \sim$ Qionic/ $\pi \mathrm{d} 2$, the bond can be broken. Then, the threshold magnetic field amplitude to break a bond can be evaluated according to this simple expression:

$\mathrm{H}_{\text {th }} \sim \mathrm{Q}_{\text {ionic }} / \pi \mathrm{d}^{2} \alpha$,

where $\mathrm{d}$ is the diameter of the nanoparticle, $\alpha$ is the ME coefficient, and $\mathrm{Q}_{\text {ionic }}$ is the displaced charge in the ionic bond. Application of an a.c. field would break the bonds in all the orientations around the nanoparticle.

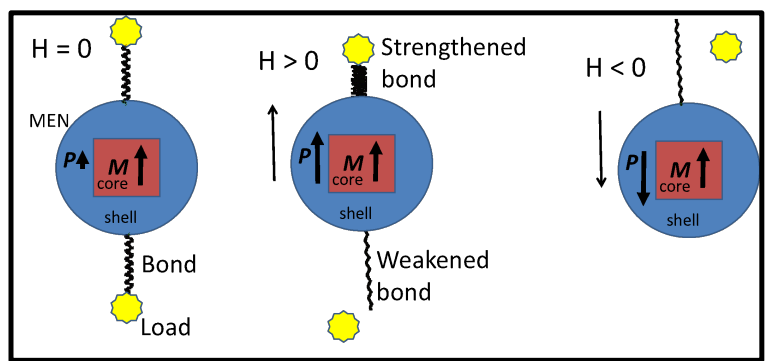

Figure 2.2. Illustration of the drug release mechanism via application of an a.c. magnetic field.

Here, it is worth reminding that it is imperative to release the drug off MENs to increase the drug bioactivity only after the drug-loaded MENs penetrate the cancer cells(76). In other words, MENs enable a drug retention control via application of external magnetic fields; the initial step of high-specificity cellular penetration and the final step of drug release off MENs are triggered via application of d.c. and a.c. fields, respectively. 
In summary, the above described three-step field-controlled process for targeted drug delivery and release, respectively, is illustrated in Fig. 2.3.

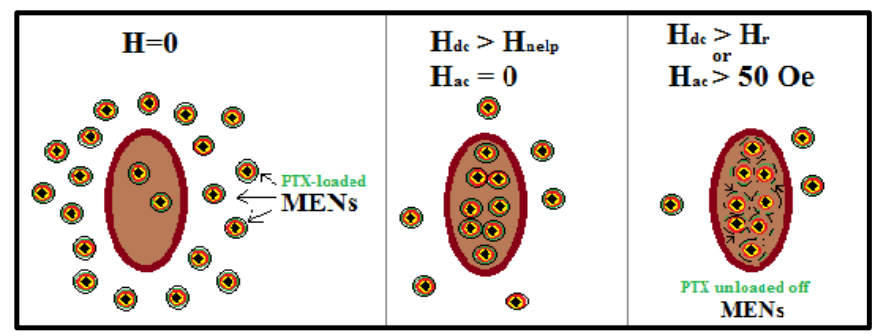

Figure 2.3. Illustration of targeted and release mechanism of delivering a therapeutic load to a cancer cell.

\section{Supporting Experiments}

Confocal microscopy study of high-specificity cellular penetration

The purpose of the first described in vitro experiment was to show how an external d.c. magnetic field could be used to induce a penetration of drug-loaded MENs into cancer cells. A popular mitotic inhibitor paclitaxel (PTX) was used as the therapeutic load. In the described microscopy experiments, the PTX's fluorescent version known as Flutax-2 was imaged at $488 \mathrm{~nm}$ (green color). A multidrug resistant cancer cell line MES-SA/DX5 was used to test the field-induced penetration. For comparison, similar images were taken for two other cases with cells incubated under equivalent conditions without any drug and just with the drug, respectively. Microscopy images of the two control cases and the cells incubated with MENs without and with exposure to a d.c. field of 30 Oe for approximately $12 \mathrm{~h}$ are shown in Figs. 2.4(a)-2.4(d), respectively. The optically measured percentages of the drug uptake per mg of protein in the four cases were 0 , less than $0.3 \%$, less than $0.2 \%$, and more than $6 \%$, respectively. According to the procedures 
of the experiment, the green light could be seen only from the drug coming from inside the cells, because all the extracellular material was washed away. The experiment clearly showed a strong field dependence of the cellular uptake of the drug-loaded MENs. Indeed, the uptake of the drug increased from less than $0.2 \%$ to over $6 \%$, i.e., by a factor of 30, after application of a relatively small d.c. field of 30 Oe.

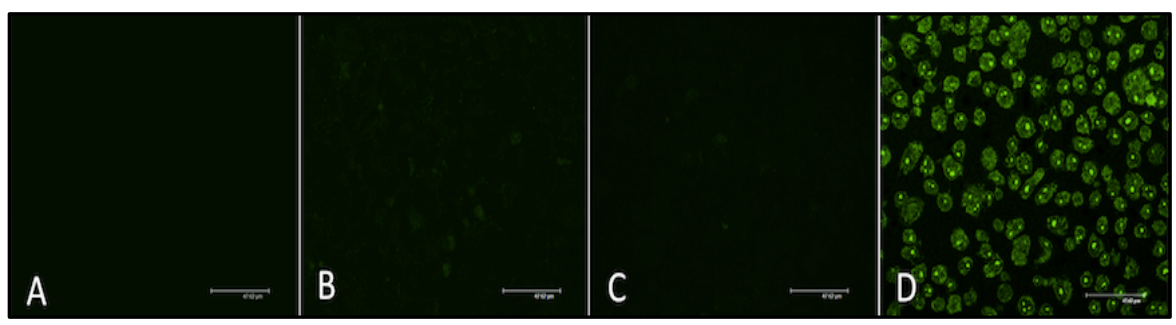

Figure 2.4. Confocal microscopy imaging of the uptake of Flutax-2 by cell line MES-SA/DX5 for four different drug-delivery-system combinations: (a) no drug, (b) free Flutax-2 (drug uptake per mg of protein: $<0.3 \%$ ), (c) MENs loaded with Flutax-2 with no field $(<0.2 \%)$, and (d) MENs loaded with Flutax-2 in a 30 Oe d.c. field $(>6 \%)$. The scale bar is approximately $50 \mathrm{um}$.

Another experiment was conducted to demonstrate a high-specificity cellular uptake with MEN-based delivery on ovarian cancer and normal cell lines SKOV-3 and HOMEC, respectively. The optically measured drug uptake depending on the applied d.c. magnetic field for cancer and normal cells is shown in Fig. 2.5. Indeed, it could be observed that there was a significant field range, from $\sim 50$ Oe to $\sim 500$ Oe, when visibly large amount of the drug penetrated the cancer cells while barely any drug penetrated the normal cells. As mentioned earlier, the effect of nanoelectroporation could be further increased via application of a periodic sequence of magnetic field pulses to effectively prolong the membrane's intermediate dielectric breakdown state which leads to the nanoparticles' cellular uptake. Application of an a.c. magnetic field partially mimics this pulsed sequence effect (53). Indeed, this a.c. field dependence was demonstrated in this study. 


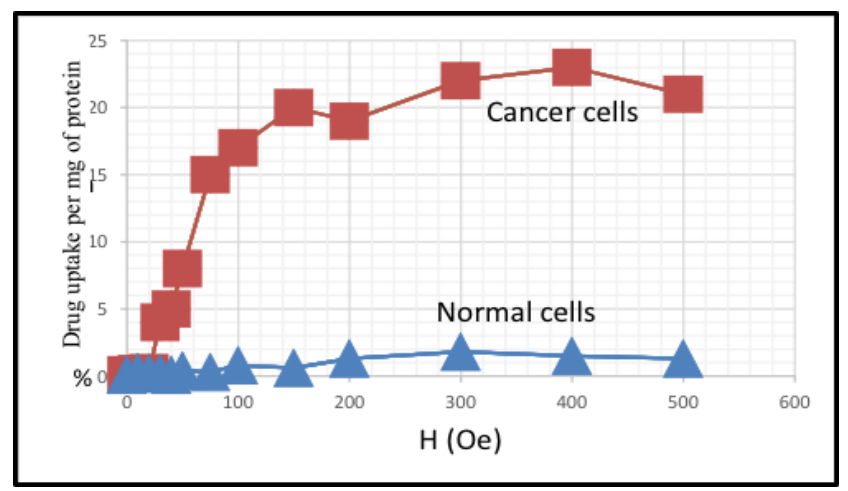

Figure 2.5. Optically measured (with a fluorometer) field dependence of the drug uptake per $\mathrm{mg}$ of protein for cancer and normal cell lines SKOV-3 and HOMEC, respectively.

Another experiment which demonstrated the field-dependent cellular penetration of MENs was conducted with atomic force microscopy (AFM) and magnetic force microscopy (MFM) imaging of cell lysates. This experiment directly confirmed the presence of MENs inside cancer cells only after application of a 100-Oe d.c. field.

Drug release off MENs via application of an a.c. field

The purpose of the following experiments was to prove that the therapeutic load could be released off MENs via application of an a.c. magnetic field. Consequently, the function of the drug release could be physically separated from the function of high-specificity targeting, in turn, achieved via application of a d.c. field.

In one experiment, the amount of the released drug (paclitaxel) was measured spectrophotometrically at its maximum absorption wavelength of approximately $230 \mathrm{~nm}$. It is known that the bioactivity of the drug significantly increases after the release due to 
the increased "free" surface area. The dependence of the released drug on the strength and frequency of the a.c. field ranging from 12 to $66 \mathrm{Oe}$ and 0 to $1000 \mathrm{~Hz}$, respectively, for different application times ranging from $1 \mathrm{~min}$ to $2 \mathrm{~h}$, is shown in a chart in Fig. 2.6.

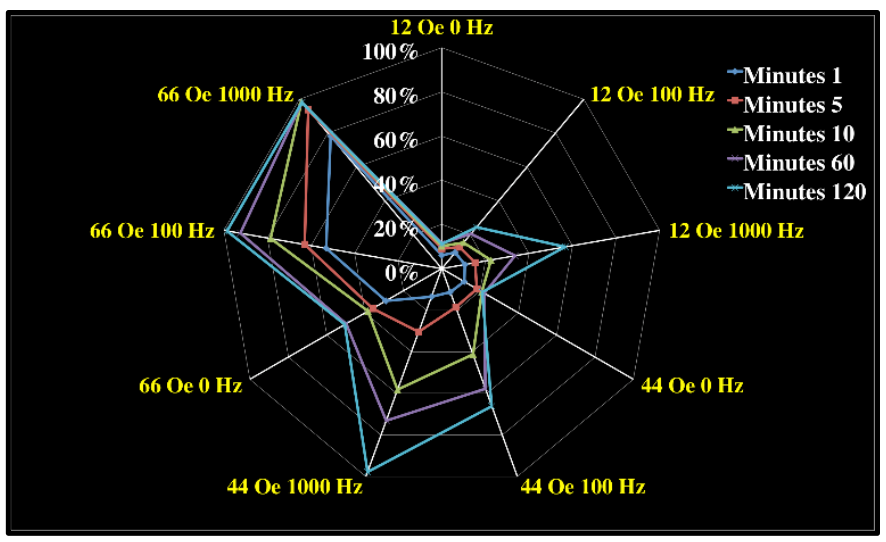

Figure 2.6. The dependence of the release of the drug, paclitaxel, on the a.c. field strength and frequency for five different application times: 1, 5, 10, 60, and $120 \mathrm{~min}$. The data were measured spectrophotometrically as the absorbance at $230 \mathrm{~nm}$ wavelength.

Liquid-environment atomic force microscopy study of the nanoparticle-cell interaction A liquid environment atomic force microscopy (AFM) study was conducted with the goal to directly measure the surface of cancer and normal cells under different experimental conditions. In the following experiment, glioblastoma (U87-MG) and endothelial cells were used as the cancer and normal cells, respectively. Glioblastomas represent the most frequent primary brain tumors while endothelial cells are characteristic normal brain cells. It was already demonstrated that drug-loaded MENs could be navigated across the blood-brain barrier (BBB) via application of a sufficiently strong d.c. magnetic field gradient (on the order of $1000 \mathrm{Oe} / \mathrm{cm}$ ) with the subsequent controlled release of the drug after the nanoparticles are placed deep in the brain (85). Typical AFM images of endothelial and glioblastoma cells are shown in Figs. 2.7(a) and (b), respectively. It can be noted that the normal cells have a more continuous surface morphology compared to 
the cancer cells with clearly visible striations with a characteristic size on the order of $100 \mathrm{~nm}$.
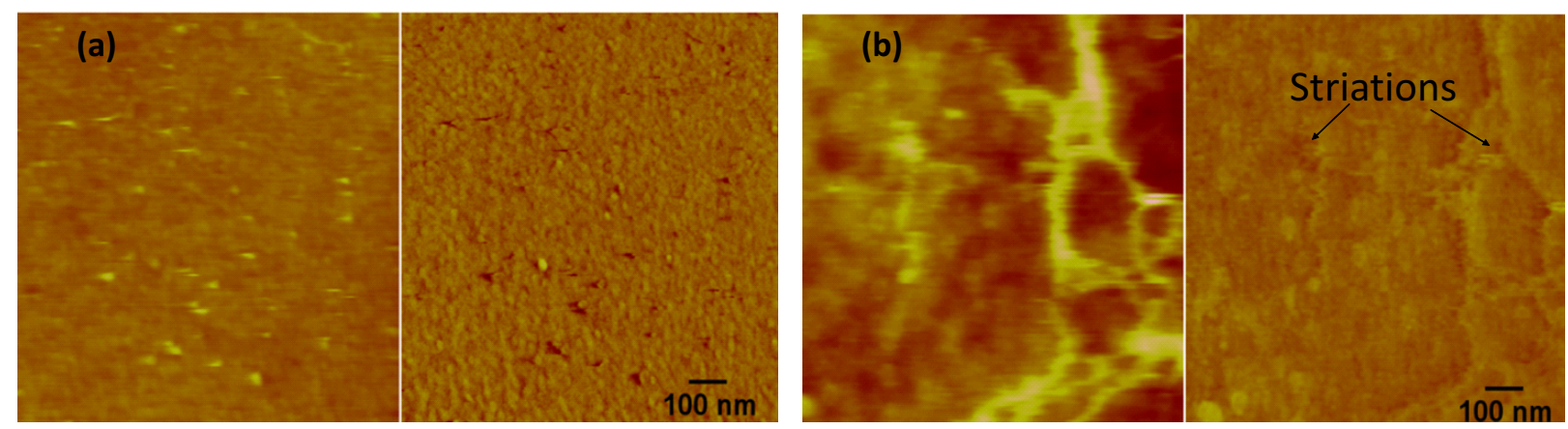

Figure 2.7. AFM image pair (z height and phase (right)) for (a) endothelial and (b) glioblastoma cells.

Another AFM experiment was conducted to understand how MENs penetrated the cancer cells. MENs were added into media with glioblastoma cells through a special Multimode liquid environment microprobe container. Here, it is worth noting that usually when nanoparticles or other nanoscale foreign reagents get attached to the membrane surface, they quite rapidly (within seconds) move across the membrane and penetrate the cell. The exact origin of this process still remains an open question; it might be defined either by a chain signaling between biomolecules within the cell or by some electric field effects in the membrane and the cellular plasma or a combination of these two effects. It is not trivial to use AFM to observe the fast dynamic of the nanoparticle-cell interaction. To slow down the cellular uptake of the nanoparticles, this experiment was conducted at a relatively high concentration of MENs to ensure the cells are saturated and as a result the nanoparticles become visible on the membrane surface. An important observation of this experiment was the fact that the nanoparticles preferred to penetrate the cancer cell through the striations in the cellular membrane, as shown in Fig. 2.8. 


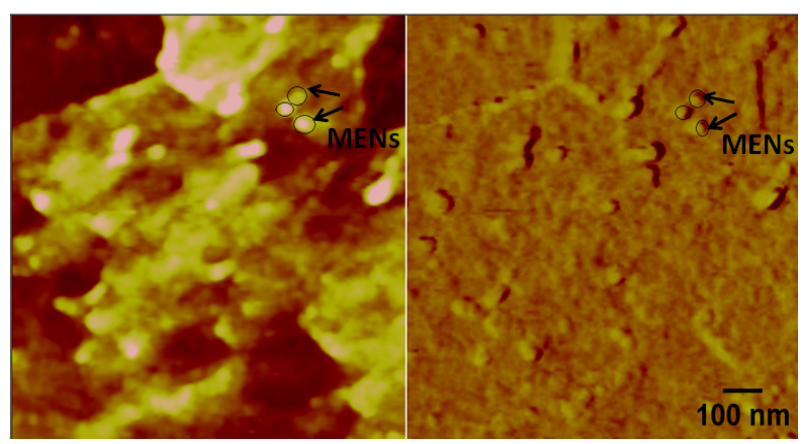

Figure 2.8. AFM image pair ( $\mathrm{z}$ height and phase (right)) for glioblastoma cells with MENs found in striations on the surface membrane. The observed nanoparticles are approximately $30-\mathrm{nm}$ in diameter.

Finally, it could be mentioned that MENs operate at relatively low fields and frequencies and thus do not cause significant heating effects, as was confirmed through infrared measurements of the cell surface at different concentrations of MENs under different field exposures

\section{Conclusion}

The discussed experiments have demonstrated that MENs could be used for externally controlled targeted drug delivery and release. Furthermore, these two important functions, i.e., delivery and release, could be physically separated via application of d.c. and a.c. external magnetic fields, respectively, as indicated by the hypothesized theory and confirmed by a number of independent experiments. For example, confocal microscopy studies have directly confirmed that the penetration of MENs into cancer cells occurs only after the application of a d.c. magnetic field on the order $100 \mathrm{Oe}$, while numerous spectrophotometry measurements have shown that the drug is released off the nanoparticles only after the application of an a.c. magnetic field with a strength on the 
order of $50 \mathrm{Oe}$ and a near-d.c. frequency of $100 \mathrm{~Hz}$. As for the high-specificity delivery, one of the most important characteristics of MENs is their ability to deliver drugs specifically into the cancer cells without affecting the surrounding normal cells. The penetration fields due to the nanoelectroporation, i.e., the mechanism according to which the delivery takes place, are different for the two cell forms, i.e., cancer and normal cells, respectively, because their membranes have different surface morphologies and charge configurations, as shown through transport measurements and AFM studies. As a result, it takes a significantly higher field to break the dielectric barrier of the normal cell membranes compared to that of the cancer cells. As mentioned above, it is well known that even at the macroscale, the cancer cells have a smaller threshold field for the electroporation compared to their normal counterparts; the difference is a factor of two to five depending on the cancer type. The discussed experiments with MENs have shown that at the nanoscale the difference becomes even more significant. For example, for the ovarian and normal cancer cell lines, SKOV-3 and HOMEC, respectively, it takes less than $100 \mathrm{Oe}$ and significantly more than $1000 \mathrm{Oe}$, respectively, to induce the nanoelectroporation via the $\mathrm{ME}$ effect. That is the reason why we refer to the electroporation (by MENs) at the nanoscale as the nanoelectroporation. The nanoelectroporation seems to have a significantly higher specificity factor compared to the traditional electroporation effect which takes place at the macroscale. The AFM imaging of equivalent glioblastoma cancer and normal endothelial cells has shown very different surface topographies for the two cell types; the normal cells are more continuous compared to the cancer cells which in turn have visible striations of the characteristic size on the order of $100 \mathrm{~nm}$. The AFM images have also shown that 30-nm 
MENs tend to accumulate in these striations and thus penetrate the cell through these striations. The fact that the nanoparticles penetrate the cancer cells through the small striations in the membrane might explain why the ratio between the nanoelectroporation threshold fields between cancer and normal cells is more significant $(\gtrsim 10)$ compared to that for the traditional electroporation at the macroscale $(\sim 2-5)$. It is worth noting that due to the intrinsic nature of the ME coupling in the multiferroic nanostructures, the magnetic field strength on the order of $100 \mathrm{Oe}$, required for enabling the high-specificity delivery and release functions, is substantially below any harmful limits as per US Food and Drug Administration (FDA) regulations (98). Eventually, because of the fundamental nature of this approach, it can be applied to any cancer type. Last but not least, it can be mentioned that most current studies have been performed with MENs of the same coreshell composition, i.e., $\mathrm{CoFe}_{2} \mathrm{O}_{4}-\mathrm{BaTiO}_{3}$. These experiments have been vital to demonstrate the feasibility of the MEN-based cancer treatment approaches. In the future, other compositions can be explored, e.g., ones made of biodegradable organic materials. 


\section{Materials and procedures}

Chemical synthesis of MENs

CoFe2O4-BaTiO3 core shell MENs were prepared according to a polyvinylpyrrolidone assisted hydrothermal method. First, $0.058 \mathrm{~g}$ of Cobalt Nitrate Hexahydrate $(\mathrm{Co}(\mathrm{NO} 3) 2 \cdot 6 \mathrm{H} 20)$ and $0.16 \mathrm{~g}$ of Ferric Nitrate Nonahydrate $(\mathrm{Fe}(\mathrm{NO} 3) 3 \cdot 9 \mathrm{H} 20)$ were dissolved by stirring in $15 \mathrm{ml}$ of distilled water. Polyvinylpyrrolidone (PVP), $0.2 \mathrm{~g}$, was dissolved in $5 \mathrm{ml}$ of aqueous solution containing $0.9 \mathrm{~g}$ of sodium borohydride. The PVPsodium borohydride solution was added dropwise to the above solution and the mixture was stirred at $120^{\circ} \mathrm{C}$ until the liquid phase evaporated. $\mathrm{CoFe} 2 \mathrm{O} 4$ particles were recovered, dispersed in distilled water through sonication, and washed 3 times using magnetic separation. Purified $\mathrm{CoFe} 2 \mathrm{O} 4$ cores were dried at $120^{\circ} \mathrm{C}$ for $24 \mathrm{~h}$ and stored at room temperature until further use. The Barium Titanate (BaTiO3) shell was prepared using the citrate gel method. Briefly, $\mathrm{CoFe} 2 \mathrm{O} 4$ cores were dispersed in distilled water through sonication. Barium Carbonate (BaCO3), $174 \mathrm{mg}$, was dissolved in $60 \mathrm{ml}$ deionized water containing $1 \mathrm{~g}$ of citric acid. This solution was mixed with a $150 \mathrm{ml}$ ethanolic solution of titanium (IV) isopropoxide $(284 \mu \mathrm{l})$ and $6 \mathrm{~g}$ citric acid. The BaTi precursor solution was added to the cores and sonicated at room temperature for $1 \mathrm{~h}$. The translucent yellow liquid was stirred at $70^{\circ} \mathrm{C}$ until the liquid phase evaporated completely. Finally, the gel was calcined at various temperatures ranging from 500 to $800{ }^{\circ} \mathrm{C}(\mathrm{CMF}-1100)$ for $5 \mathrm{~h}$ and cooled naturally to room temperature. The gelation temperature and the final temperature were important determinants of the crystal structure and the final size of CoFe2O4-BaTiO3 core shell MENs. For example, a temperature of $600{ }^{\circ} \mathrm{C}$ was required for 30-nm MENs. 
Atomic force microscopy

The imaging of both glioblastoma and brain endothelia cells in a cellular microenvironment was conducted using a MultiMode AFM system. Using a Bruker electrochemistry fluid cell probe holder that has an integrated piezo element for contact mode experiments and Bruker's DNP-S10 silicon nitride probe, we were able to achieve the desired results showing the interaction between MENs and the surface of a cell. The DNP-S10 probe comes with four different cantilevers of various dimensions each having a different nominal spring constant value and resonant frequency. The special C triangular shape cantilever was used for cell imaging; the cantilever has a nominal resonant frequency of $56 \mathrm{kHz}$ and a nominal spring constant of $0.24 \mathrm{~N} / \mathrm{m}$ which are ideal values for imaging stiff and firmly attached samples. After placing the probe in the liquid solution, which for this experiment was phosphate buffer solution (PBS), the resonant frequency dropped to $8 \mathrm{kHz}$, i.e., an order of magnitude lower compared to the frequency in air. After obtaining a lower resonant frequency, the probe was engaged with the membrane surface for scanning at a frequency rate of $0.100 \mathrm{~Hz}$ and a scan size of $100 \mathrm{~nm}$; these two parameters were gradually increased until an adequate quality image was obtained. 
CHAPTER III: NUCLEAR MAGNETIC RESOSNACE SENSITIVE NANOPROBE FOR CANCER CELL DETECTION BY MEGNETOELECTRIC NANOPARTICLES 
Introduction

Expedited detection of cancer is the first step in creating a cancer-free world. Research has shown that early detection and treatment of premalignant abnormal cells can prevent most cancer deaths from occurring. However, traditional techniques which rely on biochemical staining require a tedious sample preparation and are limited to a few biomarkers. As a result, there have been increased interests in magnetic nanoparticle bio sensing (MNPsB). Due to the external control of the magnetic moment, MNPsB promises to enable high-specificity screening and rapid diagnostics of carcinomas (99-103). However, the current progress in this area remains relatively slow; the main challenge is coupling the intrinsic cellular information to the magnetic nanoparticle with high efficiency to process the information with current magnetic detecting systems. In the cellular microenvironment each cell structure is characterized by a certain membrane surface morphology, which results in a signature electric field configuration based on cell type and prognosis stage. While current system measures magnetic fields, the intrinsic cellular information is reflected in electric fields that traditional MNPs are unable to translate $(104,105)$. To address this problem, we propose using multiferroic nanostructures known as magnetoelectric nanoparticles (MENs) capable of coupling the electric signature of cancer cells, which is based on cell type and prognosis stage, to the magnetoelectric effect property of the nanoparticles(106-110). MENs have proven to have magnetic and electric dipole moments which are correlated through the ME effect (66-69). Due to the electric charge interaction of the nanoparticle and the cellular membrane, the nanoparticle tends to attach to specific cell sites. This attachment provides access to the cells' intrinsic cellular information, which can be converted due to the ME 
effect and processed using current magnetic detectors. The ME effect created by a ferroelectric phase shift on the nanoparticle (from the cellular membrane) to the ferromagnetic core of the nanoparticle which allows the intrinsic electric field information of the cell to be translated into specific magnet field patterns, capable of being measured using current magnetic detection systems i.e. NMR systems.

\section{Experimental Results}

For comparison, MENs and conventional MNPs were integrated into media with different cancer and normal cells and measured in a NMR spectra under equivalent conditions. Specifically, the mean diameter of the core-shell MENs $\left(\mathrm{CoFe}_{2} \mathrm{O}_{4} @ \mathrm{BaTiO}_{3}\right)$ were $30 \pm 6 \mathrm{~nm}$ and displayed a strong ME effect. Compared to that of the ferromagnetic MNPs $\left(\mathrm{CoFe}_{2} \mathrm{O}_{4}\right)$ with a diameter of $15 \pm 4 \mathrm{~nm}$ and displayed no ME effect.

Figure 3.1a and b show room-temperature M-H hysteresis loops of MNPs and MENs, respectively, measured using vibrating sample magnetometry (VSM) system. The M-H hysteresis loop measures how much magnetic energy is required to align the dipole moment of a ferromagnetic material. During this measurement, once a critical field is applied to the ferromagnetic material, a saturated state is formed and the dipole moment is completely aligned with the external field causing the magnetization of the material. During magnetization, the material is magnetized indefinitely, even after removing the external magnetic field. To demagnetize the material, which depends exclusively on the coericivity of the material; heat or a much higher external magnetic field in the opposite direction must be applied. Despite the fact that the magnetic components in the two cases were equivalent, according to the magnetic hysteresis loops, MNPs and MENs had 
saturation magnetizations of approximately 40 and $1 \mathrm{emu} \mathrm{g}^{-1}$, respectively, and coercivity fields of approximately 90 and $310 \mathrm{Oe}$, respectively. To understand the MENs' temperature dependence and measure the transition into the superparamagnetic mode. In the case of superparamagnetic mode the nanoparticle is no longer stable, meaning the orientation of the magnetic dipole moment will began to randomly flip under the influence of temperature. Typical M-H hysteresis loops of MENs in a temperature range from 4 to $300 \mathrm{~K}$ were obtained via a cryogenic vibrating sample magnetometer Quantum Design PPMS. The standard magnetization versus temperature curves under zero field cooling (ZFC) and non-zero field cooling (FC) conditions that determine the blocking temperature are shown in Fig. 3.1d. The blocking temperature is the temperature above which the nanoparticles become superparamagnetic. In this case, it is above $300 \mathrm{~K}$, which confirms that the magnetic cores of MENs do not become superparamagnetic at room temperature despite their small size. The ME coefficient, $\alpha$, for these nanostructures has been previously measured to be in the range from 10 to over $100 \mathrm{mV} \mathrm{cm}-1 \mathrm{Oe}^{-1}$.

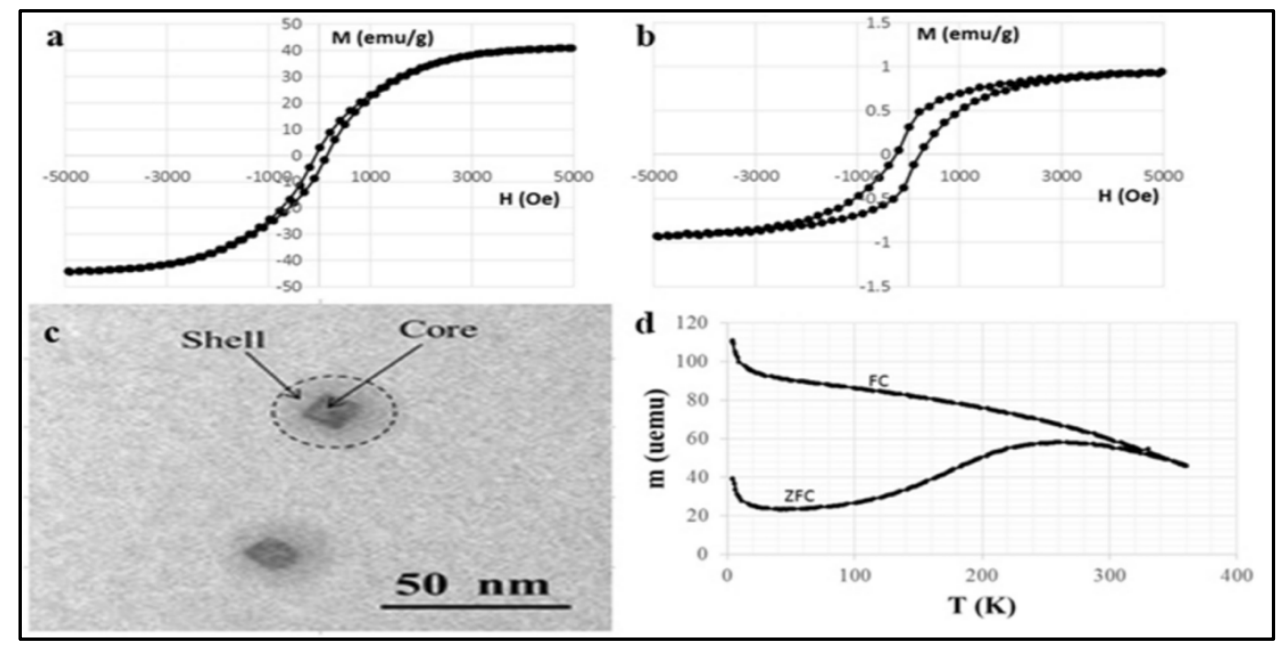

Figure 3.1. Characterization measurements of MENs. Room-temperature M-H hysteresis loops of (a) 30-nm MENs and (b) 15-nm MNPs. (c) Shows A TEM image showing a coreshell structure of 30-nm MENs. (d) Blocking temperature measurement curves including zero-field cooling (ZFC) and field cooling (FC) curves in a field of 100 Oe. 
Figure 3.2 shows continuous wave NMR (CW-NMR) spectra for three cancer and one normal cell lines under study, including ovarian carcinoma cells Skov3, glioblastoma cells U87-MG, breast adenocarcinoma cells MCF-7, and normal brain endothelial cells, respectively, all without any nanoparticles being present. Nuclear magnetic resonance spectroscopy is a technique that exploits the magnetic properties of certain atomic nuclei, which in turn provides physical and chemical information about the material. In our case, the NMR spectrum represents a chemical shift due to intrinsic molecular interactions, which was measured as an absorption energy in the field sweep range from $-5 \mathrm{G}$ to $+5 \mathrm{G}$ and at a frequency of $14,000 \mathrm{KHz}$. It can be noted that the four cell lines do not significantly differ from each other.

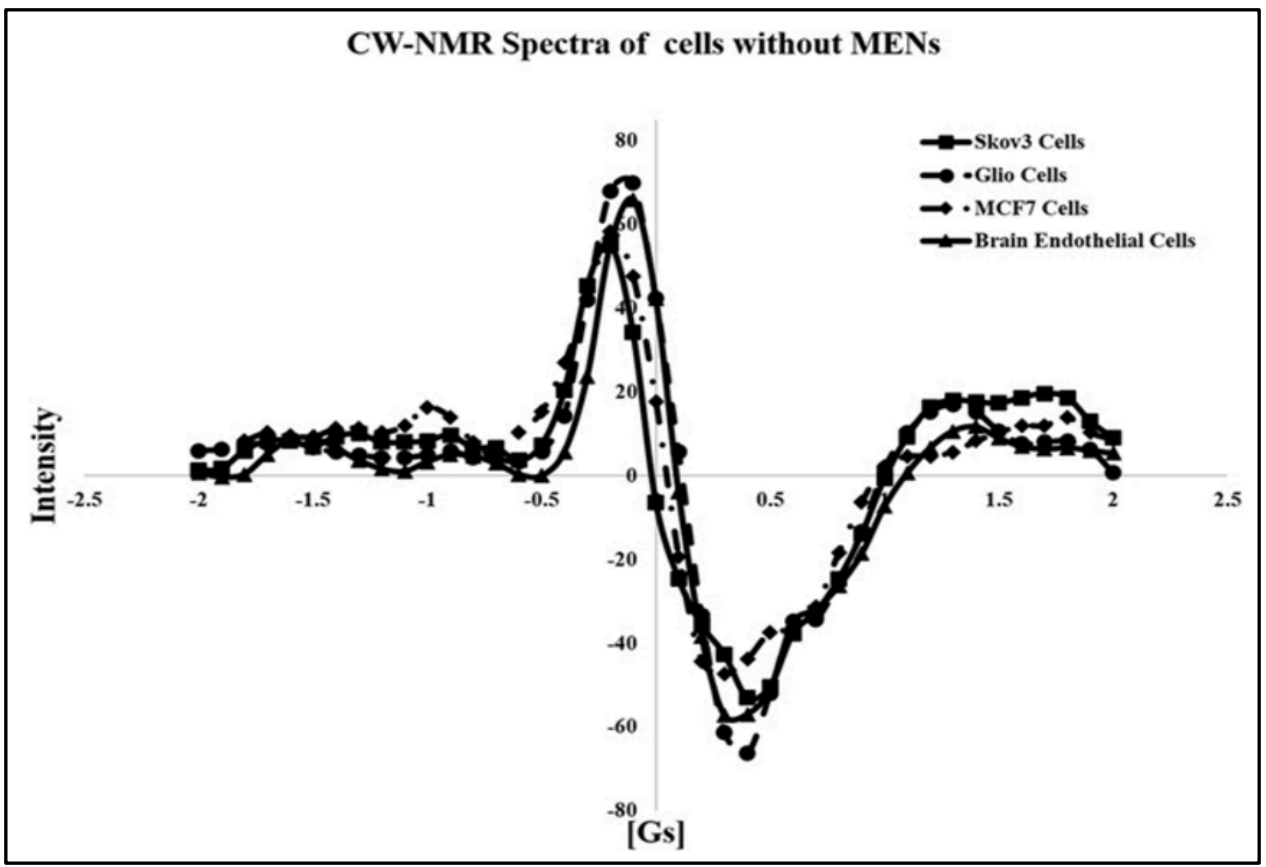

Figure 3.2. CW-NMR spectra of cell media without MENs for four types of cells: (i) ovarian carcinoma cells Skov3, (ii) glioblastoma cells U87-MG, and (iii) breast adenocarcinoma cells MCF-7, respectively, and (iv) normal brain endothelial cells. 
Figure 3.3a-d show four sets of CW-NMR spectra of media obtained by incubating the above three cancer cell lines and one non-cancerous normal cell line, respectively, for 15 hours with traditional MNPs. Each set consists of three curves including spectra for cells only, cells incubated with MNPs without the application of an external field, and cells incubated with MNPs under application of a 100 Oe d.c. magnetic field. The concentration of the nanoparticles in each media was approximately $150 \mu \mathrm{g} \mathrm{ml}^{-1}$. Similar to the case without any nanoparticles, neither of the spectra (i.e. cells + MNPs and cells + MNPs + Field) for the four cell lines significantly differs from the corresponding cell line without MNPs incubation as well as between each other.

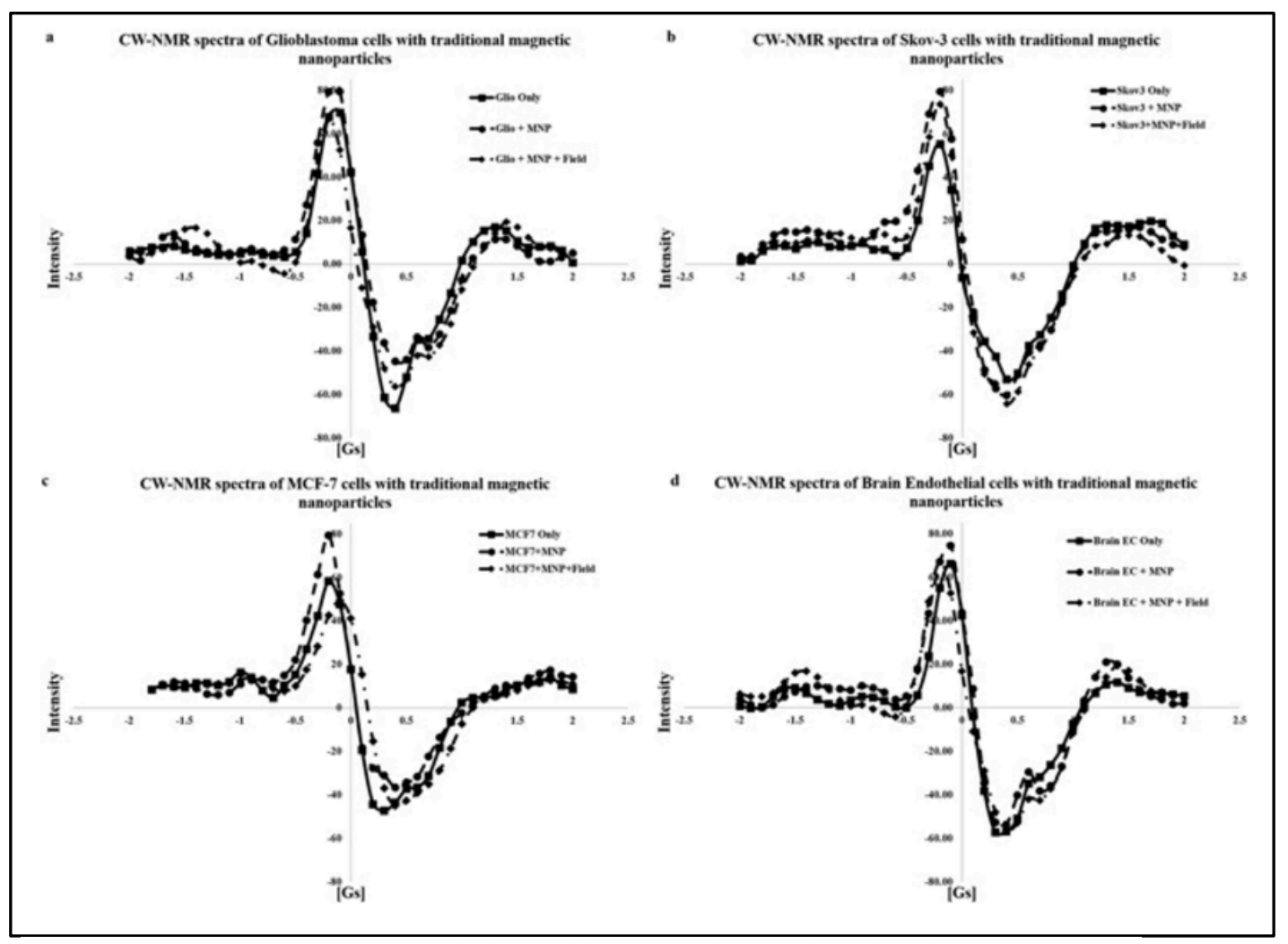

Figure 3.3. CW-NMR spectra including cells only, cells incubated with MNPs without and with application of a 100-Oe d.c. field for (a) glioblastoma cells U87-MG, (b) ovarian carcinoma cells Skov3, (c) breast adenocarcinoma cells MCF-7, respectively, and (d) normal 
However, this trend changes when MENs are used instead of MNPs. Figure 3.4 shows CW-NMR spectra obtained by incubating the same three cancer cell lines and noncancerous cell line for the same amount of time (15 hours), with the only exception of having MENs instead of MNPs at the same concentration of approximately $150 \mu \mathrm{g} \mathrm{ml}^{-1}$. According to these spectra, in great contrast to the traditional MNPs, MENs significantly affect the NMR spectrum for each cancer cell type. The only exception is the noncancerous endothelial cell line; as MNPs, MENs barely affected the spectrum. For comparison, Fig. 3.5 shows NMR spectra for the same three cancer cell lines incubated with MENs without field application under equivalent conditions with the nanoparticle concentration of approximately $150 \mu \mathrm{g} \mathrm{ml}^{-1}$. Again, unlike the previous case with the traditional MNPs and NMR spectra for the three cancer cell lines are very different from each other as much as they are different from their normal counterparts. It can be noted that the difference between the spectra is not just quantitative but rather qualitative. Each cell type displays a distinguished set of peaks in its spectrum, thus indicating an intrinsic interaction between MENs and cells. 


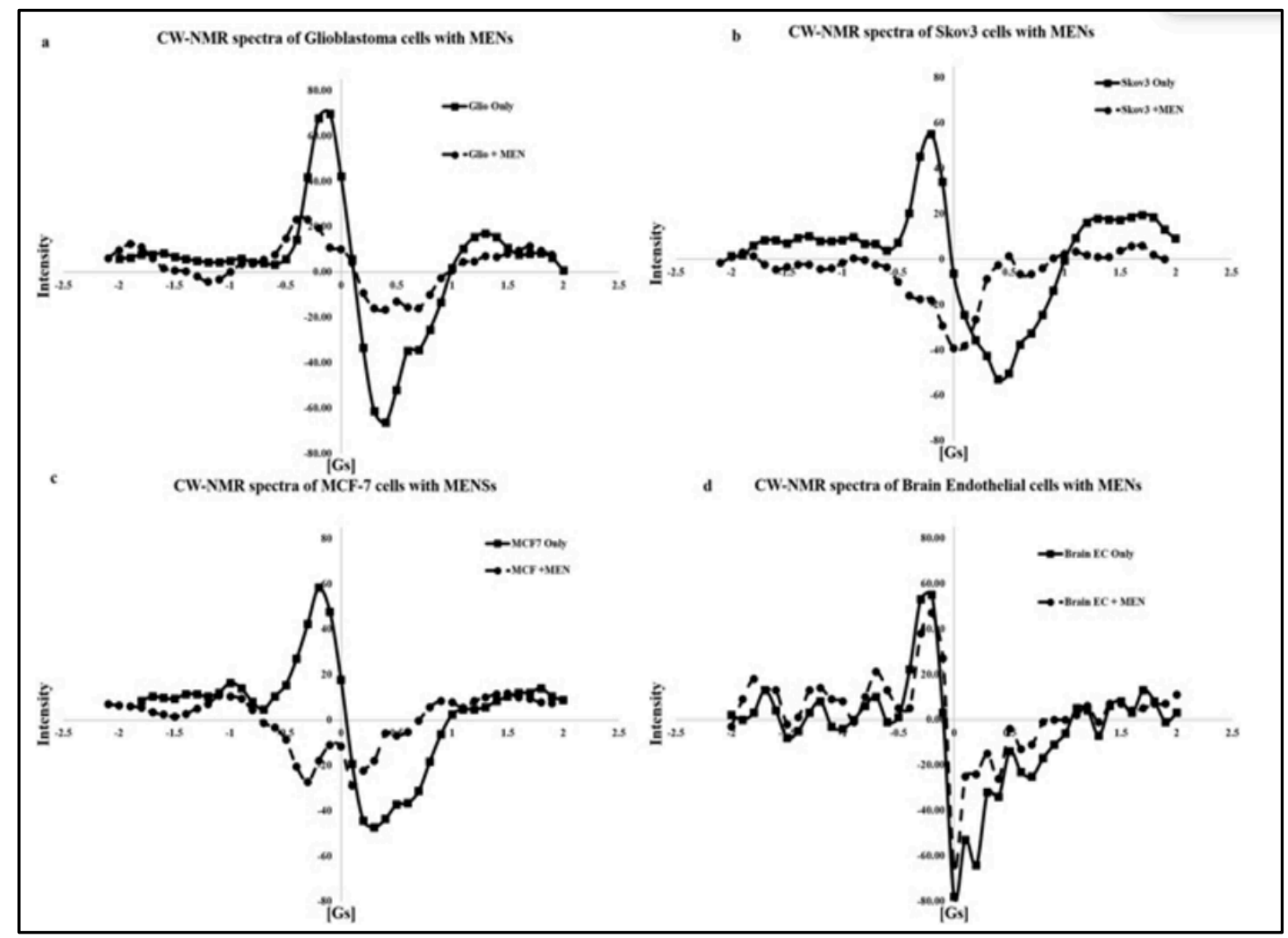

Figure 3.4. CW-NMR spectra including cells only, cells incubated with MENs for (a) glioblastoma cells U87-MG, (b) ovarian carcinoma cells Skov3, (c) breast adenocarcinoma cells MCF-7, respectively, and (d) normal brain endothelial cells. 


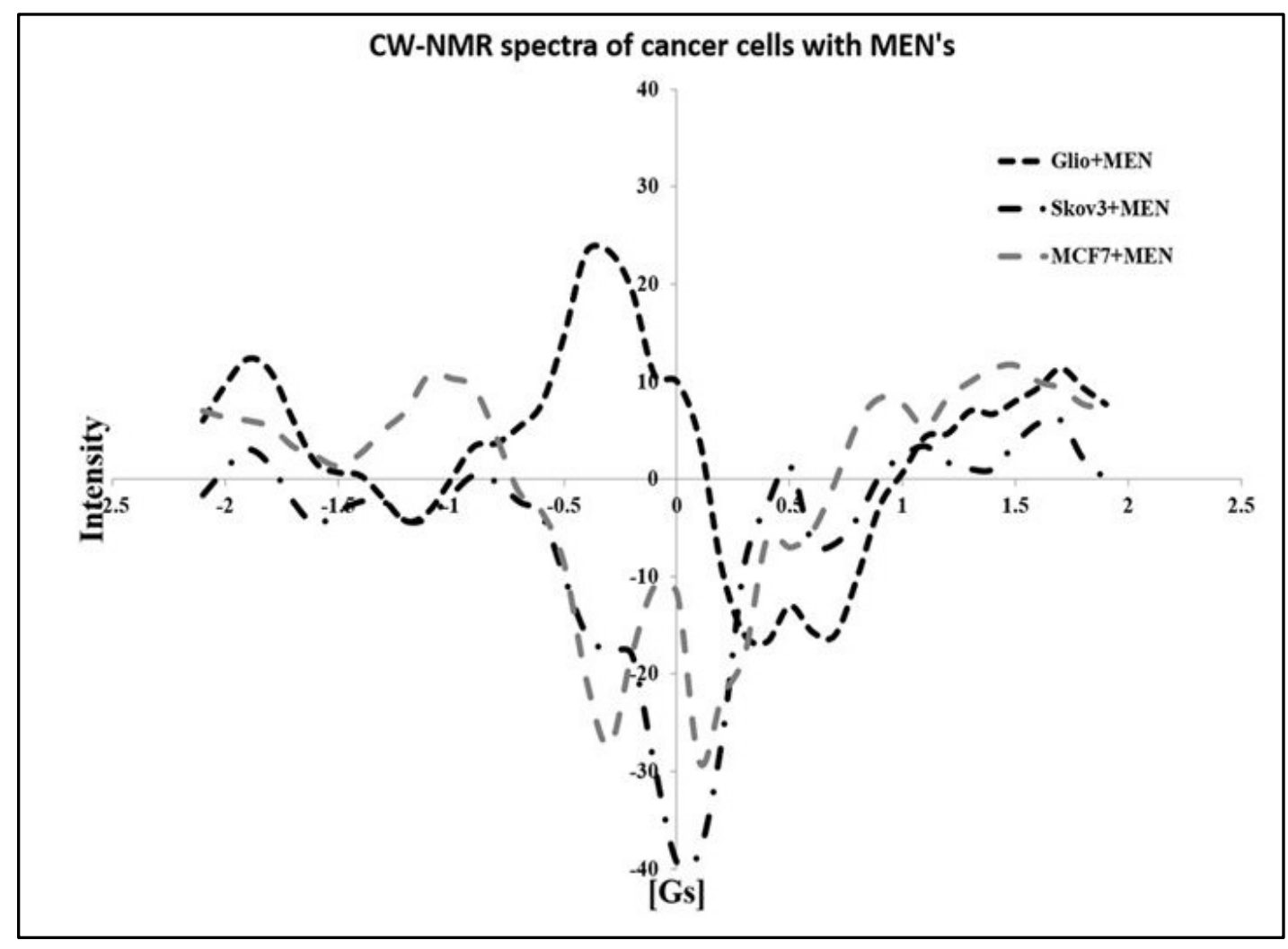

Figure 3.5. CW-NMR spectra of cell media with MENs for cancer cells. 
Figure 3.6a-d show atomic force microscopy (AFM) images of the membrane surfaces of normal brain endothelial cells with nanoparticles $(a, b)$, brain endothelial cells with/without nanoparticles, and glioblastoma cells in the presence of MENs (c,d), respectively. Each pair of scans represents z-height and phase images, respectively. The nanoparticles, represented by circled dotted lines, can be seen only in the glioblastoma images. Indicating the field applied was not sufficiently strong for MENs to effect the electric charge of the cellular membrane of the non-cancerous normal cell. It can be noted that the membranes of normal endothelial cells have a more continuous surface, unlike the membranes of glioblastoma cells which have clearly visible membrane striations with a characteristic size on the order of $100 \mathrm{~nm}$ or smaller. From the visual MENs seem to be associated with the striations. 


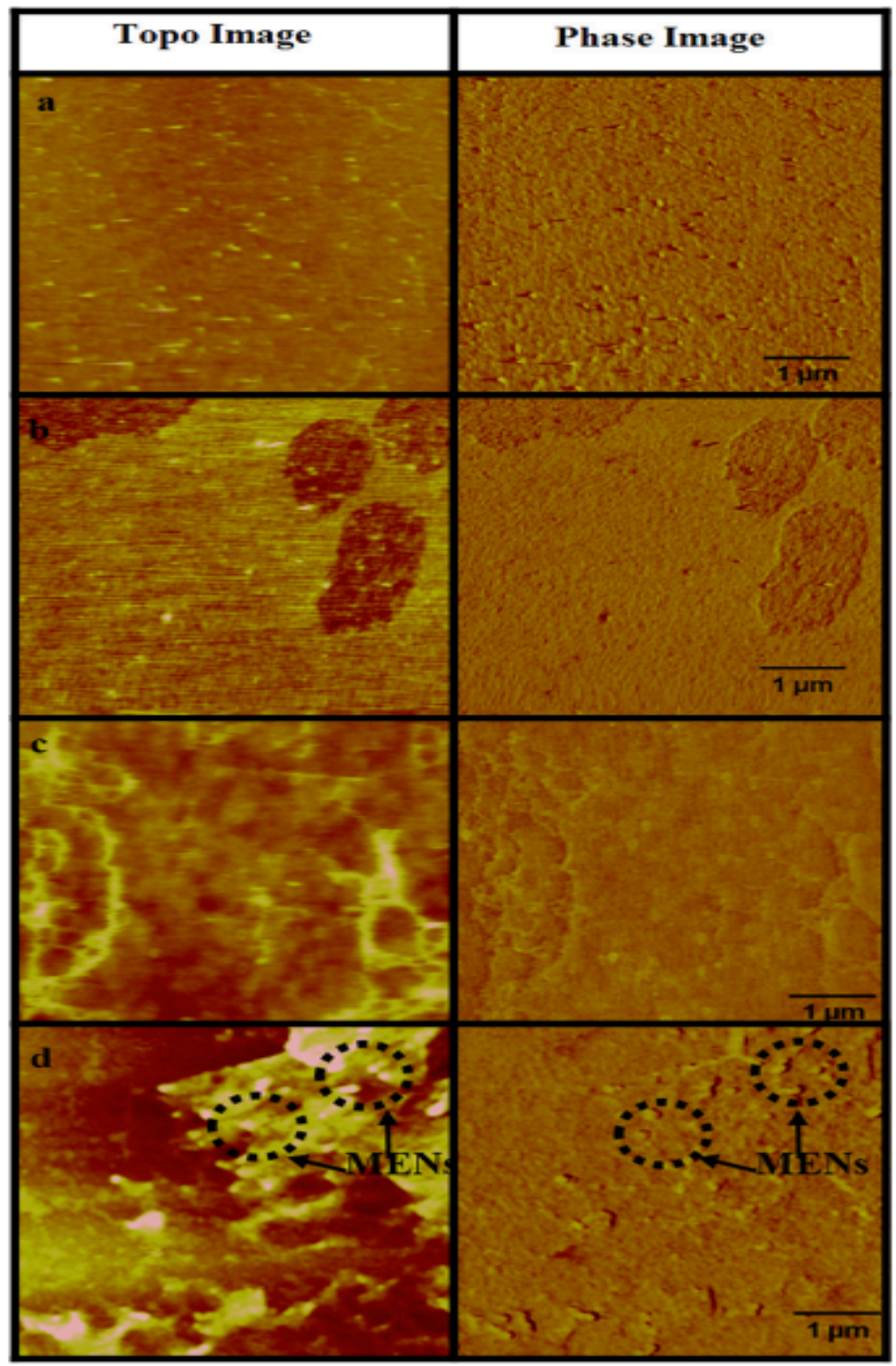

Figure 3.6. AFM images of the membrane surfaces of (a) normal brain endothelial cells, (b) normal brain endothelial cells with MENs at a saturated concentration (c) glioblastoma cells and (d) glioblastoma cells with MENs at a saturated concentration level. 


\section{Discussion}

Cellular uptake of nanoparticles is a thermodynamic phenomenon that occurs from nanoparticle adsorption on the cell membrane followed by membrane wrapping and invagination in order to minimize the chemical binding energy (114-119). As a reminder, MENs should not be confused with traditional MNPs. Despite the difference in magnetization saturation, where MNPs has a saturation magnetization of $40 \mathrm{emu} \mathrm{g}^{-1}$ and MENs only a $1 \mathrm{emu} \mathrm{g}^{-1}$, MENs evidently have a strong effect on the NMR response with or without an external magnetic field applied. This indicates the importance of the nonzero magnetoelectric (ME) effect of MENs compared to MNPs. When MENs are added into the polarized electric system of the cellular microenvironment, the binding interaction between the nanoparticle and cell cause the energy associated with the cell to be minimized, expressed as absorption energy on the CW-NMR spectroscope. Furthermore, depending on the binding sites or uptake mechanism, the intrinsic electric fields are affected in a specific way due to the electrostatic and chemical bonds at these sites. Due to the ME effect, the resulting change in the electric field triggers a change in the magnetic moment of the nanoparticle, which in turn induces a change of the local magnetic field at this location. Since the concentration of nanoparticles in the extracellular medium is very high compared to the number of cells, the adsorption of nanoparticles on cell membrane is saturated at long periods of incubation (120-123). The AFM images indeed show that MENs are attached to the membrane of glioblastoma cells. The distinct organization of MENs around glioblastoma and brain endothelial cells was further verified by fluorescence images of these cells incubated with fluorescein isothiocyanate loaded MENs. For nanoparticles with a negative zeta potential, the cellular 
uptake is strongly dependent on the cell type, the organization of nanoparticles on the membrane surface also depends on the cell type and the mode of uptake. Therefore, this would change the local net magnetic field in a very specific way depending on all the aforementioned cellular properties. Below, a simple analysis is presented to quantify the resulting change in the local net magnetic field, which in turn is observed as the appearance of new shifts in the NMR spectrum.

Each binding site contributes to the net NMR signal; the contribution, i.e. the electromagnetic energy absorption at this site, is generated when the following resonance condition is satisfied: $h \omega=\mathrm{S}_{\mathrm{n}} \mathrm{H}_{\text {net }}$, where $\mathrm{h}$ is the Plank constant, $\omega$ is the frequency of the electromagnetic wave, $S_{n}$ is the magnetic moment of the measured nuclear spin (in this study, the proton spin); $\mathrm{H}_{\text {net }}$ is the net magnetic field at this location. This local net field is made of two contributions, (i) the external field generated by the NMR magnets, $\mathrm{H}_{0}$, and (ii) the field due to the ME effect of MENs at the site, $\mathrm{H}_{\mathrm{ME}}$, respectively:

$$
\mathrm{H}_{\text {net }}=\mathrm{H}_{0}+\mathrm{H}_{\text {ME }} \text {. }
$$

To a zeroth approximation, in the vicinity of a nanoparticle, $\mathrm{H}_{\mathrm{ME}} \sim \Delta \mathrm{M}_{\mathrm{S}}=\alpha \mathrm{E}$, where $\Delta \mathrm{M}_{\mathrm{S}}$ is the nanoparticle's saturation magnetization, $\alpha$ is the $\mathrm{ME}$ coefficient, and $\mathrm{E}$ is the electric field in the vicinity of the nanoparticle. In turn, this electric field depends on the cell membrane morphology. According to this logic, due to the non-zero ME effect, the measured spectrum shifts on the order of 1 Oe should reflect contributions of MENs from different binding sites (Fig. 3.3). This is the reason for a significant dependence on the cell type and indeed the resulting changes of spectral shifts are on the order of 1 Oe. It also follows that the traditional purely magnetic nanoparticles, i.e. MNPs, which do not 
display any ME effect, could not provide this intrinsic contribution specific to each cell type, despite the fact that their saturation magnetization is almost two orders of magnitude higher than that for MENs (Fig. 3.3a,b). To evaluate the approximate value of the average magnetoelectrically induced electric field, E, that holds MENs attached to the cell and thus results in the observed spectrum shift on the order of 1 Oe, we can assume $\alpha \sim 100 \mathrm{mV} \mathrm{Oe}^{-1} \mathrm{~cm}^{-1}, \Delta \mathrm{M}_{\mathrm{S}} \sim 1 \mathrm{emu} \mathrm{cc}^{-1}$. Then, $\mathrm{E} \sim 10 \mathrm{~V} \mathrm{~cm}^{-1}$. In summary, the above comparison indicates that it is due to the ME effect that the observed signature NMR spectra of each cell line investigated occurred. According to the hypothesis, with the introduction of MENs in a saturated state, the relative modification of the averaged NMR energy could be evaluated using a trivial expression; $\mathrm{W}_{\mathrm{MEN} s} \sim \alpha \mathrm{ES}_{\mathrm{n}} \mathrm{A}$, where $\mathrm{A}$ is a constant between 0 and 1 which represents the relative surface area covered by the striations, which in turn strongly depends on the cancer cell type and the cancer progression stage.

To more directly represent the observed energy dynamics in the measured NMR spectra, an inverse Fourier Transform (IFT) operation was performed on the spectra. It can be noted that a CW-NMR spectrum represents a signal in the frequency domain while IFT curve represents the same signal in the time domain. The decaying IFT amplitudes for the cell lines under study are shown in Fig. 3.7. The decay of the IFT curves clearly show how distinguished the spectra for all the cell lines under study are, particularly in the presence of MENs. It can be noted that the time dynamic doesn't change when cells are incubated with MNPs while the NMR-associated energy transfer process for 
establishing an equilibrium is at least 5 to $20 \mathrm{~ms}$ faster when cells are incubated with MENs based on the cell type, as summarized in Table 1.

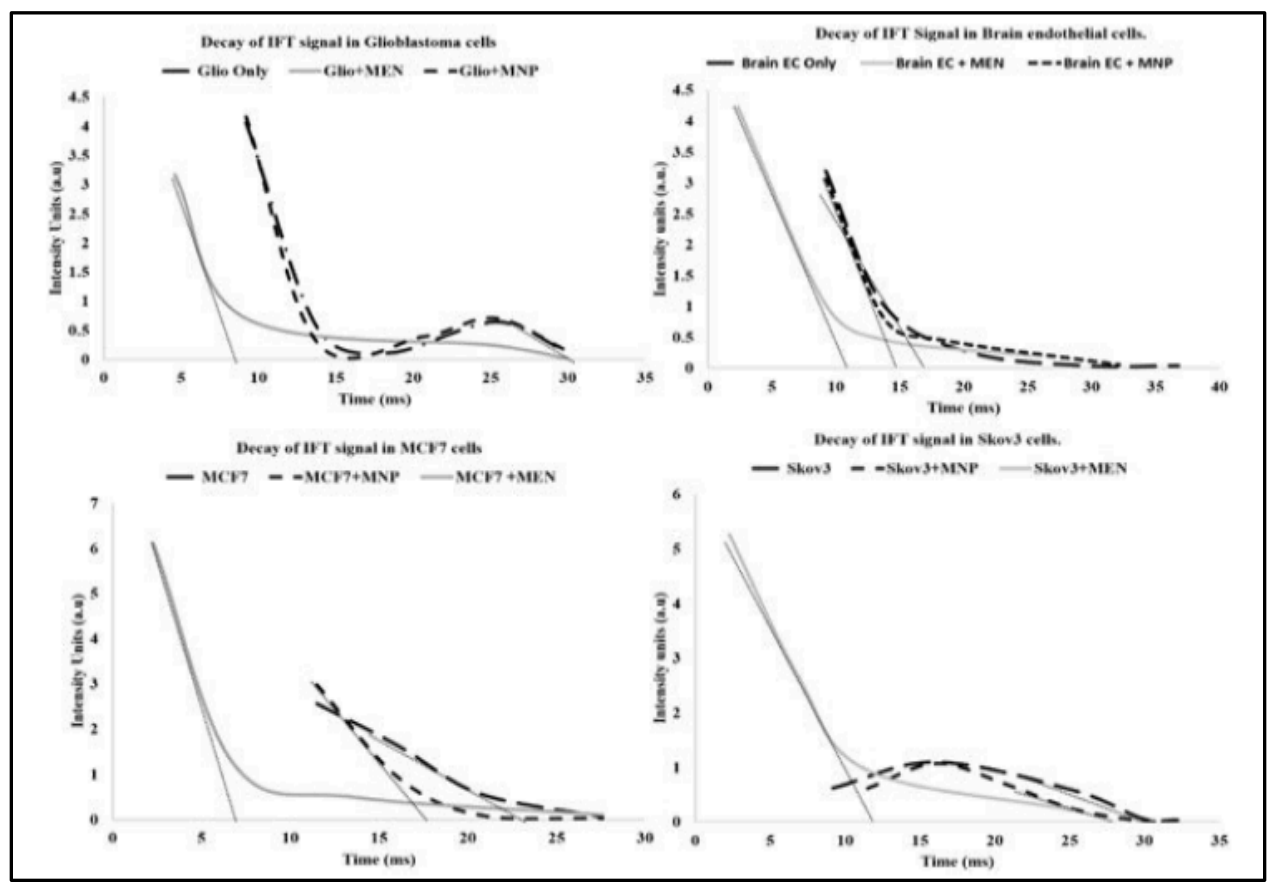

Figure 3.7. Inverse Fourier Transform (IFT) representation of CW-NMR spectra for Glioblastoma Brain EC, Skov3 and MCF7 with MENs and MNPs. The straight dotted slope lines indicate the approximate equilibration time for each type of measurement. 
Table 1: Characteristic time-constant for different cellnanoparticle combination

\begin{tabular}{|c|c|c|c|}
\hline & Cells Without Nps & With MNPs & With MENs \\
\hline Glioblastoma & $32 \mathrm{~ms}$ & $32 \mathrm{~b} \mathrm{~ms}$ & $8 \mathrm{~ms}$ \\
\hline Brain endothelial & $19 \mathrm{~ms}$ & $18 \mathrm{~ms}$ & $11 \mathrm{~ms}$ \\
\hline Breast cancer & $24 \mathrm{~ms}$ & $20 \mathrm{~ms}$ & $7 \mathrm{~ms}$ \\
\hline Ovarian cancer & $32 \mathrm{~ms}$ & $31 \mathrm{~ms}$ & $12 \mathrm{~ms}$ \\
\hline
\end{tabular}

\section{Conclusion}

Multiferroic core-shell magnetoelectric nanoparticles with a diameter of $30 \mathrm{~nm}$ 's were fabricated through a standard hydrothermal synthesis. The coupled magnetic and electric phases, due to its' multiferroic properties, categories these nanoparticles in a class of their own. Particle adsorption on the cell membrane was dependent on the membrane morphology, which was based on the cell type as observed under live-cell AFM imaging. Due to the distinct association with cells and the ME effect the NMR adsorption spectra for cells incubated with MENs was significantly different compared to cells without any MENs.

Materials and Procedures

Magnetoelectric nanoparticles preparation and characterization

$\mathrm{CoFe}_{2} \mathrm{O}_{4}-\mathrm{BaTiO}_{3}$ core shell MENs were prepared according to the following procedure. As the first step, the cores of $\mathrm{CoFe}_{2} \mathrm{O}_{4}$ were prepared by the standard hydrothermal 
method, according to which $0.058 \mathrm{~g}$ of cobalt (II) nitrate hexahydrate $\mathrm{Co}\left(\mathrm{NO}_{3}\right)_{2} \cdot 6 \mathrm{H}_{2} 0$ and $0.16 \mathrm{~g}$ of Iron (III) nitrate nonahydrate $\mathrm{Fe}\left(\mathrm{NO}_{3}\right)_{3} \cdot 9 \mathrm{H}_{2} \mathrm{O}$ were dissolved in $15 \mathrm{ml}$ of distilled water and $0.2 \mathrm{~g}$ of polyvinylpyrrolidone was dissolved in $5 \mathrm{ml}$ of aqueous solution containing $0.9 \mathrm{~g}$ of sodium borohydride at $120^{\circ} \mathrm{C}$ for 12 hours. For shell growth around the cores, a precursor solution of $\mathrm{BaTiO}_{3}$ was prepared by mixing $30 \mathrm{ml}$ of aqueous solution containing $0.029 \mathrm{~g}$ of $\mathrm{BaCO}_{3}$ and $0.1 \mathrm{~g}$ of citric acid with $30 \mathrm{ml}$ of ethanolic solution containing $1 \mathrm{~g}$ of citric acid and $0.048 \mathrm{ml}$ of titanium (IV) isopropoxide. Coreshell $\mathrm{CoFe}_{2} \mathrm{O}_{4}-\mathrm{BaTiO}_{3}$ MENs were prepared by mixing $0.1 \mathrm{~g}$ of $\mathrm{CoFe}_{2} \mathrm{O}_{4}$ nanoparticles in the $\mathrm{BaTiO}_{3}$ precursor solution and the mixture was sonicated for $2 \mathrm{hrs}$. Once the $\mathrm{CoFe}_{2} \mathrm{O}_{4}$ nanoparticles were thoroughly dispersed, the mixture was dried on the hot plate at $60^{\circ} \mathrm{C}$ overnight while being continuously stirred. The dried powder was heated to $780^{\circ} \mathrm{C}$ for $5 \mathrm{hrs}$. in a furnace (CMF-1100) and cooled at $5{ }^{\circ} \mathrm{C}$ per minute to obtain coreshell MENs of $\sim 30 \mathrm{~nm}$ diameter. The particles size distribution was measured using dynamic light scattering method (Malvern-Zetasizer) and through transmission electron microscopy.

Cell culture and sample preparation CW-NMR

All in-vitro cell experiments and biological material handling were approved and performed in accordance within the set guidelines of Florida International University. Three cancerous cell lines including Skov3 (Ovarian adenocarcinoma) (ATCC; Manassas, VA), U87-MG (Glioblastoma) (ATCC), MCF-7A (Breast adenocarcinoma) (ATCC), respectively, and two non-cancerous cell lines including brain endothelial cells (Brain EC, ATCC) and rat smooth muscle endothelial cells (RSMC, ATCC), 
respectively, were cultured at $37^{\circ} \mathrm{C}$ as per manufacturer's instructions. For nanoparticle studies, cells were detached using $0.25 \%$ trypsin solution, plated in 6 well plates and allowed to grow to $80 \%$ confluency. MENs were resuspended in cell culture media through sonication and were incubated for 30 minutes. MENs were added to each well at a concentration of $150 \mu \mathrm{g} / \mathrm{ml}$ and the cells were further incubated for 15 hours, to allow attachment of MENs with the cells. Additionally, all the cell lines were incubated with $150 \mu \mathrm{g} / \mathrm{ml}$ traditional MNP $\left(\mathrm{CoFe}_{2} \mathrm{O}_{4}\right)$ for 15 hours. In order to increase the interaction of MNP's with cell membrane a d.c magnetic field was also applied. Cells incubated with MNPs were placed at a distance from a d.c magnet, directly underneath the culture plate. The distance of magnet from cell culture plate needed to create 100 Oe field was determined using a gauss meter. After the end of incubation period, the cells were washed with phosphate buffered saline (PBS) to remove particles not strongly bound to cells. Cells were scraped from the bottom of plate and transferred to a $5 \mathrm{~mm}$ NMR tube. Continuous wave- ${ }^{1} \mathrm{H}$ NMR spectra were obtained using a continuous wave (CW) spectroscope. Sample placement, instrument parameters (B0, instrument phase, linewidth) were carefully selected to ensure optimal signal to noise ratio. Each NMR spectrum was collected at opposite phases (in our case these were 107 and 297). Signal processing such as solvent suppression, baseline correction and inverse fourier transform were performed in MATLAB ${ }^{\circledR}$ (Mathworks, MA) 
Atomic force microscopy imaging

U-87 MG and Brain endothelial cells were grown on poly-l-lysine coated cover slips and were incubated with MENs similarly as described above. After the incubation, the coverslips were washed with phosphate buffered saline (PBS) and were transferred to stubs. The live cell/wet atomic force microscopy (AFM) mode of a Multimode was used to obtain AFM images of cells with Bruker AFM probes DNP-S10 using a three-port electrochemistry tapping fluid cell element ECFC. The cantilever $\mathrm{C}$ had a resonant frequency of $56 \mathrm{kHz}$ in air and spring constant of $0.24 \mathrm{~N} / \mathrm{m}$. In the engaged mode, the frequency dropped to approximately $8 \mathrm{kHz}$. The AFM scans were performed at a rate ranging from 1.4 to $2.6 \mathrm{~Hz}$, a scan size on the order of a few microns, a Z-range of $50 \mathrm{~nm}$ and a Z-range phase of 10 degrees.

Vibrating sample magnetometry

A room-temperature Lakeshore vibrating sample magnetometer (VSM) with a 3-T magnetic field sweep was used to measure key magnetic properties of nanoparticles under study including the magnetization saturation and the magnetic coercivity. A cryogenic VSM Quantum Design PPMS with a 9-T superconducting magnet was used to measure $\mathrm{M}-\mathrm{H}$ temperatures in a wide temperature range, from $4 \mathrm{~K}$ to over $300 \mathrm{~K}$. 
Transmission electron microscopy

Phillips CM-200 $200 \mathrm{kV}$ Transmission Electron Microscope (TEM) with Energy Dispersive Spectroscopy (EDS) option was used to obtain TEM images and EDS profiles. 
CHAPTER IV: DELIVERING PEPTIDES TO GLIOBLASTOMA CELLS BY WAY OF MAGNETOELECTRIC NANOPARTICLES 
Introduction

Glioblastoma multiforme (GBM) is the most frequent malignant primary brain tumor representing $32 \%$ of all brain tumor cases in adults, and $81 \%$ of malignant tumors. Despite multidisciplinary treatment approaches, including surgical resection and radiotherapy, GBM has a low prognosis with an average survival period of $15-18$ months (124-126). A major challenge in the treatment of GBM is delivering the therapeutic drug across the blood-brain barrier (BBB), a network of specialized brain endothelial cells with intercapillary distances of $\sim 40 \mu \mathrm{m}$ that tightly regulate ionic composition, prevent macromolecules and unwanted cells from entering the brain to protect the central nervous system (CNS) from neurotoxins (127-131). The use of targeted drug delivery with relatively small magnetic particles $(<40-\mathrm{nm})$ has been suggested as an efficient way to cross BBB, target cancerous cells, and permit an ondemand release of anti-tumor drugs.

Due to the multiferroic physics of MENs, these nanoparticles offer properties that cannot be achieved by any other nanoparticles, such as the traditional ferromagnetic nonsuperparamagnetic and superparamagnetic iron oxide nanoparticles (SPIONs). MENs display an intrinsic non-zero magnetoelectric (ME) effect which is an important trait that ultimately defines drug carrier properties, mainly; (i) the strength of the bond between the nanoparticle and the loaded drug, and (ii) the local electric field on the MENs' surface that contributes to the cellular membrane penetration, these two properties can be controlled via application of special sequences of d.c. and a.c. magnetic fields.

MIA690 peptide is a recently discovered growth-hormone and release-hormones (GHRH) antagonist with promising anticancer effects on GBM cells. Hypothalamic 
growth hormone-releasing hormone $(\mathrm{GHRH})$ regulates the synthesis and release of $\mathrm{GH}$ in the pituitary gland. GHRH and its mRNS are expressed in many human cancers, suggesting that it may act as a tumor growth factor $(132,133)$. GHRH antagonists have been studied as a treatment for this tumor type. However, major challenges in treatment with GHRH antagonist exist include prolonging of the drug half-life and delivering the drug across the BBB for localized drug release specifically to GBM cells.

It is well-established that the MIA class of GHRH antagonists exhibits high binding affinities to GHRH receptors and display anticancer properties. MIA690 is a synthetic peptide that has been recently developed as a promising treatment for glioblastomas.

The unprecedented properties of MENs combined with the effectiveness of MIA GHRH forecast a promising therapy treatment for GBM. However, open questions include whether MIA690 peptides can bind to MENs with sufficient affinity to penetrate human glioblastoma cell membrane and then released on-demand. Furthermore, it is important to note that MENs penetrate the BBB and specifically enter cancer cells while avoiding cellular uptake from non-malignant cells in the brain vasculature when exposed to equivalent d.c. fields.

The primary objective is to present an in vitro study in which (i) MIA690 is efficiently bound to MENs as a drug delivery carrier, (ii) MIA690 loaded MENs penetrate human glioblastoma cell membranes by application of a relatively weak d.c. magnetic field, and (iii) the release of the MIA690 antagonist drug in the cell cytoplasm through the application of an a.c. magnetic field. Demonstrating these specific aims will revolutionize nanomedicine and provide a solution to overcome the challenges in the treatment of GBM. 


\section{Results}

\section{Characterization of MENs}

AFM and TEM-EDS images of 30-nm MENs are shown in Fig. 4.1a,b, respectively. Xray diffraction (XRD) confirmed the tetragonal crystal structure of $\mathrm{BaTiO}_{3}$ shell (space group $\mathrm{P} 4 \mathrm{~mm}, \mathrm{a}=3.9940 \AA \mathrm{c}=4.0380 \AA$ ) and the cubic structure of $\mathrm{CoFe}_{2} \mathrm{O}_{4}$ cores. Vibrating sample magnetometry (VSM) results showed that the saturation magnetization and coercivity of MENs were approximately $1 \mathrm{emu} / \mathrm{g}$ and 310-Oe, respectively, and those of the $\mathrm{CoFe}_{2} \mathrm{O}_{4}$ core particles were approximately $40 \mathrm{emu} / \mathrm{g}$ and $90-\mathrm{Oe}$, respectively, shown in Fig.4.2.

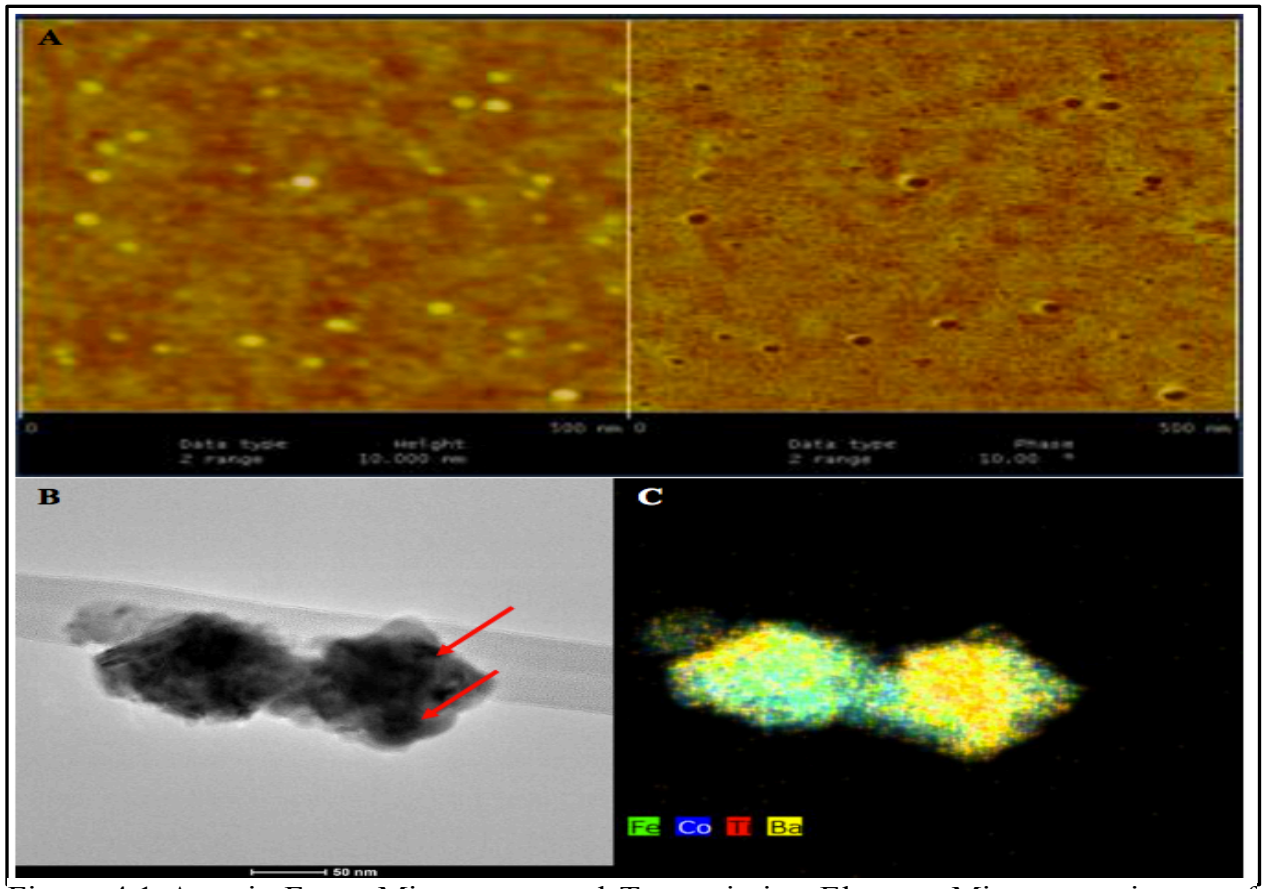

Figure 4.1 Atomic Force Microscopy and Transmission Electron Microscopy image of Magnetoelectric nanoparticles. (A) AFM images taken at $5.0 \mu \mathrm{m} \mathrm{X} 5.0 \mu \mathrm{m}$ and a vertical scale of $0.10 \mu \mathrm{m}$. (B) TEM image of MENs, arrows indicate isolated magnetoelectric nanoparticles within the aggregated structure particle agglomeration occurs during preparation (drying) of colloidal stable fluids for TEM investigation. (C) EDS mapping of elemental composition of MENs. Scale bar is $50 \mathrm{~nm}$. 


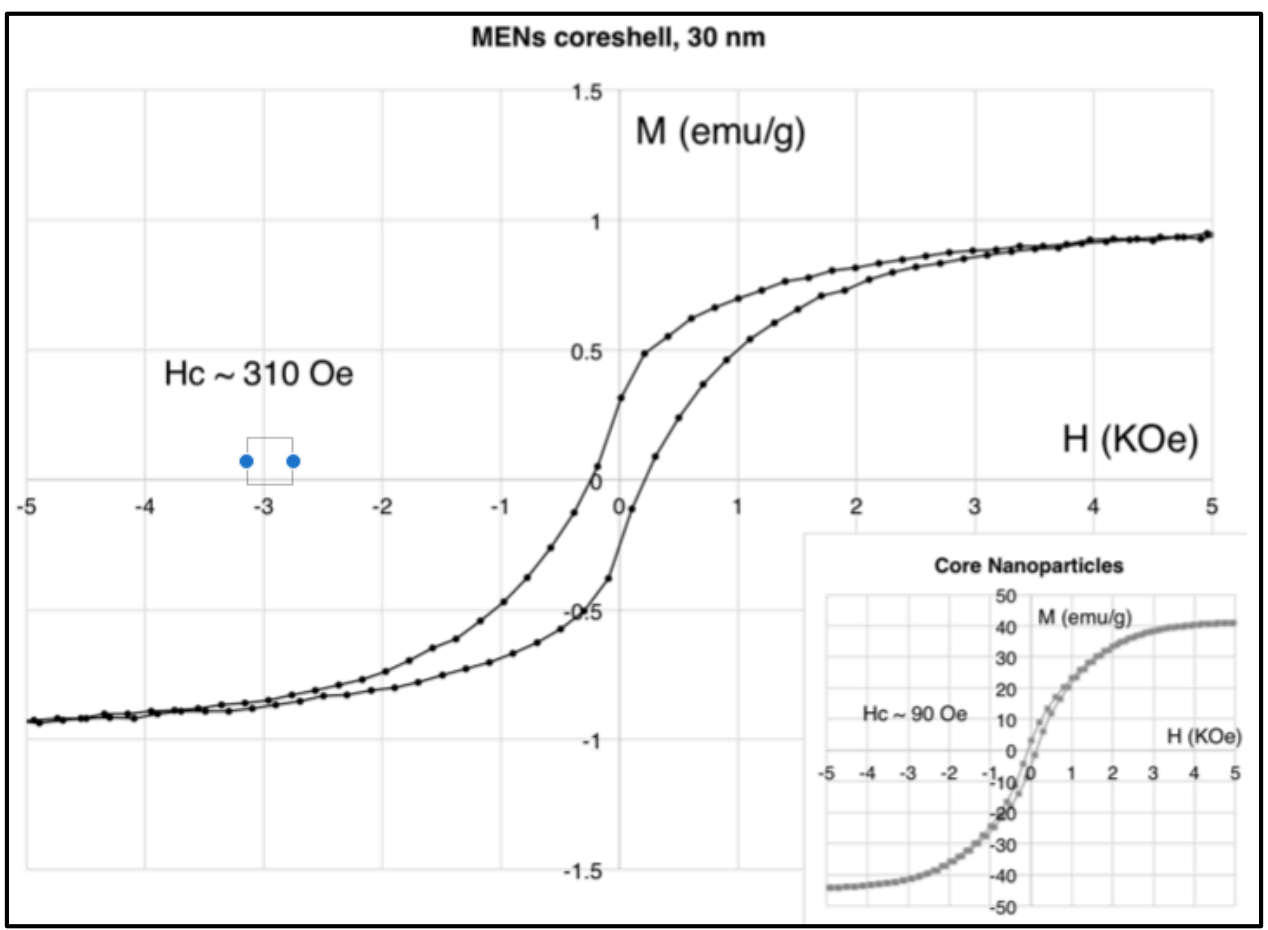

Figure 4.2. VSM measurements of MENs coreshell and core structures. M-H hysteresis loops showing the saturation magnetization and coercivity of MENs were approximately $1 \mathrm{emu} / \mathrm{g}$ and $310 \mathrm{Oe}$, respectively. The insert shows the M-H hystereis loops for the $\mathrm{CoFe} 2 \mathrm{O} 4$ core with a greater saturation magnetization and lower coercivity of approximately $40 \mathrm{emu} / \mathrm{g}$ and $90 \mathrm{Oe}$, respectively. 


\section{GHRH antagonist MIA690 loaded MENs}

To ensure adequate biocompatibility, MENs were coated with glycerol; monooleate (GMO) before conjugation with MIA690, as described in detail in section Methods. Using GMO ensured that the field necessary for inducing local electroporation of the cell membrane and consequent release of the peptide into the cell were within adequate ranges of magnitude $(\sim<100-\mathrm{Oe})$ and frequencies $(\sim<1000-\mathrm{Hz})$. The effectiveness of the conjugation procedure was tested by creating a standard calibration curve from MIA690 stock solution and by measuring the absorbance maxima of the unbound MIA690. Percent retained of MIA690-GMO-MENs was calculated using the following equation:

Results indicated that the functionalized GMO-MENs carriers could retain $72.7 \%$ of MIA690 Fig.4.3.

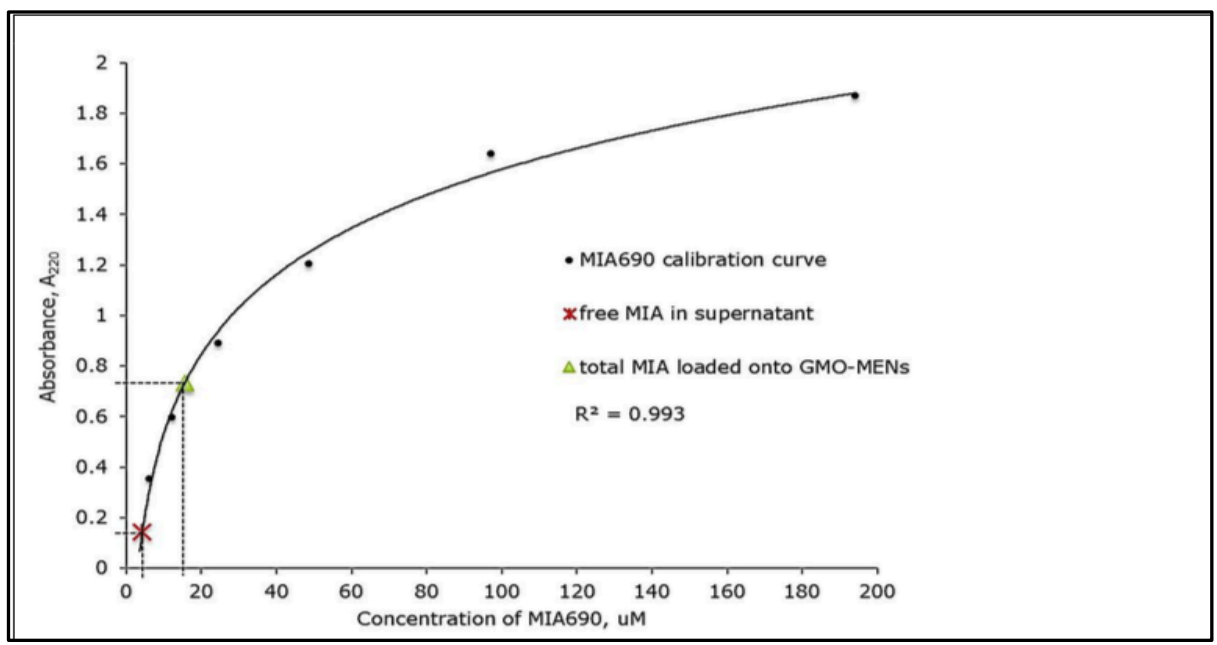

Figure 4.3. Bioconjugation of MIA690 to GMO-MENs. GMO-MENs can effectively bind MIA690 at room temperature in PBS solution $(\mathrm{pH}=7.4)$. 
Field controlled uptake and on-demand release of MIA690 in U-87MG cells

Several controls and experimental U-87MG cell treatments were utilized to compare the effect of drug delivery treatment vs. treatment alone (outlined in Method section). Briefly, cell were treated with (i) PBS vehicle solution; (ii) GMO-MENs vehicle solution; (iii) MIA690 treatment only; and (iv) GMO-MENs + MIA690 treatment. Each treatment group was exposed to magnetic fields categorized as "before on-demand release" (d.c. fields only) or "after on-demand release" (d.c. field, then a.c. field). Duration of magnetic field exposure was introduced as a third variable to investigate the effect of time on intracellular drug release (i.e. 2 hours or 12 hours d.c. exposure +30 min or 2 hours a.c. exposure). Data was collected at two separate time points (24 hours and 48 hours after field application) in replicates of at least $n=2$. Free MIA690 drug in cell lysate was measured spectrophometrically against a standard calibration curve of MIA690, and the results were normalized to the protein content in the cell lysate. The absorbance maxima of MIA690 in cell lysate was 220-nm, which corresponds to the peptide bonds of MIA690. The Bradford method to detect proteins normalized drug content in lysate to the relative number of cells in the sample. The Bradford method detects proteins $>300 \mathrm{kDa}$, which is beyond the limit of MIA690 (MW=3934 Da). To ensure the peptide MIA690 did not significantly contribute to absorbances obtained by the Bradford method, we measured the maximum concentration of the peptide treatment (1- $\mu$ M MIA690) using the Bradford method. Results indicated absorbances of MIA690 were negligible compared to 
the average protein content of cells indicating that MIA690 does not contribute to protein values Fig. 4.4. Results from intracellular measurements suggest that MIA690 uptake increased significantly only in cells treated with Mia690 loaded MENs and exposed to 100-Oe for 12 hours in lysate collected 24 hours post treatment. Drug uptake increased by a factor of 6.9 for MIA690 carried by field-controlled MENs exposed to an extended d.c. field compared to the drug administered alone, and this factor increased to 11 with on-demand release using a.c. magnetic field for 2 hours. Fig.4.5a. Notably, cells exposed to brief d.c. fields ( $\sim 2$ hours) did not significantly increase intracellular release of MIA690 regardless of a.c. field exposure. In cell lysate measurements 48 hours post treatment, uptake of MIA690 is increased by a factor of at least 4.6 in U-87MG cells treated with MIA690 loaded MENs and exposed to 100-Oe for 12 hours with and without the application of an a.c. field Fig 4.5b; however, these results did not reach statistical significance.

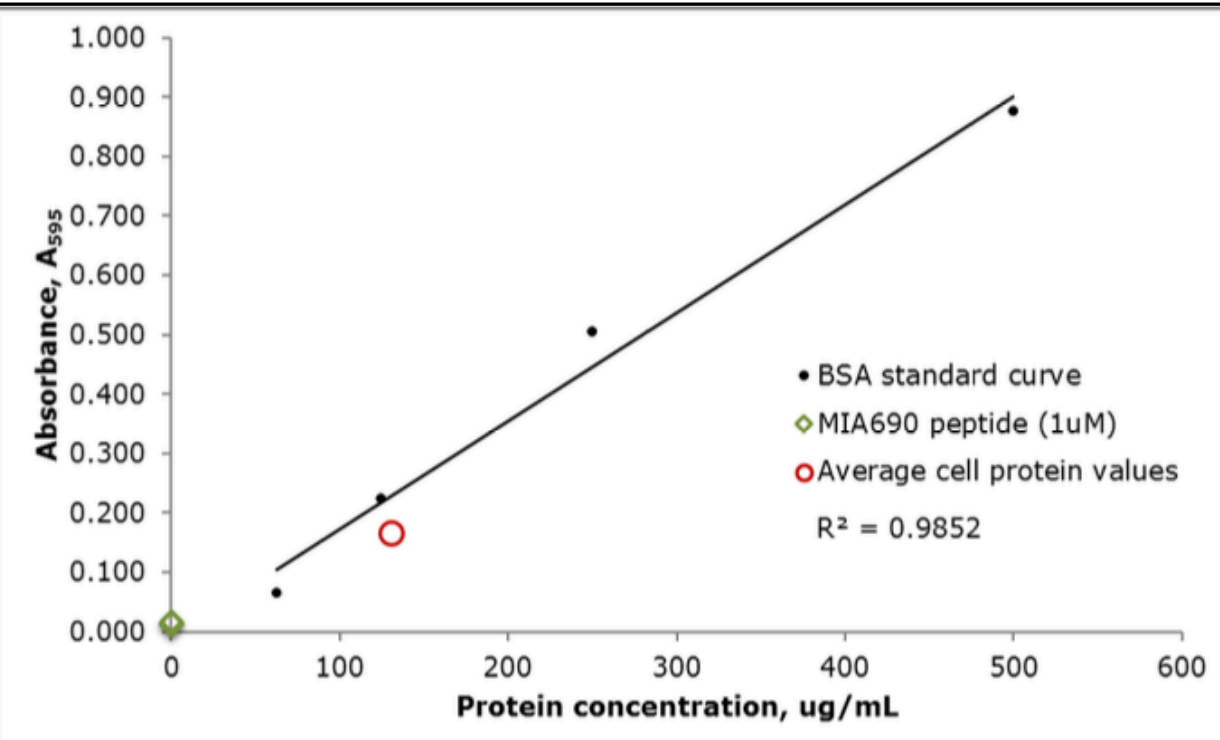

Figure 4.4. Bradford assay results are not affected by MIA690 peptide indicating that MIA690 peptide does not contribute to average cell protein content. 


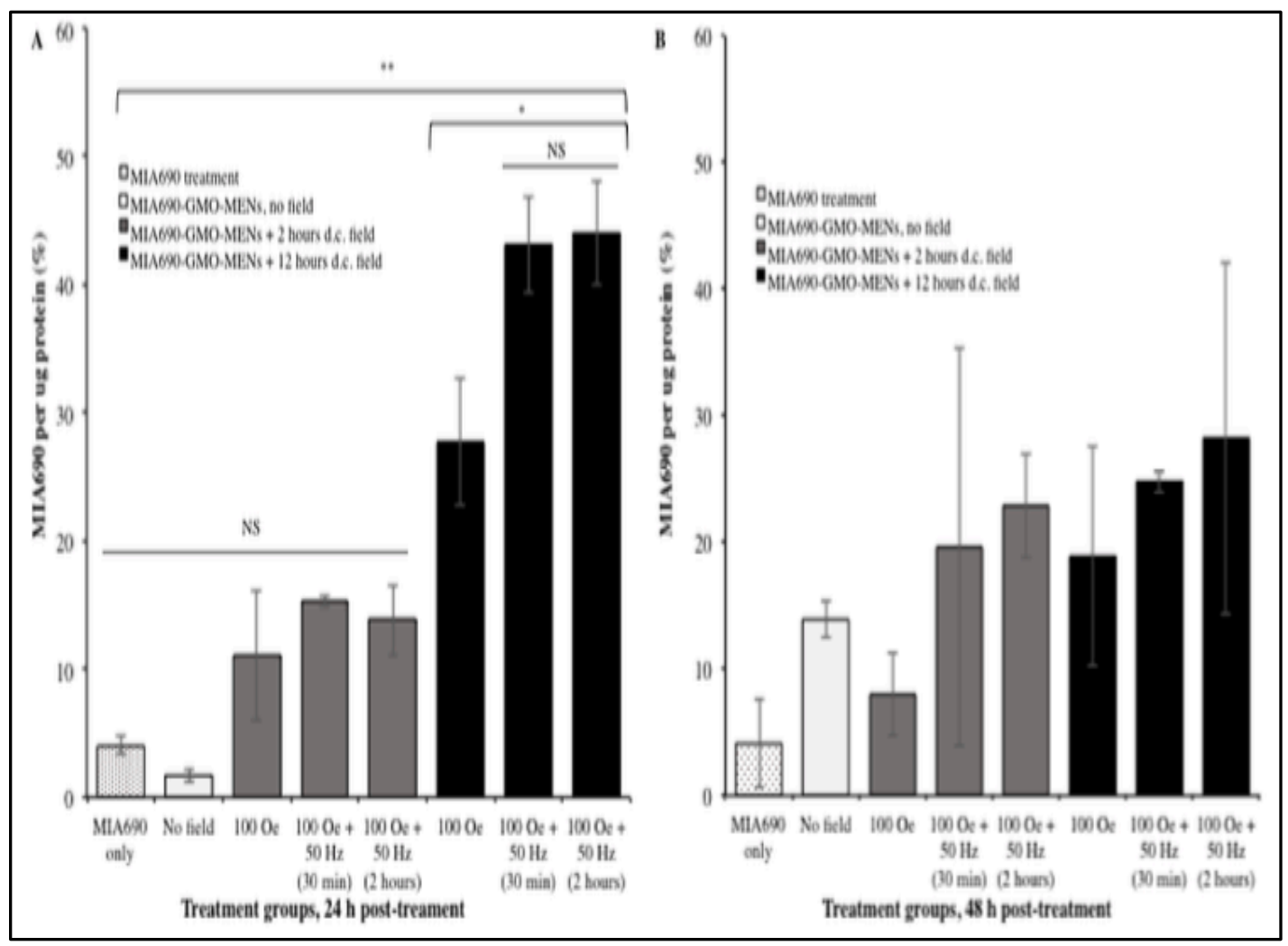

Figure 4.5. GHRH antagonist (MIA690) uptake relative to protein content in cell lysate across treatment groups. (A) Intracellular levels of MIA690 increased significantly $(\mathrm{p}<0.01)$ when U$87 \mathrm{MG}$ cells were treated with MIA690 bound to GMO-MENs and exposed to a prolong d.c. magetic field (12 hours) compared to MIA690 treatment alone. Release of MIA690 was further increased with the application of an a.c. field $(p<0.05)$. Intracellular levels of MIA690 did not differ significantly when drug was free in media or delivered bound to MENs carrier and not exposed to a magnetic field or a short duration of magnetic field ( $\sim 2$ hours d.c. field). (B) Drug uptake 48 hours post- treatment did not show significant differences between groups when measured in cell lysate. Reported values were normalized relative to control treatments of PBS or PBS+MENs only vehicle solutions

U-87MG cell viability decreased with MIA690-loaded MENs delivery

A key mechanism of action of the GHRH antagonist MIA690 is to inhibit cancer cell proliferation (134-138). We investigated the effect on cell inhibition when MIA690 was delivered to U-87MG cells using field controlled MENs as drug delivery vehicles. Vehicles controls included PBS only and GMO-MENs only. Viability was measured by 
taking an aliquot from the sample of cells and staining it with trypan blue, a dye that will distinguish between viable cells and dead cells using hemacytometer in triplicate. Results show a decrease in cell viability at 24 hours post treatment when MIA690 was delivered through GMO-MENs and exposed to a field of 100-Oe d.c. for 12 hours and 50-Hz for 2 hours, however the results were not statistically significant compared to traditional treatment of MIA690 alone $(-7.8 \%, \mathrm{p}=0.285)$. Cell death was enhanced at 48 hours in cell treatment with MIA690 bound to GMO-MENs and exposed to 100-Oe for 12 hours then $50-\mathrm{Hz}$ for 2 hours compared to MIA690 treatment alone $(-18.3 \%, \mathrm{p}=0.03)$, Fig. 4.6a. The relationship between \% intracellular MIA690 levels and \% cell inhibition is plotted in Fig. 4.6b. There is a significant relationship between intracellular MIA690 levels and \% cell inhibition indicating that increased intracellular MIA690 is significantly associated with cell growth inhibition $\left(\mathrm{R}^{2}=0.43, \mathrm{p}=0.001\right)$. 


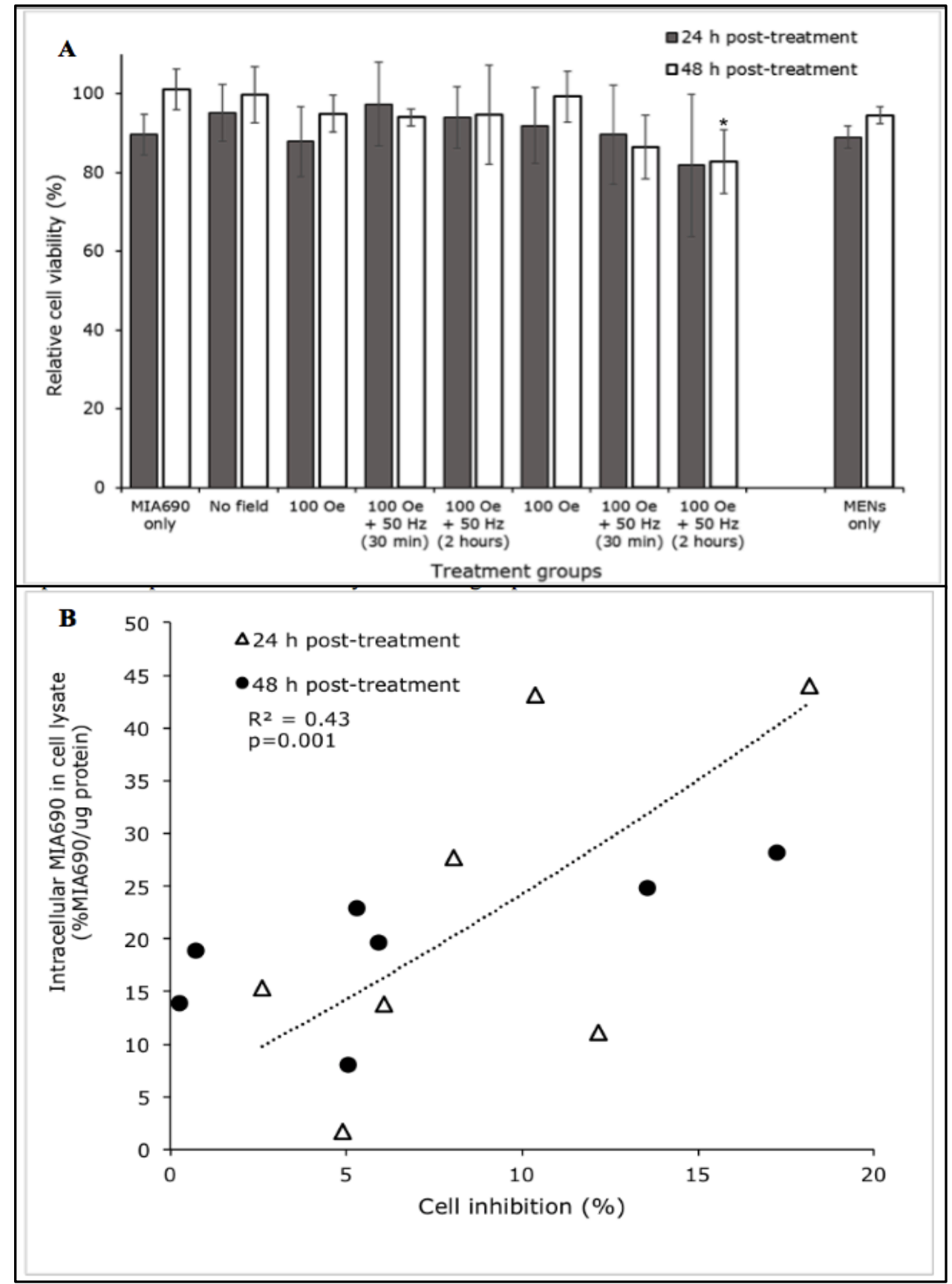

Figure 4.6. Intracellular MIA690 release affects relative cell viability across treatment groups. (A) Significant decrease in cell viability occurred in cells treated with MIA690GMO-MENs for 12 hours $100 \mathrm{Oe}+50 \mathrm{~Hz}$ for 2 hours, compared to MIA treatment alone $(-18.3 \%, p=0.030)$. The results are mean \pm SEM of three independent measurements. (B) Intracellular MIA690 is significantly associated with cell growth inhibition in a linear regression model using data collected at 24 hours and 48 hours post-treatment ( $22=0.43$, $\mathrm{p}=0.001)$. 
The effect of a low a.c. magnetic field on heat dissipation and cell viability The expected, relatively low magnetic fields used to couple with MENs did not produce significant heating across treatment group. The a.c. frequency used in this study is in the near-d.c. range and thus barely induces hysteresis-triggered thermal dissipation. FIIR-i3 infrared (IR) imaging measured heat dissipation at each stage of field exposure to magnetic field. There were no significant differences between flask temperatures of control and GMO-MENs treated flasks, regardless of the length of time or magnetic field exposure (d.c. or a.c.). Cell viability did not differ significantly between GMO-MENs treated cells with or without exposure to a.c. magnetic fields Fig. 4.7. 

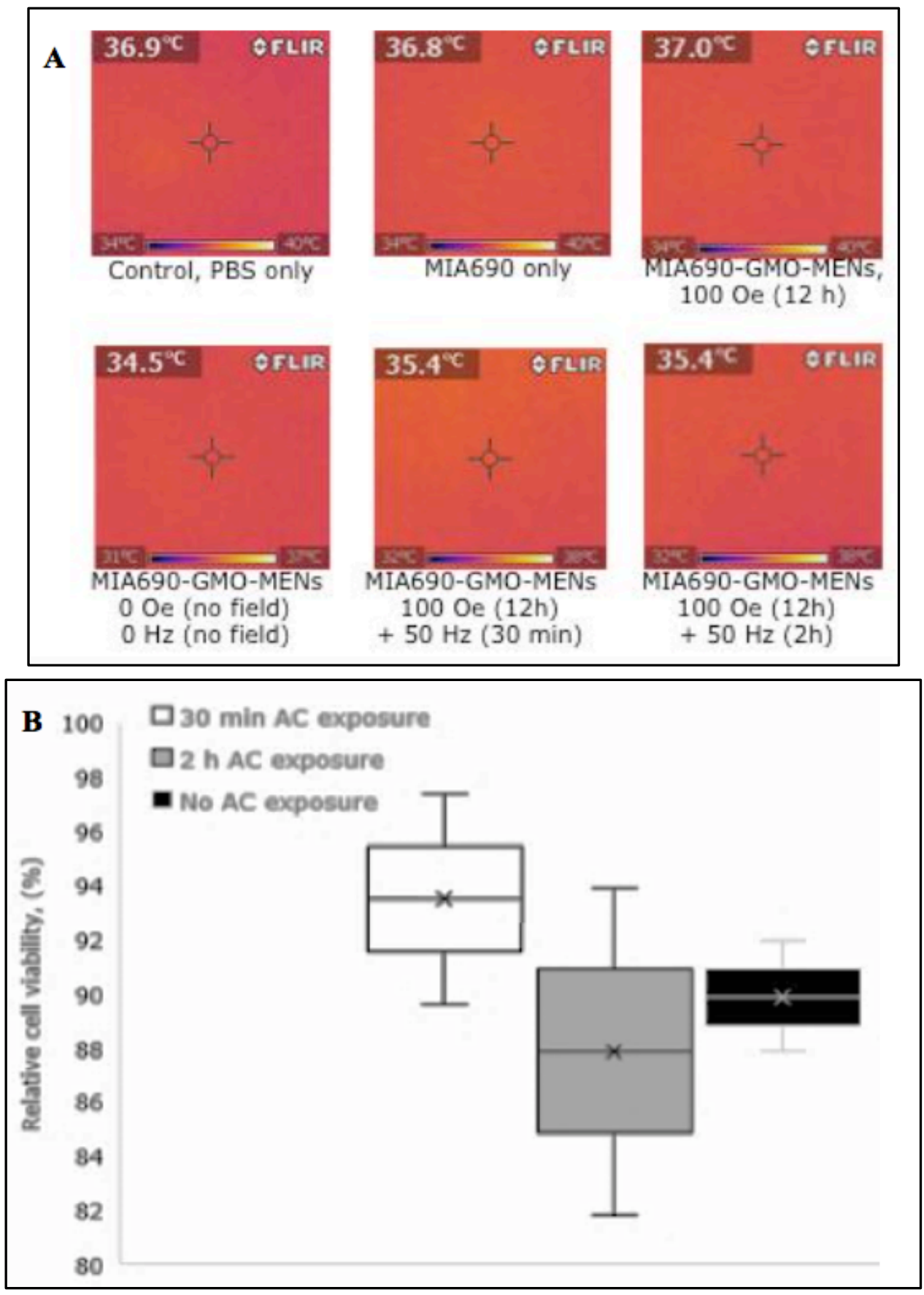

Figure 4.7. The effect of a.c.magnetic fields on heat dissipation of MENs and cell viability. (A)Heatimages displaying surface temperatures of cell cultures treated with MENs compared to controls. No significant differences in temperatures were observed between groups. (B) Relative cell viability between groups exposed to varying durations of a.c. magnetic fields. Exposure to a.c. magnetic fields had no significant effects on cell viability. 
MENs specifically penetrate U-87MG cells

The intracellular uptake of MENs was imaged across treatment groups using EDS-SEM. The EDS-SEM provides an atomic-level elemental composition of the material and identifies atomic signatures of GMO-MENs. Because MENs are composed of a $\mathrm{CoFe}_{2} \mathrm{O}_{4}$ core with a $\mathrm{BaTiO}_{3}$ shell, the atomic signatures of $\mathrm{Ba}$ and $\mathrm{Ti}$ indicate the presence of MENs in the cell lysate. The samples showing the highest traces of $\mathrm{Ba}$ and Ti were exposed to 100-Oe for 12 hours compared to controls, indicating that MENs loaded with MIA690 effectively penetrate U-87MG cells with the application of a d.c. magnetic field Fig. 4.8a. ICP-MS was performed to quantify amounts of $\mathrm{Ba}$ and $\mathrm{Ti}$ in the cell lysate. Results showed that following d.c. treatment for 12 hours, the average Ba concentration was $18.7 \pm 2.7 \mu \mathrm{g} / \mathrm{L}$, and Ti concentration was $98.6 \pm 2.5 \mu \mathrm{g} / \mathrm{L}$ confirming the presence of MENs particles in cell lysate.

Specificity of MENs to target cancer cells was investigated by treating healthy cells (HBMECs) and cancer cells (U-87MGs) with fluorescently labeled MENs. FITCloaded MENs were redispersed in cell media and exposed to a d.c. magnetic field ( 100Oe) hypothesized to produce electroporation in cancer cells while sparing healthy cells. Results of confocal fluorescent images indicate that FITC-MENs are highly localized in the cytoplasm of the malignant U-87MG cells and are not associated with the nonmalignant HMBEC cells Fig. 4.8b. 

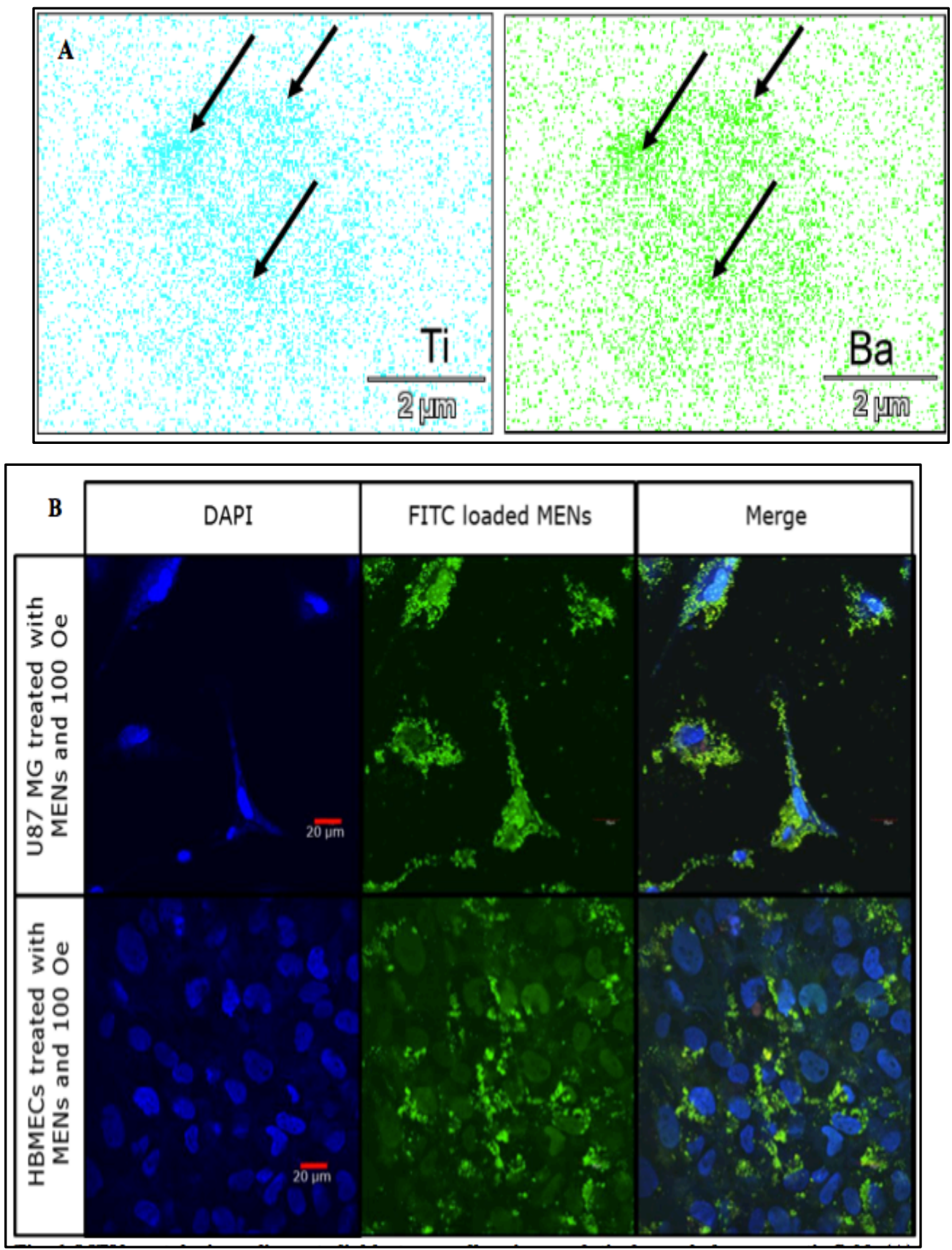

Figure 4.8. MENs uptake in malignant glioblastoma cells using a relatively weak d.c. magnetic field. (A) EDS-SEM images of signature trace elements $\mathrm{Ti}$ and $\mathrm{Ba}$ in the cell lysate of U-87MG cells treated with MIA-GMO-MENs exposed to 100 Oe d.c. magnetic field. The arrows indicate where the MENs are most concentrated in the sample. (B) Confocal images showing the specific interaction of MENs with malignant glioblastoma cells. FITC-MENs are specifically associated with U-87MG cells. Uptake is not evident in non-malignant HBMECs. 
MENs cross blood-brain barrier in vivo

EDS-SEM imaging detected elemental signature traces of MENs coreshell in the brain slices of mice. Results show the presence of $\mathrm{Ba}$ and $\mathrm{Ti}$ signature elements of the MENs coreshell in the parenchyma of the mouse brain shown in Fig. 4.9.

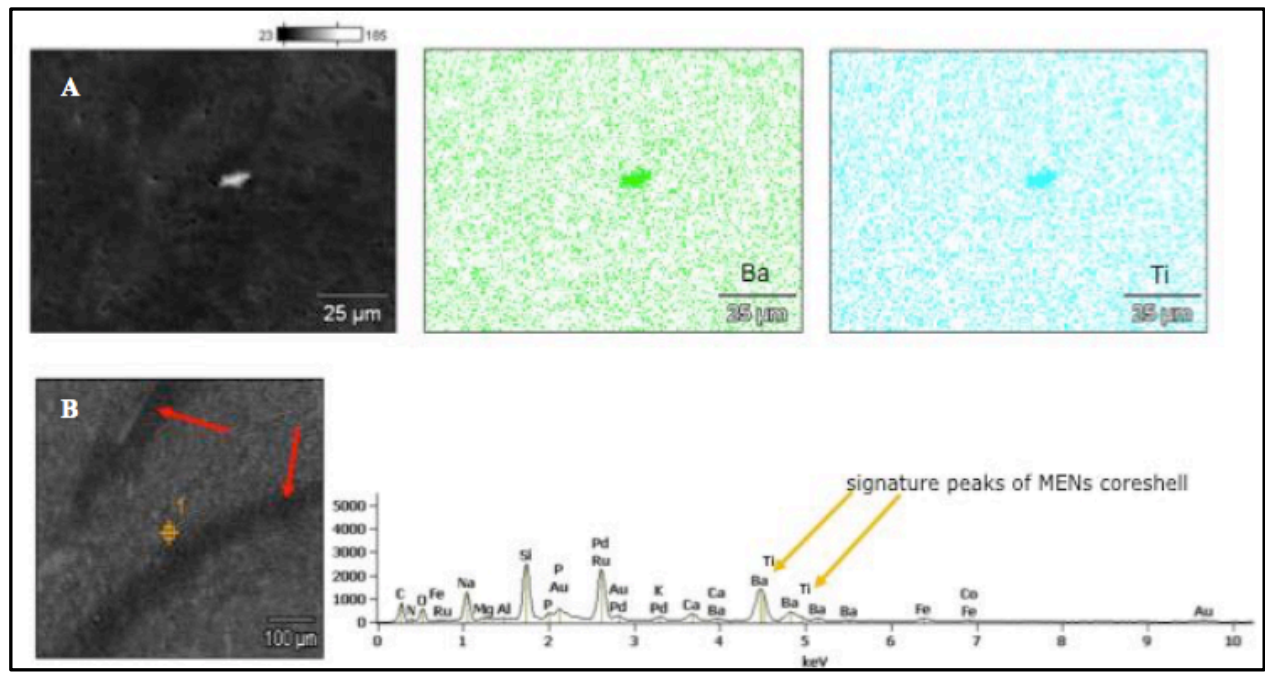

Figure 4.9. EDS-SEM images of signature trace elements $\mathrm{Ti}$ and $\mathrm{Ba}$ in the parenchyma brain tissue in mice injected IV with MENs. (A) High-resolution image of MENs fixed in the brain parenchyma of a mouse. The green and blue images show the concentrated regions of $\mathrm{Ba}$ and $\mathrm{Ti}$, respectively. (B) The red arrows show the blood vessels of the $\mathrm{BBB}$, the orange target indicates the location of EDS analysis, and the orange arrows on corresponding EDS spectrum indicate detection of $\mathrm{Ba}$ and $\mathrm{Ti}$. The signature trace elements of MENs coreshell were detected outside of the brain vasculature, indicating MENs are able to cross the BBB in vivo. 


\section{Discussion}

Current treatment for malignant glioblastoma including surgery, radiotherapy, and chemotherapy are being applied with limited success (139-142). GHRH antagonists are being developed to improve the outcome of the treatment to improve the overall survival rate of GMB patients. The effects of GHRH antagonist in experimental treatment have demonstrated beneficial models that include the suppression of the pituitary hepatic IGF axis, and secondly, direct inhibition of the autocrine/paracrine activity of GHRH. However, delivery of GHRH antagonist to target sites in the brain is limited by their short half-life in circulation and relatively inefficient delivery to glioblastoma across the BBB. Therefore, an approach for tightly binding GHRH antagonist to a carrier particle to avoid degradation, directing the drug-loaded conjugate across the $\mathrm{BBB}$, and controlling the release of the drug will provide improved treatment outcomes.

The use of MENs as drug delivery vehicles for cancer therapies is being studied both in vitro and in vivo $(143,144)$. MENs as drug carriers can be loaded with a GHRH antagonist, administrated intravenously, and then navigated across BBB via application of a d.c. magnetic field gradient. In general, MRI or MPI can be used as an imaging modality to provide an image guided delivery of MENs directly to tumor sites using d.c. magnetic field gradient, recently, it has been shown that MENs can be localized to tumor sites due to a physical mechanism which acts independently of the enhanced permeability and retention (EPR) effect (143). According to this mechanism, drug-loaded MENs are attracted to the tumor cells due to their more conductive membrane surface and the resulting stronger Coulomb force compared to that of the normal cells. When in close 
proximity to the tumor cell membrane, MENs induce local electroporation to the cell membrane, the effect known as the nanoelectroporation, which further pulls the nanoparticles inside the cells. The specificity exists because the nanoelectroporation threshold field for the malignant cell is significantly lower than that for the surrounding non-malignant cells. Upon entering into the cytosol, an on-demand release of the peptide into the intracellular microenvironment is achieved by application of an a.c. magnetic field. The physical mechanism of the release relies on the strong a.c. field dependence of the bond affinity between the nanoparticle and the drug due to the ME effect (66-69).

The present data support the concept that MENs can effectively bind to GHRH antagonist MIA690 at physiological $\mathrm{pH}$ and can deliver MIA690 more efficiently to malignant glioblastoma cells than the free drug alone in vitro. Furthermore, the data confirm that MENs exposed to magnetic field increases specificity to malignant glioblastoma cells while sparing non-malignant cells and can cross the BBB in vivo, which may lead to localization of MIA690 to glioblastoma cells in the brain.

Conjugation of MIA690 to GMO-MENs using an EDC-linker resulted in $72 \%$ of MIA690 loaded onto the GMO-MENs carrier at physiological $\mathrm{pH}$. This result is consistent with the binding capacity of chemotherapeutic drugs to MENs previously reported. An important challenge in the administration of GHRH antagonist is their short half-life. Various nanocarriers are emerging as delivery systems to improve half-life of therapeutic peptides. The binding force between MIA690 and MENs at physiological pH indicates that GHRH antagonist may avoid early degradation when loaded onto MENs 
carriers in order to reach targeted sites. It is worth noting that MENs-based delivery and release across the $\mathrm{BBB}$ is independent of the biochemical microenvironment; in contrast, it is mostly determined by externally d.c. and a.c. magnetic fields.

\section{Conclusion}

Overall, this study reports major improvements in therapy of human glioblastoma with a GHRH antagonist. Taking advantage of the unique properties of magnetoelectric nanoparticle. These results suggest that (1) GMO-MENs effectively bind MIA690, (2) provide controlled intracellular drug delivery, (3) specifically target human glioblastoma cells, and (4) penetrate the blood-brain barrier. As a final remark, it is worth mentioning that, in general, this nanotechology could be applied to treat not only brain tumors but also neurodegenerative diseases such as Alzheimer's Disease and Parkinson's Disease.

\section{Materials and Procedures}

Reagents and chemicals

Sigma- Aldrich (MO, USA). Cellular experiments in vitro utilized the human glioblastoma cell line U- 87MG and human brain microvascular endothelial cells (HBMECs) obtained from the commercial provider American Tissue Culture Collection (ATCC, VA, USA). Modified Eagle's medium (MEM), Dulbecco's Modified Eagle's medium (DMEM), fetal bovine serum (FBS) from Gibco (NY, USA), and penicillinstreptomycin (penstrep) obtained from Science-Cell, Inc. (CA, USA). For fluorescence experiments, fluorescein isothiocyanate (FITC) amine reactive dye and 4',6-Diamidino2-Phenylindole (DAPI) were purchased from Thermo Fisher Scientific (MA, USA). All 
reagents met or exceeded ACS standards for procedures requiring stringent quality specifications.

Synthesis and characterization of MENs

Magnetoelectric nanoparticle (MENs) were synthesized in our laboratory by conventional methods.52 In the first step, $\mathrm{CoFe} 2 \mathrm{O} 4$ core particles were prepared by the standard hydrothermal method. Thus, $0.58 \mathrm{~g}$ of $\mathrm{Co}(\mathrm{NO} 3) 2$. $6 \mathrm{H} 2 \mathrm{O}$ and $0.16 \mathrm{~g}$ of $\mathrm{Fe}(\mathrm{NO} 3) 3$. $9 \mathrm{H} 2 \mathrm{O}$ were dissolved in $150 \mathrm{~mL}$ of aqueous solution. An aqueous mixture of polyvinylpyrrolidone $(0.2 \mathrm{~g})$ and sodium borohydride $(0.9 \mathrm{~g})$ was then added and stirred at $70^{\circ} \mathrm{C}$ for 12 hours. The precursor solution of $\mathrm{BaTiO} 3$ was prepared by mixing $174 \mathrm{mg}$ of $\mathrm{BaCo} 3$ and $5 \mathrm{~g}$ citric acid with $240 \mathrm{uL}$ titanium isopropoxide in ethanolic solution. $\mathrm{CoFe} 2 \mathrm{O} 4$ cores were added to the $\mathrm{BaTiO} 3$ precursor solution and sonicated until fully dispersed ( $\sim 2$ hours). The mixture was heated at $90^{\circ} \mathrm{C}$ with continuous stirring overnight to form a milky opaque gel. The gel was placed in the KSL-1100x high temperature muffle furnace from MTI Corporation (CA, USA) to calcine at $600^{\circ} \mathrm{C}$ for 5 hours with controlled ramping temperatures to obtain coreshell of MENs of $\sim 30 \mathrm{~nm}$ diameter. Size distribution of MENs was confirmed by atomic force microscope (AFM) imaging to assess grain height using the Bruker Nanoscope IIIa Multimode (MA, USA) and TEM imaging using the FEI Talos F200X instrument (Oregon, USA).

\section{Conjugation of GHRH antagonist peptide MIA690 to MENs}

Five grams of $30 \mathrm{~nm} \mathrm{CoFe} 2 \mathrm{O} 4-\mathrm{BaTiO} 3$ coreshell MENs particles were resuspended in 1 $\mathrm{mL}$ sterile phosphate buffered saline (PBS, $\mathrm{pH}$ 7.4) and sonicated for 1 minute. To 
improve the biocompatibility of MENs, $0.1 \mathrm{~mL}$ of glycerol monooleate (GMO) was mixed with the MENs coreshell in and rotated for 1 hour. GMO-MENs were washed thrice with PBS, then N-(3- Dimethylaminopropyl)-N'-ethyl-carbodiimide hydrochloride (EDC) at $1 \mathrm{mg} / \mathrm{ml}$ concentration was added to the solution and incubated for 1 hour by slow mechanical stirring. The GHRH antagonist, synthesized by R-Z. Cai and A.V. Schally using solid phase methods was conjugated to the functionalized GMO-MENs to produce a stock solution of MIA690-GMO-MENs that could be mixed with cell culture media to a final peptide concentration of $1 \mu \mathrm{M}$ MIA690. The treatment with GHRH antagonists at the concentration of $1 \mu \mathrm{M}$ has previously reduced cell viability and generated antitumor effects in GBM cell culture.25 To determine the binding efficacy of MIA690 to GMO-MENs, stock solution was centrifuged at 4,000 rpm to separate unbound peptide from the pellet. The supernatant was resuspended in PBS and absorbance was measured spectrophotometrically and concentrations were plotted against a calibration curve of known MIA690 concentration.

\section{Cell Culture}

U-87MG cells were grown in T-25 flasks seeded with $0.5 \mathrm{X} 106$ cells/flask and cultured with MEM media supplemented with 5\% FBS and 1\% penstrep. Human brain microvascular endothelial cells (HBMECs) were grown in DMEM media supplemented with $10 \% \mathrm{FBS}$ and $1 \%$ penstrep. Cell cultures were incubated at $37^{\circ} \mathrm{C}$ with $5.0 \% \mathrm{CO} 2$ in a humidified atmosphere. Media was replaced every 2-3 days until cells reached confluency. Confluent cells were detached with $0.25 \%$ trypsin/EDTA solution and reseeded. Drug uptake experiments were performed at $80 \%$ confluency, and data 
collected at 24 hours and 48 hours post-treatment with MIA690-loaded MENs or MIA690 alone. Samples were read in duplicate and triplicate when necessary to obtain acceptable \% CV values.

In vitro treatment

Cells were treated with MIA690 alone or MIA690-GMO-MENs in fresh media at a concentration of $1 \mu \mathrm{M}$ of MIA690. Equivalent volumes of the vehicle solutions ("naked" GMO-MENs, or PBS) were added to the media as controls. Each treatment group (MIA690, MIA690-GMO- MENs, GMO-MENs, PBS) was exposed to several magnetic field conditions to test the effect of a d.c. magnetic field gradient (reported in Oe) to induce penetration into U-87MG cells. Subsequently, selected treatment groups were exposed to an a.c. magnetic field (reported in $\mathrm{Hz}$ ) to examine the on-demand release of MIA690 from the nanoparticle. The duration of exposure to a magnetic field was controlled to determine the optimal exposure time that would improve MIA690 uptake. We chose a combination of treatment groups based on prior MENs data14; U- 87MG cells treated with MIA-GMO-MENs were exposed to the following magnetic fields in sequence (a) no field, $0 \mathrm{Oe}+0 \mathrm{~Hz}$; (b) 2 hours $100 \mathrm{Oe}+0 \mathrm{~Hz}$ (c) 2 hours $100 \mathrm{Oe}+50$ Hz 30 min; (d) 2 hours $100 \mathrm{Oe}+50 \mathrm{~Hz} 2$ h; (e) 12 hours $100 \mathrm{Oe}+50 \mathrm{~Hz} 30 \mathrm{~min}$; (f) 12 hours $100 \mathrm{Oe}+50 \mathrm{~Hz} 2$ hours

Intracellular release of GHRH antagonist MIA690 from MENs in GBM To determine the amount of intracellular uptake and release of MIA690, the amount of free drug in the cell lysate was quantified spectrophometrically. It is accepted that cell 
lysate components represent the intracellular content of cells.53 Following the treatment and exposure to magnetic fields, U-87MG cells were allowed to incubate further for 24 hours or 48 hours. Then media was discarded, cells were washed with PBS and detached with $0.25 \%$ trypsin/EDTA solution. Cells were collected in a conical tube, pelleted by centrifugation and washed thrice with ice cold PBS. Cells were resuspended in $1 \mathrm{~mL}$ DMSO and sonicated briefly to induce cell lysis. After 1 hour of incubation at $37^{\circ} \mathrm{C}$, the solution was centrifuged at 10,000 RPM for 5 minutes to pellet cellular debris and MENs. The supernatant containing the cell lysate was collected to measure the intracellular concentration of MIA690.

Quantification of MIA690 uptake in cell lysate

An aliquot $(20 \mu \mathrm{L})$ of cell lysate from each treatment group was diluted in buffer and measured spectrophometrically on scan mode to capture peak signatures of the peptide. A standard curve was generated by resuspending known concentrations of MIA690 and creating serial dilutions. Peak absorbance of MIA690 was captured at the maximum wavelength of $220 \mathrm{~nm}$. MIA690 uptake was normalized to the protein content of cells lysate, which is representative of the number of cells in culture. Protein content was determined immediately after collection to avoid protein degradation with the Bradford method using Bio-Rad Protein Assay Kit at an absorbance of $595 \mathrm{~nm}$ according to BioRad protocol (CA, USA). Final results were reported as \% MIA690 per ug protein. Spectrophometric measurements were performed by Cary 100 UV-VIS spectrophotometer (CA, USA). 
Imaging intracellular uptake and specificity of MENs in U-87MG cells

Cell lysate from each treatment group 24 hours after treatment was collected for imaging with electron-dispersive spectroscopy (EDS) mode of scanning electron microscopy (SEM). EDS- SEM detects signature traces of Ba and Ti that is unique to MENs outer shell. The presence of Ba and Ti in cell lysate indicates efficient nanoelectroporation of U-87MG cells. One drop of lysate $(\sim 10 \mu \mathrm{L})$ diluted in TE buffer was dried on a precleaned Si wafer and placed on copper tape mounting for imaging with a JEOL- JIB 4500 multibeam system (FIB/SEM). The Thermo- scientific Noran system 7 performed EDS analysis. Intracellular uptake of GMO-MENs was observed by comparing the density of $\mathrm{Ba}$ and Ti signal in each image. ICP-MS confirmed the presence of $\mathrm{Ba}$ and Ti in the cell lysate. For specificity data of MENs, malignant U-87MG cells and non-malignant HBMECs were cultured as previously described and treated with FITC-loaded MENs (FITC MENs) and DAPI for nuclear staining. U-87MG cells and HBMECs were exposed to a magnetic field gradient of 100 Oe and intracellular uptake of MENs was quantified using a confocal fluorescent microscope Olympus Fluoview FS1200 (PA, USA).

Cell viability and magnetic nanoparticles hyperthermic effects In vitro cell viability of U-87MG cells after treatment with MIA690 or MIA690-GMOMENs and magnetic field exposure was determined using the trypan blue protocol.54 Experimental conditions were identical to those of the treatment groups described previously. Reported results are relative to the control group treated with a PBS vehicle solution. 
The magnetic fields used to induce nanoelectroporation may cause heat dissipation known to produce hyperthermic effects resulting in cell death. Infrared (IR) imaging captured by the FIIR- i3 camera (OR, USA) measured heat dissipation at each stage of treatment to ensure that cell culture temperatures remained within normal ranges. Temperatures were captured at the maximal magnetic field exposures.

The penetration of the blood-brain barrier by MENs in vivo Immunocompromised mice (Taconic, Inc., NY, USA) were maintained in pathogen-free conditions in the institutional animal care facility at Florida International University (FIU). Mice were injected IV into the tail vein with $200 \mathrm{ug} / \mathrm{mL}$ GMO-MENs. Following application of magnetic fields, mice were euthanized be means of $\mathrm{CO} 2$ inhalation, immediately after which tissues were excised and stored in $10 \%$ formalin solution overnight $4^{\circ} \mathrm{C}$. The tissues were cleaned under a stereomicroscope and a small piece of the brain was sectioned and washed with PBS to remove excess fixative. Brain tissue was carefully dried and transferred to a plastic mold containing OCT. The tissue was frozen by immersing the mold in a bath of 2- methlybutane/liquid nitrogen, then transferred to a $-80^{\circ} \mathrm{C}$ freezer overnight before being cut into $10 \mu \mathrm{m}$ sections with a Leica CM3050 Cryostat (IL, USA). Finally, tissues slices were mounted on VWR Superfrost Plus microscope slides and dried on a slide warmer at $37^{\circ} \mathrm{C}$ for $1-2$ hours. Slides were then ready for EDS-SEM analysis to detect signature peaks of the elemental composition of MENs core-shell ( $\mathrm{Ba}$ and $\mathrm{Ti})$. All methods used in the study were carried out in accordance with the approved guidelines of the institutional animal care and use committee (IACUC) at FIU. 
Vibrating sample magnetometry

A room-temperature Lakeshore VSM system with a 3-T magnetic field sweep was used to measure key magnetic properties of nanoparticles under study including the magnetization saturation and the magnetic coercivity. The vibration was induced at a 60 $\mathrm{Hz}$ frequency. The sensitivity of the system is on the order of $1 \mu \mathrm{emu}$. The system was calibrated by measuring the saturation magnetization of iron oxide and permalloy thin films.

X-ray diffraction measurements

XRD measurements were conducted using diffractometer BRUKER D5000 with the following specifications: X-Ray tube: Kalfa C, KBeta filter: Ni (12 micron thickness); scan type: locked coupled; 2tetha: 20-80 degress; increment: 0.1 degrees; scan speed: 6 sec/step current: $35 \mathrm{~mA}$; Voltage: $40 \mathrm{kV}$; aperture diagram path: $1 \mathrm{~mm}$

Statistical analysis

Results are presented as means \pm S.D. or percentages. Student's t-test and one-way ANOVA with posthoc analyses were conducted to assess significant differences between treatment groups. All data was collected in replicated of at least $n=2$ and data were reevaluated when $\mathrm{CV}$ values were greater than $10 \%$. Linear regression models were used to assess relationships between variables of interest. Statistical analysis was performed using IBM SPSS software (IL, USA). P-values $<0.05$ were considered statistically significant 
FUTURE WORK 
The overall objective of the dissertation was to implement and study the underline physics of a novel nanotechnology capable of exploiting the electric properties of the cellular microenvironment. To summarize, via application of an external magnetic field we are able to control the magnetoelectric effect of our multiferroic nanoparticles due to its' strongly coupled magnetostrictive and piezoelectric properties.

In chapter II we explored the differences between magnetoelectric nanoparticle (MENs) and other magnetic nanoparticles (MNPs). To clearly differentiate between the two type of nanoparticles, we explained how like MNPs, MENs have a non-zero magnetic moment and therefore can be transported throughout the circulatory system via application of an external magnetic field gradient. However, unlike MNPs, MENs' magnetoelectric effect provides a unique way to control an intrinsic electric field that underlies the chemical bond between the nanoparticles and the loaded drug as well as the interaction between the drug-loaded nanoparticle and the cellular microenvironment. The targeting mechanism occurs when in close proximity to the cellular membrane; the electric field on the surface of the nanoparticle induces a dielectric breakdown affecting the membrane of cancer cells but not that of normal cells. When MENs enter the cytoplasm of the cancer cell, application of an a.c. magnetic field breaks the bond between the nanoparticle and the therapeutic drug, ultimately eradicating the cancer cells while completely avoiding surrounding normal cells. 
In chapter III the application of MENs as nuclear magnetic resonance (NMR) nanoprobes for rapid cancer diagnostic was explored. The intrinsically coupled ferromagnetic and ferroelectric phases allowed the nanoparticles to be used as NMR sensitive nanoprobe detectors of biological cells; based on the knowledge that the cellular membrane is an electrically charged medium that can be influenced by the electric field associated with MENs. The study showed that MENs can significantly enhance the electric charge configuration on the cellular membrane that can serve as a characteristic signature of the cell, depending on the cell type and prognosis stage. The enhanced electric field from the nanoparticle-cell interaction was observed in NMR absorption spectra of cells incubated with MENs, in contrast to conventional MNPs that showed no change in the NMR absorption spectra.

In chapter IV an in-vitro study was conducted to deliver MIA690 peptides across the blood brain barrier (BBB) to glioblastoma multiforme (GBM) cancer cells. The targeting and treatment of glioblastomas is extremely difficult due to the many variety of cancer cells associated with the tumor. Taking advantage of the properties of MENs described in chapter 1, we successfully brought MIA690-MENs across the blood brain barrier via an external magnetic field gradient. After bypassing the BBB, the loaded MIA690 MENs was able to penetrate and release the peptide drug in the cellular membrane of the human glioblastoma cells by way of a relatively weak d.c. and a.c. magnetic fields applications, respectively. 
To conclude, future work consists of studying the dynamics of intracellular transport. Specifically, to distinguish the transport due to the traditional cascade process and the charge-associated transport due to the intrinsic intracellular fields. The hypothesis of these two processes is characterized by very different time scales. We will use magnetoelectric nanoparticles (MENs) as an enabling tool to study externally, the charges associated with intracellular transport in different cellular media to understand how cells form information circuits that detects, process, and respond to signals in its cellular microenvironment. 


\section{REFERENCES}

1. Geng SB, Cheung JK, Narasimhan C, Shameem M, Tessier PM. Improving monoclonal antibody selection and engineering using measurements of colloidal protein interactions. J Pharm Sci. 2014 November 01;103(11):3356-63.

2. Kennedy PJ, Oliveira C, Granja PL, Sarmento B. Monoclonal antibodies: technologies for early discovery and engineering. Crit Rev Biotechnol. 2017 August 08:1-15.

3. Kuo CY, Liu TY, Wang KS, Hardiansyah A, Lin YT, Chen HY, et al. Magnetic and Thermal-sensitive Poly(N-isopropylacrylamide)-based Microgels for Magnetically Triggered Controlled Release. J Vis Exp. 2017 July 04;(125). doi(125):10.3791/55648.

4. Li L, Fu L, Zhou J, Ai X, Zhang J. Design and Fabrication of Temperature-Sensitive Nanogels with Controlled Drug Release Properties for Enhanced Photothermal Sterilization. Chemistry. 2017 August 15.

5. Luo Z, Jin K, Pang Q, Shen S, Yan Z, Jiang T, et al. On-Demand Drug Releasing from Dual Targeting Small Nanoparticles Triggered by High Intensity Focused Ultrasound Enhanced Glioblastoma Targeting Therapy. ACS Appl Mater Interfaces. 2017 September 01 .

6. Liang P, Zheng J, Dai S, Wang J, Zhang Z, Kang T, et al. pH triggered re-assembly of nanosphere to nanofiber: The role of peptide conformational change for enhanced cancer therapy. J Control Release. 2017 August 28;260:22-31.

7. Khutale GV, Casey A. Synthesis and characterization of a multifunctional golddoxorubicin nanoparticle system for $\mathrm{pH}$ triggered intracellular drug release. Eur J Pharm Biopharm. 2017 July 20.

8. Chen Y, Su M, Li Y, Gao J, Zhang C, Cao Z, et al. Enzymatic PEG-Poly(amine-codisulfide ester) Nanoparticles as $\mathrm{pH}$ - and Redox-Responsive Drug Nanocarriers for Efficient Antitumor Treatment. ACS Appl Mater Interfaces. 2017 September 01.

9. Hua X, Yang Q, Dong Z, Zhang J, Zhang W, Wang Q, et al. Magnetically triggered drug release from nanoparticles and its applications in anti-tumor treatment. Drug Deliv. 2017 November 01;24(1):511-8.

10. Oh Y, Moorthy MS, Manivasagan P, Bharathiraja S, Oh J. Magnetic hyperthermia and $\mathrm{pH}$-responsive effective drug delivery to the sub-cellular level of human breast cancer cells by modified CoFe2O4 nanoparticles. Biochimie. 2017 February 01;133:7-19.

11. Kautzka Z, Clement S, Goldys EM, Deng W. Light-triggered liposomal cargo delivery platform incorporating photosensitizers and gold nanoparticles for enhanced 
singlet oxygen generation and increased cytotoxicity. Int J Nanomedicine. 2017 February 02;12:969-77.

12. Khutale GV, Casey A. Synthesis and characterization of a multifunctional golddoxorubicin nanoparticle system for $\mathrm{pH}$ triggered intracellular drug release. Eur J Pharm Biopharm. 2017 July 20.

13. Xu Y, Liu Q, He R, Miao X, Ji M. Imaging Laser-Triggered Drug Release from Gold Nanocages with Transient Absorption Lifetime Microscopy. ACS Appl Mater Interfaces. 2017 June 14;9(23):19653-61.

14. Cantu T, Walsh K, Pattani VP, Moy AJ, Tunnell JW, Irvin JA, et al. Conductive polymer-based nanoparticles for laser-mediated photothermal ablation of cancer: synthesis, characterization, and in vitro evaluation. Int J Nanomedicine. 2017 January $16 ; 12: 615-32$.

15. Mocan L, Tabaran FA, Mocan T, Pop T, Mosteanu O, Agoston-Coldea L, et al. Laser thermal ablation of multidrug-resistant bacteria using functionalized gold nanoparticles. Int J Nanomedicine. 2017 March 23;12:2255-63.

16. Kong FY, Zhang JW, Li RF, Wang ZX, Wang WJ, Wang W. Unique Roles of Gold Nanoparticles in Drug Delivery, Targeting and Imaging Applications. Molecules. 2017 August 31;22(9):10.3390/molecules22091445.

17. Farka Z, Jurik T, Kovar D, Trnkova L, Skladal P. Nanoparticle-Based Immunochemical Biosensors and Assays: Recent Advances and Challenges. Chem Rev. 2017 August 09;117(15):9973-10042.

18. Lan L, Yao Y, Ping J, Ying Y. Recent advances in nanomaterial-based biosensors for antibiotics detection. Biosens Bioelectron. 2017 May 15;91:504-14.

19. Yu T, Dai PP, Xu JJ, Chen HY. Highly Sensitive Colorimetric Cancer Cell Detection Based on Dual Signal Amplification. ACS Appl Mater Interfaces. 2016 February $01 ; 8(7): 4434-41$.

20. Rodzinski A, Guduru R, Liang P, Hadjikhani A, Stewart T, Stimphil E, et al. Targeted and controlled anticancer drug delivery and release with magnetoelectric nanoparticles. Sci Rep. 2016 February 15;6:20867.

21. K. S. Chan , C. G. Koh, and H. Y. Li , Cell Death Dis. 3, e411 (2012). https://doi.org/10.1038/cddis.2012.148.

22. J. K. Vasir and V. Labhasetwar, Technol. Cancer Res. Treat. 4(4), 363-374 (2005). https://doi.org/10.1177/153303460500400405. 
23. M. Yoshida, R. Takimoto, K. Murase, Y. Sato , M. Hirakawa , F. Tamura, T. Sato , S. Iyama , T. Osuga , K. Miyanishi , K. Takada , T. Hayashi , M. Kobune, and J. Kato , PLoS One 7(7), e39545 (2012). https://doi.org/10.1371/journal.pone.0039545.

24. E. M. Pridgen , R. Langer , and O. C. Farokhzad , Nanomedicine (London) 2(5), 669680 (2007). https://doi.org/10.2217/17435889.2.5.669.

25. S. Shah , Y. Liu , W. Hu , and J. Gao , J. Nanosci. Nanotechnol. 11(2), 919-928 (2011). https://doi.org/10.1166/jnn.2011.3536.

26. D. Peer, J. M. Karp, S. Hong, O. C. Farokhzad, R. Margalit, and R. Langer, Nat. Nanotechnol. 2(12), 751-760 (2007). https://doi.org/10.1038/nnano.2007.387.

27. A. Z. Wang, R. Langer, and O. C. Farokhzad, Annu. Rev. Med. 63, 185-198 (2012). https://doi.org/10.1146/annurev-med-040210-162544.

28. I. Brigger, C. Dubernet, and P. Couvreur, Adv. Drug Delivery Rev. 54(5), 631-651 (2002). https://doi.org/10.1016/S0169-409X(02)00044-3.

29. S. Barua , J. W. Yoo , P. Kolhar , A. Wakankar , Y. R. Gokarn , and S. Mitragotri , Proc. Natl. Acad. Sci. U. S. A. 110(9), 3270-3275 (2013). https://doi.org/10.1073/pnas.1216893110.

30. R. Tong, H. D. Hemmati, R. Langer, and D. S. Kohane, J. Am. Chem. Soc. 134(21), 8848-8855 (2012). https://doi.org/10.1021/ja211888a.

31. U. Prabhakar, H. Maeda , R. K. Jain , E. M. Sevick-Muraca , W. Zamboni , O. C. Farokhzad, S. T. Barry, A. Gabizon , P. Grodzinski, and D. C. Blakey, Cancer Res. 73(8), 2412-2417 (2013). https://doi.org/10.1158/0008-5472.CAN-12-4561.

32. H. Maeda , Adv. Enzyme Regul. 41, 189-207 (2001). https://doi.org/10.1016/S00652571(00)00013-3.

33. S. Kunjachan, R. Pola , F. Gremse, B. Theek, J. Ehling, D. Moeckel , B. Hermanns-Sachweh, M. Pechar, K. Ulbrich , W. E. Hennink, G. Storm , W. Lederle , F. Kiessling , and T. Lammers , Nano Lett. 14(2), 972-981 (2014). https://doi.org/10.1021/n1404391r.

34. F. Danhier , O. Feron, and V. Preat , J. Controlled Release 148(2), 135-146 (2010). https://doi.org/10.1016/j.jconrel.2010.08.027.

35. F. Brasseur, P. Couvreur, B. Kante , L. Deckers-Passau, M. Roland, C. Deckers , and P. Speiser , Eur. J. Cancer 16(11), 1441-1445 (1980). https://doi.org/10.1016/00142964(80)90053-5. 
36. I. Cheong, X. Huang, C. Bettegowda, L. A. Diaz, Jr., K. W. Kinzler, S. Zhou, and B. Vogelstein , Science 314(5803), 1308-1311 (2006). https://doi.org/10.1126/science.1130651.

37. D. W. Lee, D. M. Barrett, C. Mackall, R. Orentas, and S. A. Grupp, Clin. Cancer Res. 18(10), 2780-2790 (2012). https://doi.org/10.1158/1078-0432.CCR-11-1920.

38. R. K. Oldham and R. O. Dillman, J. Clin. Oncol. 26(11), 1774-1777 (2008). https://doi.org/10.1200/JCO.2007.15.7438.

39. V. P. Torchilin , Nat. Rev. Drug Discovery 4(2), 145-160 (2005). https://doi.org/10.1038/nrd1632.

40. W. Tai , R. Mahato , and K. Cheng, J. Controlled Release 146(3), 264-275 (2010). https://doi.org/10.1016/j.jconrel.2010.04.009.

41. M. A. Firer and G. Gellerman , J. Hematol. Oncol. 5, 70 (2012). https://doi.org/10.1186/1756-8722-5-70.

42. X. Wei , X. Chen, M. Ying, and W. Lu , Acta Pharm. Sin. B 4(3), 193-201 (2014). https://doi.org/10.1016/j.apsb.2014.03.001.

43. F. Danhier, E. Ansorena, J. M. Silva, R. Coco, A. Le Breton, and V. Preat, J Controlled Release 161(2), 505-522 (2012). https://doi.org/10.1016/j.jconrel.2012.01.043

44. B. P. Timko, T. Dvir, and D. S. Kohane, Adv. Mater. 22(44), 4925-4943 (2010). https://doi.org/10.1002/adma.201002072.

45. X. Li , Q. Zhao , and L. Qiu , J. Controlled Release 171(2), 152-162 (2013). https://doi.org/10.1016/j.jconrel.2013.06.006.

46. G. Wu , A. Mikhailovsky, H. A. Khant, C. Fu , W. Chiu, and J. A. Zasadzinski , J. Am. Chem. Soc. 130(26), 8175-8177 (2008). https://doi.org/10.1021/ja802656d.

47. W. Zhang, K. Gilstrap , L. Wu , K. C. Remant Bahadur, M. A. Moss, Q. Wang, X. Lu, and X. He , ACS Nano 4(11), 6747-6759 (2010). https://doi.org/10.1021/nn101617n

48. M. C. Cochran, J. R. Eisenbrey, M. C. Soulen, S. M. Schultz, R. O. Ouma, S. B. White, E. E. Furth, and M. A. Wheatley, Acad. Radiol. 18(11), 1341-1348 (2011). https://doi.org/10.1016/j.acra.2011.06.013.

49. C. Y. Lin, J. R. Li , H. C. Tseng, M. F. Wu and W. L. Lin, Nanomedicine 8(6), 900-907 (2012). https://doi.org/10.1016/j.nano.2011.10.005. 
50. E. K. Lim , Y. M. Huh , J. Yang, K. Lee, J. S. Suh , and S. Haam , Adv. Mater. 23(21), 2436-2442 (2011). https://doi.org/10.1002/adma.201100351.

51. D. Putnam and J. Kopecek, Bioconjugate Chem. 6(4), 483-492 (1995). https://doi.org/10.1021/bc00034a019.

52. S. C. McBain , H. H. Yiu , and J. Dobson, Int. J. Nanomed. 3(2), 169-180 (2008).

53. S. L. McGill , C. L. Cuylear, N. L. Adolphi, M. Osinski, and H. D. Smyth , IEEE Trans. Nanobiosci. 8(1), 33-42 (2009). https://doi.org/10.1109/TNB.2009.2017292.

54. B. Liu, X. Zhang, C. Li , F. He, Y. Chen, S. Huang, D. Jin , P. Yang, Z. Cheng, and J. Lin , Nanoscale 8(25), 12560-12569 (2016). https://doi.org/10.1039/C5NR06322A

55. T. Hoare, J. Santamaria , G. F. Goya, S. Irusta, D. Lin, S. Lau, R. Padera, R. Langer , and D. S. Kohane, Nano Lett. 9(10), 3651-3657 (2009). https://doi.org/10.1021/n19018935.

56. M. R. Prausnitz, V. G. Bose, R. Langer, and J. C. Weaver, Proc. Natl. Acad. Sci. U. S. A. 90(22), 10504-10508 (1993). https://doi.org/10.1073/pnas.90.22.10504.

57. D. C. Chang, Guide to Electroporation and Electrofusion ( Academic Press, San Diego, 1992).

58. H. Y. Wang and C. Lu , Biotechnol. Bioeng. 95(6), 1116-1125 (2006). https://doi.org/10.1002/bit.21066.

59. C. Chen, S. W. Smye, M. P. Robinson, and J. A. Evans, Med. Biol. Eng. Comput. 44(1-2), 5-14 (2006). https://doi.org/10.1007/s11517-005-0020-2.

60. H. Y. Wang and C. Lu , Biotechnol. Bioeng. 100(3), 579-586 (2008). https://doi.org/10.1002/bit.21784.

61. K. Cahill , Phys. Biol. 7, 16001 (2009). https://doi.org/10.1088/14783975/7/1/016001.

62. V. Novickij, A. Grainys, E. Lastauskiene, R. Kananaviciute, D. Pamedytyte, L. Kalediene , J. Novickij , and D. Miklavcic , Sci. Rep. 6, 33537 (2016). https://doi.org/10.1038/srep33537.

63. A. Silve , I. Leray , M. Leguebe, C. Poignard, and L. M. Mir, Bioelectrochemistry 106(Pt B), 369-378 (2015). https://doi.org/10.1016/j.bioelechem.2015.06.002.

64. K. Redmann, V. Muller, S. Tanneberger, and W. Kalkoff, Acta Biol. Med. Ger. 28(5), 853-856 (1972). 
65. S. Betal , B. Shrestha , M. Dutta , L. F. Cotica, E. Khachatryan, K. Nash , L. Tang, A. S. Bhalla, and R. Guo, Sci. Rep. 6, 32019 (2016). https://doi.org/10.1038/srep32019.

66. K. Yue , R. Guduru , J. Hong, P. Liang, M. Nair , and S. Khizroev , PLoS One 7(9), e44040 (2012). https://doi.org/10.1371/journal.pone.0044040.

67. R. Guduru, P. Liang, C. Runowicz, M. Nair, V. Atluri, and S. Khizroev, Sci. Rep. 3, 2953 (2013). https://doi.org/10.1038/srep02953.

68. R. Guduru , P. Liang, J. Hong, A. Rodzinski , A. Hadjikhani , J. Horstmyer , E. Levister , and S. Khizroev, Nanomedicine (London) 10(13), 2051-2061 (2015). https://doi.org/10.2217/nnm.15.52.

69. A. Rodzinski , R. Guduru , P. Liang, A. Hadjikhani , T. Stewart, E. Stimphil , C. Runowicz, R. Cote, N. Altman, R. Datar, and S. Khizroev, Sci. Rep. 6, 20867 (2016). https://doi.org/10.1038/srep20867.

70. T. Lammers , F. Kiessling, W. E. Hennink , and G. Storm , J. Controlled Release 161(2), 175-187 (2012). https://doi.org/10.1016/j.jconrel.2011.09.063.

71. A. Kaushik, R. D. Jayant, R. Nikkhah-Moshaie , V. Bhardwaj , U. Roy , Z. Huang, A. Ruiz , A. Yndart , V. Atluri , N. El-Hage , K. Khalili , and M. Nair , Sci. Rep. 6, 25309 (2016). https://doi.org/10.1038/srep25309.

72. W. Eerenstein, N. D. Mathur, and J. F. Scott, Nature 442(7104), 759-765 (2006). https://doi.org/10.1038/nature05023.

73. S. Xie , F. Ma , Y. Liu , and J. Li , Nanoscale 3(8), 3152-3158 (2011). https://doi.org/10.1039/c1nr10288e.

74. S. Wang, W. Yang, H. Du , F. Guo , H. Wang, J. Chang, X. Gong, and B. Zhang, Nanotechnology 27(16), $165101 \quad$ (2016). https://doi.org/10.1088/0957$4484 / 27 / 16 / 165101$.

75. N. Singh , G. J. Jenkins , R. Asadi , and S. H. Doak , Nano Rev. 1, 5358 (2010). https://doi.org/10.3402/nano.v1i0.5358.

76. N. D. Thorat, O. M. Lemine, R. A. Bohara, K. Omri , L. El Mir, and S. A. Tofail , Phys. Chem. Chem. Phys. 18(31), 21331-21339 (2016). https://doi.org/10.1039/C6CP03430F.

77. T. Fu , Q. Kong, H. Sheng, and L. Gao , Neural Plast. 2016, 2412958 (2016). https://doi.org/10.1155/2016/2412958. 
78. M. Peng, H. Li , Z. Luo , J. Kong, Y. Wan, L. Zheng, Q. Zhang, H. Niu , A. Vermorken, W. Van de Ven , C. Chen , X. Zhang , F. Li , L. Guo, and Y. Cui , Nanoscale 7(25), 11155-11162 (2015). https://doi.org/10.1039/C5NR01382H.

79. T. Kimura , T. Goto , H. Shintani , K. Ishizaka, T. Arima, and Y. Tokura, Nature 426(6962), 55-58 (2003). https://doi.org/10.1038/nature02018.

80. K. Ulbrich , K. Hola , V. Subr , A. Bakandritsos , J. Tucek, and R. Zboril , Chem. Rev. 116(9), 5338-5431 (2016). https://doi.org/10.1021/acs.chemrev.5b00589.

81. L. C. Barnsley, D. Carugo , M. Aron , and E. Stride , Phys. Med. Biol. 62, 2333 (2017). https://doi.org/10.1088/1361-6560/aa5d46.

82. N. V. Long, Y. Yang, T. Teranishi, C. M. Thi, Y. Cao, and M. Nogami, J. Nanosci. Nanotechnol. 15(12), 10091-10107 (2015). https://doi.org/10.1166/jnn.2015.11691.

83. A. Busato , R. Bonafede , P. Bontempi , I. Scambi , L. Schiaffino, D. Benati , M. Malatesta , A. Sbarbati , P. Marzola , and R. Mariotti , Int. J. Nanomed. 11, 2481-2490 (2016). https://doi.org/10.2147/IJN.S104152.

84. J. Weizenecker, B. Gleich, J. Rahmer, H. Dahnke, and J. Borgert, Phys. Med. Biol. 54(5), L1-L10 (2009). https://doi.org/10.1088/0031-9155/54/5/L01.

85. M. Nair, R. Guduru, P. Liang, J. Hong, V. Sagar, and S. Khizroev, Nat. Commun. 4, 1707 (2013). https://doi.org/10.1038/ncomms2717.

86. R. Binggeli and I. L. Cameron, Cancer Res. 40(6), 1830-1835 (1980).

87. S. J. Beebe, N. M. Sain, and W. Ren, Cells 2(1), 136-162 (2013). https://doi.org/10.3390/cells2010136.

88. V. Corral-Flores, D. Bueno-Baqués, and R. Ziolo, Acta Mater. 58, 764 (2010). https://doi.org/10.1016/j.actamat.2009.09.054.

89. C. Schmitz-Antoniak, D. Schmitz, P. Borisov , F. M. de Groot, S. Stienen , A. Warland, B. Krumme, R. Feyerherm, E. Dudzik, W. Kleemann, and H. Wende, Nat. Commun. 4, 2051 (2013). https://doi.org/10.1038/ncomms3051.

90. M. Scigaj , N. Dix , J. Gazquez, M. Varela , I. Fina , N. Domingo , G. Herranz , V. Skumryev , J. Fontcuberta, and F. Sanchez, Sci. Rep. 6, 31870 (2016). https://doi.org/10.1038/srep31870.

91. H. Zheng, J. Wang, S. E. Lofland, Z. Ma , L. Mohaddes-Ardabili, T. Zhao , L. Salamanca-Riba , S. R. Shinde, S. B. Ogale , F. Bai , D. Viehland, Y. Jia, D. G. Schlom 
, M. Wuttig , A. Roytburd, and R. Ramesh, Science 303(5658), 661-663 (2004). https://doi.org/10.1126/science.1094207.

92. B. R. Pieters, D. Z. D. Back, C. C. Koning, and A. H. Zwinderman, Radiother. Oncol. 93, 168 (2009). https://doi.org/10.1016/j.radonc.2009.08.033.

93. J. Hong, E. Bekyarova , P. Liang, W. A. D. Heer, R. C. Haddon , and S. Khizroev, Sci. Rep. 2, 624 (2012). https://doi.org/10.1038/srep00624.

94. I. Weinberg, "MRI-guided nanoparticle cancer therapy apparatus and methodology," U.S. patent 2013/0046169 A1 (2013).

95. H. Nakamura, F. Jun , and H. Maeda, Expert Opin. Drug Delivery 12, 53 (2014). https://doi.org/10.1517/17425247.2014.955011.

96. C. C. Roth , G. P. Tolstykh, J. A. Payne, M. A. Kuipers, G. L. Thompson, M. N. Desilva , and B. L. Ibey , J. Biomed. Opt. 18, 035005 (2013). https://doi.org/10.1117/1.JBO.18.3.035005.

97. F. M. Veronese and G. Pasut, Drug Discovery Today 10, 1451 (2005). https://doi.org/10.1016/S1359-6446(05)03575-0.

98. G. Pillai , SOJ Pharm. Pharm. Sci. $1, \quad 1 \quad$ (2014). https://doi.org/10.1166/jpsp.2014.1001.

99. Fratila RM, Moros M, de la Fuente, J M. Recent advances in biosensing using magnetic glyconanoparticles. Anal Bioanal Chem. 2016 March 01;408(7):1783-803.

100. Haun JB, Yoon TJ, Lee H, Weissleder R. Magnetic nanoparticle biosensors. Wiley Interdiscip Rev Nanomed Nanobiotechnol. 2010 June 01;2(3):291-304.

101. Kurlyandskaya GV, Portnov DS, Beketov IV, Larranaga A, Safronov AP, Orue I, et al. Nanostructured materials for magnetic biosensing. Biochim Biophys Acta. 2017 June 01;1861(6):1494-506.

102. Lin G, Makarov D, Schmidt OG. Magnetic sensing platform technologies for biomedical applications. Lab Chip. 2017 May 31;17(11):1884-912.

103. Wang W, Ma P, Dong H, Krause HJ, Zhang Y, Willbold D, et al. A magnetic nanoparticles relaxation sensor for protein-protein interaction detection at ultra-low magnetic field. Biosens Bioelectron. 2016 June 15;80:661-5.

104. Martins P, Silva M, Lanceros-Mendez S. Determination of the magnetostrictive response of nanoparticles via magnetoelectric measurements. Nanoscale. 2015 June 07;7(21):9457-61. 
105. Xu X, Huang F, Shao Y, Zhou M, Ren X, Lu X, et al. Improved magnetic and magnetoelectric properties in BaFe12O19 nanostructures. Phys Chem Chem Phys. 2017 July 21;19(27):18023-9.

106. Escalona Y, Garate JA, Araya-Secchi R, Huynh T, Zhou R, Perez-Acle T. Exploring the Membrane Potential of Simple Dual-Membrane Systems as Models for Gap-Junction Channels. Biophys J. 2016 June 21;110(12):2678-88.

107. Forest V, Pourchez J. Preferential binding of positive nanoparticles on cell membranes is due to electrostatic interactions: A too simplistic explanation that does not take into account the nanoparticle protein corona. Mater Sci Eng C Mater Biol Appl. 2017 January 01;70(Pt 1):889-96.

108. Kim DY, Kwon JS, Lee JH, Jin LM, Kim JH, Kim MS. Effects of the Surface Charge of Stem Cell Membranes and DNA/Polyethyleneimine Nanocomplexes on Gene Transfection Efficiency. J Biomed Nanotechnol. 2015 March 01;11(3):522-30.

109. Michel JP, Wang YX, De E, Fontaine P, Goldmann M, Rosilio V. Charge and aggregation pattern govern the interaction of plasticins with LPS monolayers mimicking the external leaflet of the outer membrane of Gram-negative bacteria. Biochim Biophys Acta. 2015 November 01;1848(11 Pt A):2967-79.

110. Szeremeta M, Petelska AD, Kotynska J, Pepinski W, Naumowicz M, Figaszewski ZA, et al. Changes in Surface Charge Density of Blood Cells in Fatal Accidental Hypothermia. J Membr Biol. 2015 December 01;248(6):1175-80.

111. Guduru R, Liang P, Runowicz C, Nair M, Atluri V, Khizroev S. Magneto-electric nanoparticles to enable field-controlled high-specificity drug delivery to eradicate ovarian cancer cells. Sci Rep. 2013 October 16;3:2953.

112. Nair M, Guduru R, Liang P, Hong J, Sagar V, Khizroev S. Externally controlled ondemand release of anti-HIV drug using magneto-electric nanoparticles as carriers. Nat Commun. 2013;4:1707.

113. Rodzinski A, Guduru R, Liang P, Hadjikhani A, Stewart T, Stimphil E, et al. Targeted and controlled anticancer drug delivery and release with magnetoelectric nanoparticles. Sci Rep. 2016 February 15;6:20867.

114. Ahn S, Seo E, Kim KH, Lee SJ. Physical Property Control on the Cellular Uptake Pathway and Spatial Distribution of Nanoparticles in Cells. J Biomed Nanotechnol. 2015 June 01;11(6):1051-70.

115. Ihse E, Yamakado H, van Wijk XM, Lawrence R, Esko JD, Masliah E. Cellular internalization of alpha-synuclein aggregates by cell surface heparan sulfate depends on aggregate conformation and cell type. Sci Rep. 2017 August 21;7(1):5. 
116. Lojk J, Bregar VB, Strojan K, Hudoklin S, Veranic P, Pavlin M, et al. Increased endocytosis of magnetic nanoparticles into cancerous urothelial cells versus normal urothelial cells. Histochem Cell Biol. 2017 August 18.

117. Saneja A, Kumar R, Singh A, Dhar Dubey R, Mintoo MJ, Singh G, et al. Development and evaluation of long-circulating nanoparticles loaded with betulinic acid for improved anti-tumor efficacy. Int J Pharm. 2017 August 18;531(1):153-66.

118. Takehara M, Takagishi T, Seike S, Oda M, Sakaguchi Y, Hisatsune J, et al. Cellular Entry of Clostridium perfringens Iota-Toxin and Clostridium botulinum C2 Toxin. Toxins (Basel). 2017 August 11;9(8):10.3390/toxins9080247.

119. Werner RA, Sheikhbahaei S, Jones KM, Javadi MS, Solnes LB, Ross AE, et al. Patterns of uptake of prostate-specific membrane antigen (PSMA)-targeted 18F-DCFPyL in peripheral ganglia. Ann Nucl Med. 2017 August 22.

120. Imai S, Morishita $\mathrm{Y}$, Hata $\mathrm{T}$, Kondoh M, Yagi K, Gao JQ, et al. Cellular internalization, transcellular transport, and cellular effects of silver nanoparticles in polarized Caco-2 cells following apical or basolateral exposure. Biochem Biophys Res Commun. 2017 March 11;484(3):543-9.

121. Silva E, Barreiros L, Segundo MA, Costa Lima SA, Reis S. Cellular interactions of a lipid-based nanocarrier model with human keratinocytes: Unravelling transport mechanisms. Acta Biomater. 2017 April 15;53:439-49.

122. Soriano GB, da Silva Oliveira R, Camilo FF, Caseli L. Interaction of non-aqueous dispersions of silver nanoparticles with cellular membrane models. J Colloid Interface Sci. 2017 June 15;496:111-7.

123. Thimiri Govinda Raj, D B, Khan NA. Designer nanoparticle: nanobiotechnology tool for cell biology. Nano Converg. 2016;3(1):x. Epub 2016 Sep 15.

References

124. Brandes AA, Bartolotti M, Tosoni A, Poggi R, Bartolini S, Paccapelo A, et al. Patient outcomes following second surgery for recurrent glioblastoma. Future Oncol. 2016;12(8):1039-44.

125. Brandes AA, Franceschi E, Paccapelo A, Tallini G, De Biase D, Ghimenton C, et al. Role of MGMT Methylation Status at Time of Diagnosis and Recurrence for Patients with Glioblastoma: Clinical Implications. Oncologist. 2017 April 01;22(4):432-7.

126. Paquette B, Vernerey D, Chauffert B, Dabakuyo S, Feuvret L, Taillandier L, et al. Prognostic value of health-related quality of life for death risk stratification in patients with unresectable glioblastoma. Cancer Med. 2016 August 01;5(8):1753-64. 
127. Kim DG, Kim KH, Seo YJ, Yang H, Marcusson EG, Son E, et al. Anti-miR delivery strategies to bypass the blood-brain barrier in glioblastoma therapy. Oncotarget. 2016 May 17;7(20):29400-11.

128. Miranda A, Blanco-Prieto M, Sousa J, Pais A, Vitorino C. Breaching barriers in glioblastoma. Part I: Molecular pathways and novel treatment approaches. Int $\mathrm{J}$ Pharm. 2017 July 27.

129. Rodriguez GA, Shah AH, Gersey ZC, Shah SS, Bregy A, Komotar RJ, et al. Investigating the therapeutic role and molecular biology of curcumin as a treatment for glioblastoma. Ther Adv Med Oncol. 2016 July 01;8(4):248-60.

130. Su CH, Tsai CY, Tomanek B, Chen WY, Cheng FY. Evaluation of blood-brain barrier-stealth nanocomposites for in situ glioblastoma theranostics applications. Nanoscale. 2016 April 21;8(15):7866-70.

131. Wise J. Laser treatment opens temporary window in blood-brain barrier. BMJ. 2016 February 24;352:i1154.

132. Jaeger LB, Banks WA, Varga JL, Schally AV. Antagonists of growth hormonereleasing hormone cross the blood-brain barrier: a potential applicability to treatment of brain tumors. Proc Natl Acad Sci U S A. 2005 August 30;102(35):12495-500.

133. Kovacs M, Schally AV, Hohla F, Rick FG, Pozsgai E, Szalontay L, et al. A correlation of endocrine and anticancer effects of some antagonists of GHRH. Peptides. 2010 October 01;31(10):1839-46.

134. Bellyei S, Schally AV, Zarandi M, Varga JL, Vidaurre I, Pozsgai E. GHRH antagonists reduce the invasive and metastatic potential of human cancer cell lines in vitro. Cancer Lett. 2010 July 01;293(1):31-40.

135. Jaeger LB, Banks WA, Varga JL, Schally AV. Antagonists of growth hormonereleasing hormone cross the blood-brain barrier: a potential applicability to treatment of brain tumors. Proc Natl Acad Sci U S A. 2005 August 30;102(35):12495-500.

136. Jaszberenyi M, Schally AV, Block NL, Nadji M, Vidaurre I, Szalontay L, et al. Inhibition of U-87 MG glioblastoma by AN-152 (AEZS-108), a targeted cytotoxic analog of luteinizing hormone-releasing hormone. Oncotarget. 2013 March 01;4(3):422-32.

137. Okada Y, Sugita Y, Ohshima K, Morioka M, Komaki S, Miyoshi J, et al. Signaling of ghrelin and its functional receptor, the growth hormone secretagogue receptor, promote tumor growth in glioblastomas. Neuropathology. 2016 December 01;36(6):53543. 
138. Pozsgai E, Schally AV, Zarandi M, Varga JL, Vidaurre I, Bellyei S. The effect of GHRH antagonists on human glioblastomas and their mechanism of action. Int J Cancer. 2010 November 15;127(10):2313-22.

139. Awad AW, Karsy M, Sanai N, Spetzler R, Zhang Y, Xu Y, et al. Impact of removed tumor volume and location on patient outcome in glioblastoma. J Neurooncol. 2017 July 06.

140. Behling F, Kaltenstadler M, Noell S, Schittenhelm J, Bender B, Eckert F, et al. The prognostic impact of ventricular opening in glioblastoma surgery: a retrospective single center analysis. World Neurosurg. 2017 July 17.

141. Du Z, Cai C, Sims M, Boop FA, Davidoff AM, Pfeffer LM. The effects of type I interferon on glioblastoma cancer stem cells. Biochem Biophys Res Commun. 2017 September 16;491(2):343-8.

142. Whittaker S, Madani D, Joshi S, Chung SA, Johns T, Day B, et al. Combination of palbociclib and radiotherapy for glioblastoma. Cell Death Discov. 2017 July 03;3:17033.

143. Boyd BJ, Galle A, Daglas M, Rosenfeld JV, Medcalf R. Traumatic brain injury opens blood-brain barrier to stealth liposomes via an enhanced permeability and retention (EPR)-like effect. J Drug Target. 2015;23(9):847-53. 
VITAE

EMMANUEL STIMPHIL

Miami, Florida

Education

2014-2017 Florida International University Ph.D. Electrical Engineering

2011-2013 Florida International University $\quad$ B.Sc. Electrical Engineering

2007-2010 Miami Dade College A.A Engineering

2016 IEEE Magnetic Society 2016 Summer School at the Tohoku University in Sendai, Japan (only $85 \mathrm{PhD}$ Graduate Students with a research focus in nanomagnetism/spintronic from across the globe were selected for this event)

2014 Graduate Student Member of National Science Foundation (NSF) Center for Energy-efficient Electronics Science including UC-Berkeley, MIT, Stanford, FIU, and UT-El-Paso

2014 Research Fellowship from National Institute of Health (NIH)-National Institute of General Medical Science (NIGMS)- Research Initiative for Scientific Enhancement(RISE) Program-(R25 grant award)

Publications

1. Emmanuel Stimphil, Abhignyan Nagesetti, Rakesh Guduru, Tiffanie Stewart, Alexandra Rodzinski, Ping Liang, Sakhrat Khizroev, "Physics Consideration in Targeted Anticancer Drug Delivery by Magneto Electric Nanoparticles", Applied Physics Reviews (2016 Impact Factor: 12) (Pub 2017)

2. Abhignyan Nagesetti, Emmanuel Stimphil, Tiffanie Stewart, Rakesh Guduru, Alexandra Rodzinski, Ali Hadjikhani, and Sakhrat Khizroev, "Multiferroic CoreShell Magneto-Electric Nanoparticle as NMR sensitive Nanoprobe for Cancer Cell Detection" Scientific Reports, (Pub. 2017)

3. Alexandra Rodzinski, Rakesh Guduru, Ping Liang, Ali Hadjikhani, Tiffanie Stewart, Emmanuel Stimphil, Carolyn Runowicz, Richard Cote, Norman Altman, Ram Datar, and Sakhrat Khizroev, "Targeted and controlled anticancer drug delivery and release with magnetoelectric nanoparticles", Scientific Reports (Pub.2016)

4. T. Stewart, A. Nagesetti, E. Stimphil, R. Guduru, A. Hadjikhani, L. Salgueiro, P. Liang, J. Horstmyer, A. Schally, and S. Khizroev, "Magnetoelectric nanoparticles to deliver and release anti-tumor peptide into glioblastoma cells across bloodbrain barrier via external application of d.c. and a.c. magnetic fields," Theranostics (2016 Impact Factor: 9), (Pub.2017) 